\title{
Classification, Characterization and Comparison of Aquatic Ecosystems in the Landscape of Adilabad District, Telangana, Deccan Region, India
}

\author{
Medagam Thirupathi Reddy ${ }^{*}$, Natarajan Sivaraj ${ }^{2}$, Venkateswaran Kamala ${ }^{2}$, \\ Someswara Rao Pandravada ${ }^{2}$, Neelam Sunil'2, Nilamani Dikshit ${ }^{3}$ \\ ${ }^{1}$ Vegetable Research Station, Sri Konda Laxman Telangana State Horticultural University, Hyderabad, India \\ ${ }^{2}$ National Bureau of Plant Genetic Resources, Regional Station, Hyderabad, India \\ ${ }^{3}$ National Bureau of Plant Genetic Resources, Regional Station, Dr. PDKV Campus, Akola, India \\ Email: *medagamtr@yahoo.co.in
}

How to cite this paper: Reddy, M.T., Sivaraj, N., Kamala, V., Pandravada, S.R., Sunil, N. and Dikshit, N. (2018) Classification, Characterization and Comparison of Aquatic Ecosystems in the Landscape of Adilabad District, Telangana, Deccan Region, India. Open Access Library Journal, 5: e4459. https://doi.org/10.4236/oalib.1104459

Received: March 1, 2018

Accepted: April 16, 2018

Published: April 19, 2018

Copyright $\odot 2018$ by authors and Open Access Library Inc.

This work is licensed under the Creative Commons Attribution International License (CC BY 4.0).

http://creativecommons.org/licenses/by/4.0/

\section{Open Access}

\begin{abstract}
A landscape is a mosaic of natural and/or artificial communities and waterbodies and may contain several distinct ecosystems. Human life depends on many services delivered by the water-based aquatic and land-based terrestrial ecosystems. A wide variety of aquatic ecosystems exist and although they represent a low percentage of the Earth's surface, their roles and functions make them crucial. Aquatic ecosystems especially inland aquatic ecosystems are rich in biodiversity and home to a diverse array of species and habitats, providing numerous economic and societal benefits to humans. Understanding diversity of aquatic ecosystems within landscape is a fundamental goal of both basic and applied ecological research. This study recognizes, defines, classifies, characterizes and compares for the first time the aquatic resources vis-à-vis aquatic ecosystems in the landscape of Adilabad District, Telangana, "Deccan Region", India, which was selected as the study area. The study was based on a review of available data on aquatic ecosystems in the District, discussions with key personnel, a week day reconnaissance survey over the study area during the pre- and post-monsoon season and a week day field visit during the dry season, 2010-11 by Vegetable Research Station, Rajendranagar in collaboration with National Bureau of Plant Genetic Resources, Regional Station, Rajendranagar. The study recognizes inland waters as important landscape features and reports exclusively freshwater in these inland waters across the study area. About $4.28 \%$ of the total geographical area of the study area is covered by inland water resources and/or inland aquatic ecosystems. We de-
\end{abstract}


veloped preliminary three-tiered classification system, which is based on a top-down, hierarchical classification of aquatic ecosystems, following the functionally-oriented hydrogeomorphic (HGM) approach to classification but incorporating structural attributes at the lower level of the hierarchy. The study reports on only one HGM class of aquatic ecosystems namely inland aquatic ecosystems at first level of classification system. The study reports on four HGM sub-classes of inland aquatic ecosystems namely lotic, lentic, wetland and riparian ecosystems at second level of classification system. Adilabad is in many ways abundant by its 19 diverse HGM units including 8 lotic (rivers, rivulets, tributaries, streams, creeks, waterfalls, springs and canals), 8 lentic (lakes, ponds, vernal pools, seeps, reservoirs, farm ponds and reservoirs, drainage ditches and water tanks) and 3 wetland (swamps, marshes and rice fields) at third level of classification system. Adilabad's complex edaphic, climatic and topographic conditions might have created a diverse array of HGM units. The HGM units in the study area varied in size from small ephemeral pool to large river. These HGM units are intricately tied to the landscape and provide a variety of ecosystem services. These HGM units as standardized ecosystems, recognized and described for the entire District at a relatively fine scale, are useful for a variety of biodiversity conservation and resource management applications. These data can be used to identify areas deserving of management attention due to their value for biodiversity conservation, as well as the production of ecosystem goods and services. In conclusion, the present investigation emphasizes the differences in biophysical and ecogeographic attributes of HGM classes, sub-classes and units of different types and suggests that a complex ecosystem made up of a plurality of aquatic ecosystem types, such as the Adilabad District's landscape, constitutes an interesting field laboratory in which to test directly hypotheses concerning factors that limit and regulate detritus processing in aquatic ecosystems. Our study also reports known inland aquatic ecosystem services and characteristics and, where appropriate, highlights important research gaps.

\section{Subject Areas}

Ecosystem Science

\section{Keywords}

Artificial Aquatic Ecosystems, Ecosystem Classification, Ecosystem Comparisons, Ecosystem Description, Freshwater Ecosystems, Hydrogeomorphic Classification, Inland Waters, Lentic Ecosystems, Lotic Ecosystems, Natural Aquatic Ecosystems, Wetland Ecosystems

\section{Introduction}

In geographical context, relevant scales for ecosystems often include units commonly used in management and decision making, such as field, farm, landscape, regional and global. Landscape is a concrete space which developed as a result of 
various effects and processes of natural or anthropogenic character while these processes and effects had different impact and duration of exposure [1]. The term landscape refers to gross features of the land surface, including but not limited to slope, aspect, topographic variation and position relative to other landforms. Landscape includes not only all forms of natural or planted trees, shrubs, grasses and crops but also waterbodies (waterways or watercourses) to foster ecological services and enhance aesthetic value. A landscape is defined as a large area encompassing an interacting mosaic of several distinct ecosystems and human systems that is characterized by a set of intersecting management concerns. Landscape management strives to maintain a variety of ecological states in some desired spatial and temporal distribution [2]. Management at that scale attempts to address the dynamics of individual ecosystems, the external factors that influence the ecosystems that comprise the landscape and the dynamics of the aggregate ecosystems [3].

An ecosystem (or ecological system), is a functional unit comprised of a given environment or biotope and the organisms that live in it, known as the biocenosis [4]. Our daily life depends on many services delivered by the planet's ecosystems. Habitable planet's ecosystems are generally classified into two major classes: water-based aquatic and land-based terrestrial ecosystems. Terrestrial ecosystem is an ecosystem of or relating to the land as distinct from the water [5]. Aquatic ecosystems are a subset of ecosystems in which water is a key component [4]. Aquatic ecosystems are defined as ecosystems that depend on freshwater inundation most or part of the time [5]. Aquatic ecosystems are all living and non-living elements and the relationship between them, of a water-based environment [5]. An aquatic ecosystem in good condition can carry out diverse functions: production, regulation and organization [4]. Aquatic ecosystems are numerous and diverse and they also provide several roles and functions, benefiting to mankind [4]. Aquatic ecosystems are not simply isolated bodies or conduits but are tightly connected to terrestrial environments [6]. Further, aquatic ecosystems are connected to each other and provide essential migration routes for species [6]. Understanding diversity of aquatic ecosystems within landscape is a fundamental goal of both basic and applied ecological research. The complexity and variability in space and time, of the aquatic ecosystems is still being documented by scientists but their importance is unquestioned. Ongoing research is crucial to underpin improved understanding of aquatic ecosystem function, inter-relationships with other ecosystems and water movement through the landscape [5]. As a type, aquatic ecosystems can be classified again into three varieties (inland, estuarine and marine), defined by the kind of water with which organisms interact. However, we will focus here on inland surface water aquatic ecosystems.

The association of man and aquatic ecosystem is ancient. Aquatic ecosystems, in general, cover $71 \%$ of the Earth's surface. Freshwater ecosystems occupy a tiny fraction of the Earth's surface, unlike saltwater habitats, which cover three-fourths 
of the planet. Almost 70\% of the world's population lives in areas bordering bodies of water such as rivers, coastlines and lakes, where civilizations have traditionally arisen [7]. About $40 \%$ of the world's population living in 80 countries is already facing water shortages [8]. At least $20 \%$ of the world's peoples do not have clean water for drinking [9]. Population growth and elevated living standards have been coupled with ever increasing demands for clean water [10]. The expected population increase coupled with economic development and changing life-styles over the next 25 years will result in that availability of freshwater resources is predicted to be one of the great issues for humankind to solve in the $21^{\text {st }}$ century [11]. Global population growth is expected to outpace freshwater supplies by $56 \%$ by 2025 unless patterns of use change radically [12]. As pressure on the world's water resources has increased, there has been growing concern that increased investment in water management needs to include investments to sustain these aquatic ecosystems and the benefits they provide.

Freshwaters are tightly coupled to climate and land use [13]. Freshwaters are critical for sustainability of ecosystems and society [13]. Freshwaters have typically been viewed through natural sciences (e.g., limnology, hydrology and ecology), which emphasize water quality, hydrological flows and habitat quality as potential ecosystem services [14]. Clean water supply, recreation and transportation via waters have been identified as freshwater ecosystem services [15] [16]. Streams, rivers and lakes provide freshwater that supports life and services vital to human well-being [17] [18] [19]. Freshwater ecosystems have been described as biological assets that are both disproportionately rich and disproportionately imperiled [6]. Freshwaters have disproportionately large species richness given their surface area, particularly for vertebrates [20]. Freshwater extinction rates are also among the most rapid of all ecosystems [21]. Freshwater resources, which are limited and random, are increasingly used, wasted and polluted, with the result that aquatic ecosystems are threatened and sometimes destroyed [4]. Freshwaters have been neglected and overlooked in research planning for global change [22]. In a context of global changes, improved governance that respects the environment is one of the main keys to ecologically sustainable development and poverty alleviation. Identification, definition and understanding of the characteristics of freshwater ecosystems are needed for their full appreciation. Consequently, understanding and appreciation can lead to a better protection and improved management of all freshwater ecosystems so that freshwater ecosystem services can be utilized and guaranteed sustainably.

Classification is the arrangement and division of things into classes or categories according to shared characteristics; categorization [23]. There is an implicit use of classification in ecology, because it provides a basis for distinguishing between different units of assessment. Generally speaking, ecosystem classification is the process of mapping ecologically distinctive areas on Earth. In the context of ecosystems, the development and adoption of a classification system is often the starting point for the compilation of an inventory, while the 
information collected through ecosystem inventories is in turn regarded as a necessary prerequisite for holistic conservation and management of these ecosystems. The classification of ecosystems, as opposed to vegetation, involves the description of relationships between the abiotic environment and its biotic overlay [24]. In contrast to terrestrial classifications, there are fewer examples of aquatic classifications [25] [26] [27]. Stream classifications based on a single variable, such as tributary confluence breaks, are the simplest form of aquatic classification [28] [29] [30]. Most modern classifications are based on multiple environmental variables and are much more complex than this [31]. Complexity is generally addressed using a hierarchical or multi-scale approach in which the entire system is subdivided into groups based on various criteria that determine how objects are arranged into successively finer levels of detail [32] [33]. There are three main approaches to multilevel, hierarchical classifications that can be found in the literature on aquatic ecosystems namely bottom-up, top-down and hybrid top-down/bottom-up approaches [27]. As with any ecological classification, terrestrial or aquatic, there is a hierarchical component to the methodology [34]. This hierarchical framework will enable aquatic scientists to utilize the classification at various spatial scales depending on the level of depth or breadth of information needed to answer their questions (i.e., at the landscape level or the local reach scale). The hydrogeomorphic (HGM) approach to wetland classification is founded [35], whereby hydrological and geomorphological characteristics are used to distinguish primary wetland units. The HGM approach was used for developing classification system for wetlands and other aquatic ecosystems in South Africa [23]. The HGM approach was adopted for national implementation in permit evaluations and watershed planning in the USA [35] [36]. Classifications that incorporate hydrological processes, geomorphology and physical habitats have also been proposed [37] [38]. The emerging perspective of ecosystems as both non-equilibrium and dynamic fits aquatic ecosystems as well as terrestrial systems [2]. Because aquatic ecosystems are highly complex and variable, many differences in response to different stressors are possible under different circumstances. Freshwater ecosystems differ greatly from one another depending on type, location and climate, but they nevertheless share important features [6].

Aquatic ecosystems are a diverse group of water dependent habitats that support important biodiversity and provide a wide range of benefits to people. Aquatic ecosystems including wetlands provide habitats for many plants and a space for animals to feed, rest and reproduce [4]. Aquatic ecosystems are rich in biodiversity and home to a diverse array of species and habitats, providing numerous economic and societal benefits to the country. On the Earth's surface, freshwater is the habitat of a large number of species. These aquatic organisms and the ecosystem in which they live represent a substantial sector of the Earth's biological diversity. The world's biodiversity is decreasing [39] and this is af- 
fecting organisms associated with inland aquatic ecosystems more than other major groups (e.g., terrestrial, marine). Relative to scale, inland water systems are species-rich and levels of endemism of freshwater species are particularly high [40]. Biodiversity hotspots contain high species diversity and many locally endemic species [41] Biodiversity hotspots have lost at least $70 \%$ of their native vegetation [41]. Many biodiversity hotspots are in the tropics [42]. The "Deccan Region", covering Telangana, Maharashtra and Karnataka, is one of the 22 agrobiodiversity hotspots of India [43]. In the "Deccan Region", the wild flora is blessed with rich fascinating plant species and holds a large number of curious, botanically interesting, exquiarea, economically important, rare, threatened, endangered and endemic plants [44]. Yet, despite its strategic importance for the conservation management within the "Deccan Region", ecosystem types in the "Deccan Region" are poorly studied. In the "Deccan Region", no suitable ecosystem classification existed, aligned with an environmental framework. Our study area was Adilabad District in the "Deccan Region", which is considered an important natural region within the state of Telangana, India [45]. Our study is one of the first surveys addressing the aquatic ecosystems in this important District. The need to classify Adilabad's diverse and complex ecosystems is driven not only by scientific curiosity, but also by increased land use planning activity. Currently, Adilabad District has a traditional nine-fold land use classification system that identifies land uses based on land use and vegetation cover. This classification system does not adequately represent the diversity of aquatic ecosystems in the landscape. The design of an aquatic classification requires consideration of the diversity of HGM units in Adilabad. Unique aquatic ecosystem classes are defined as areas that are homogeneous in the characteristics of interest. Similar classes should respond similarly to natural and anthropogenic disturbances and thus, should respond well to class specific management. The current paper also describes aquatic ecosystems, which is a prerequisite for future scientific research, management and environmental legislation in Adilabad District. We discuss the position of our system in the context of other classification systems and point out its advantages for scientists, decision makers, politicians and the local population.

Against this background, our overall goal is to establish a comprehensive and consistent District-wide approach to aquatic ecosystem description, inventory and interpretation that can complement the current land use classification system for ecologically sustainable development of the landscape. For those that want to go further, some direction is given towards the process of recognizing and improving aquatic ecosystems. The immediate purpose of the information generated was the conservation of the landscape. The specific objectives of this study were 1) to study the nature and extent of aquatic resources vis-à-vis aquatic ecosystems, 2) to recognize, define and classify aquatic ecosystems, 3) to characterize and compare the characteristics of different aquatic ecosystems in the landscape of Adilabad District, Telangana, "Deccan Region”, India. 


\section{Materials and Methods}

\subsection{Ethics Statement}

The field studies had essentially no effect on local human or animal populations. No specific permits were required for the described reconnaissance surveys and field visits. Forest authorities and land-holders granted us permission to access their property and conduct the systematic field visits.

\subsection{Study Area}

We conducted our study in Adilabad District of Telangana State, India. Telangana State is situated in the central stretch of the eastern seaboard of the "Indian Peninsula". Adilabad District is one of the 17 Districts included in Deccan Region. Adilabad District lies between $18.623^{\circ}-19.8742^{\circ}$ North latitudes and $77.7788^{\circ}-80.0169^{\circ}$ East longitudes. It is in the $159-358 \mathrm{~m}$ elevation range. Study area is located on the northwestern periphery of the "Deccan Region" in the "Deccan Plateau", India. The "Deccan Plateau" is unique because of its varied geography and great diversity in its natural ecosystem that is immensely rich in agricultural diversity including wild plant biodiversity and various farms of faunal diversity. The "Deccan Region" has spread over 17 Districts covering Telangana, Maharashtra and Karnataka, is one among the 22 agrobiodiversity hotspots in India [43]. DIVA-GIS version 7.5.0, free downloadable software [46] was used to map the case study area in the map of India (Figure 1) and Deccan Region (Figure 2). The "Deccan Region" is believed to be unique for its species richness, endemism, taxonomic uniqueness, unusual ecological or evolutionary phenomena and global rarity [43]. The "Deccan Region" has its own unique combination of living species, habitats, landscapes and ecosystems, which together make up its diversity rich resource. The continuous anthropogenic threat in this highly populous agrobiodiversity hotspot of India, coupled with the forest's rich biodiversity, is making the "Deccan Region" one of the "hottest hotspots" of agrobiodiversity in India. Our study area is with a complex geography, represented by various hills, valleys, plains and a variety of plant and animal species and constitutes an ecological network. The varied edaphic, climatic and topographic conditions have resulted in a wide range of ecosystems and habitats such as forests, grasslands and wetlands. This study area differs markedly in their human colonization history [47]. Adilabad District lies within the tropical deciduous belt which occupies $43.9 \%$ of total geographic area of the District [48]. Adilabad is with subtropical climate. It is too hot and too cool, in summer and winter, respectively. Adilabad District lies within the humid and sub humid tropical rain forest zone with diverse relief, climate and vegetation [45] (Reddy et al., 2017a). The annual average rainfall is $900-1137 \mathrm{~mm}$ mostly by south-west monsoon [49]. The climate of the District is characterized by hot summers; the climate is generally dry except during the south-west monsoon season [50]. The minimum and maximum temperatures range between $5^{\circ} \mathrm{C}$ and $52^{\circ} \mathrm{C}$ [51]. The maximum and minimum temperatures during south-west monsoon range from 


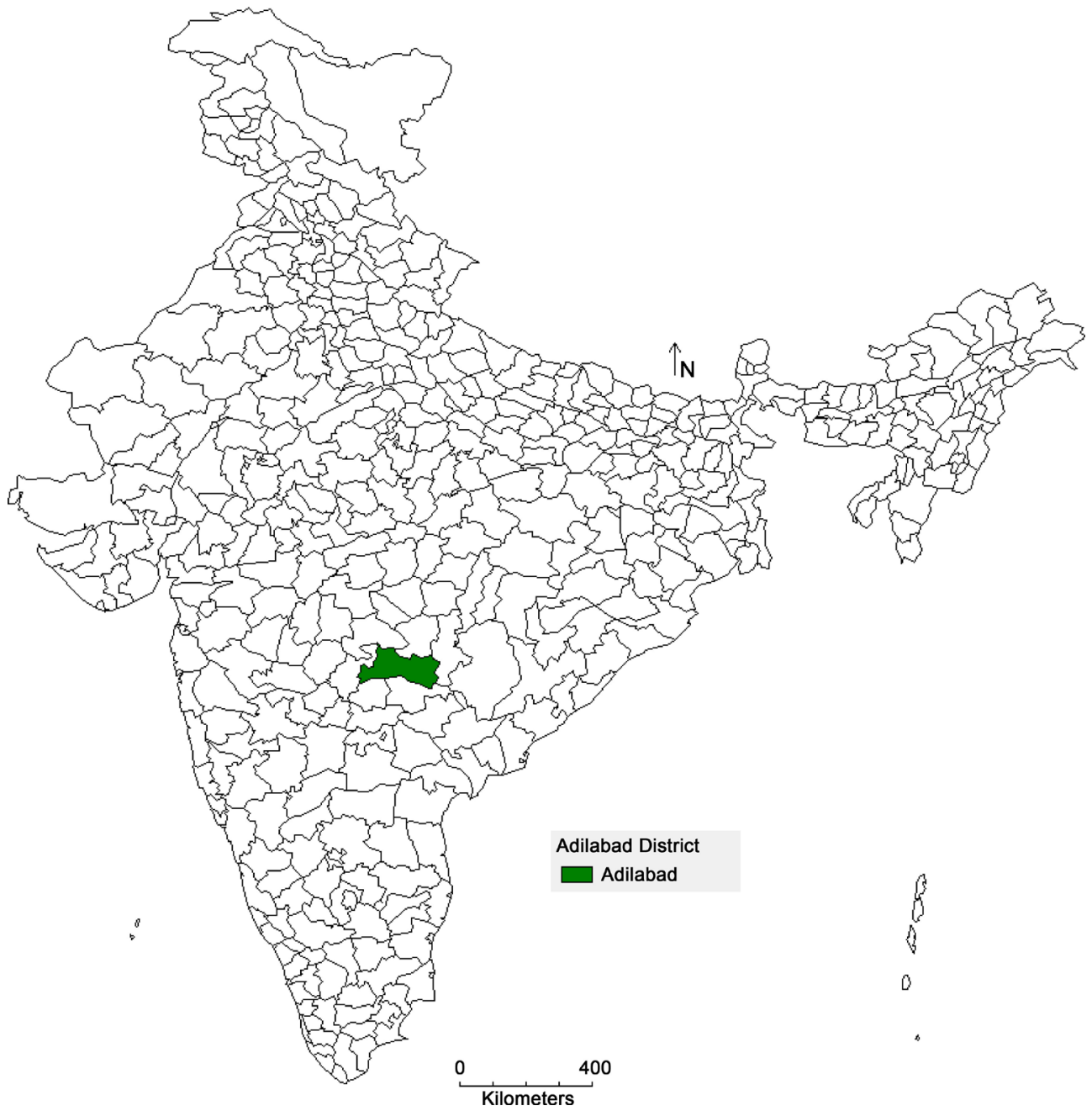

Figure 1. DIVA-GIS mapping of the Adilabad District in the map of India.

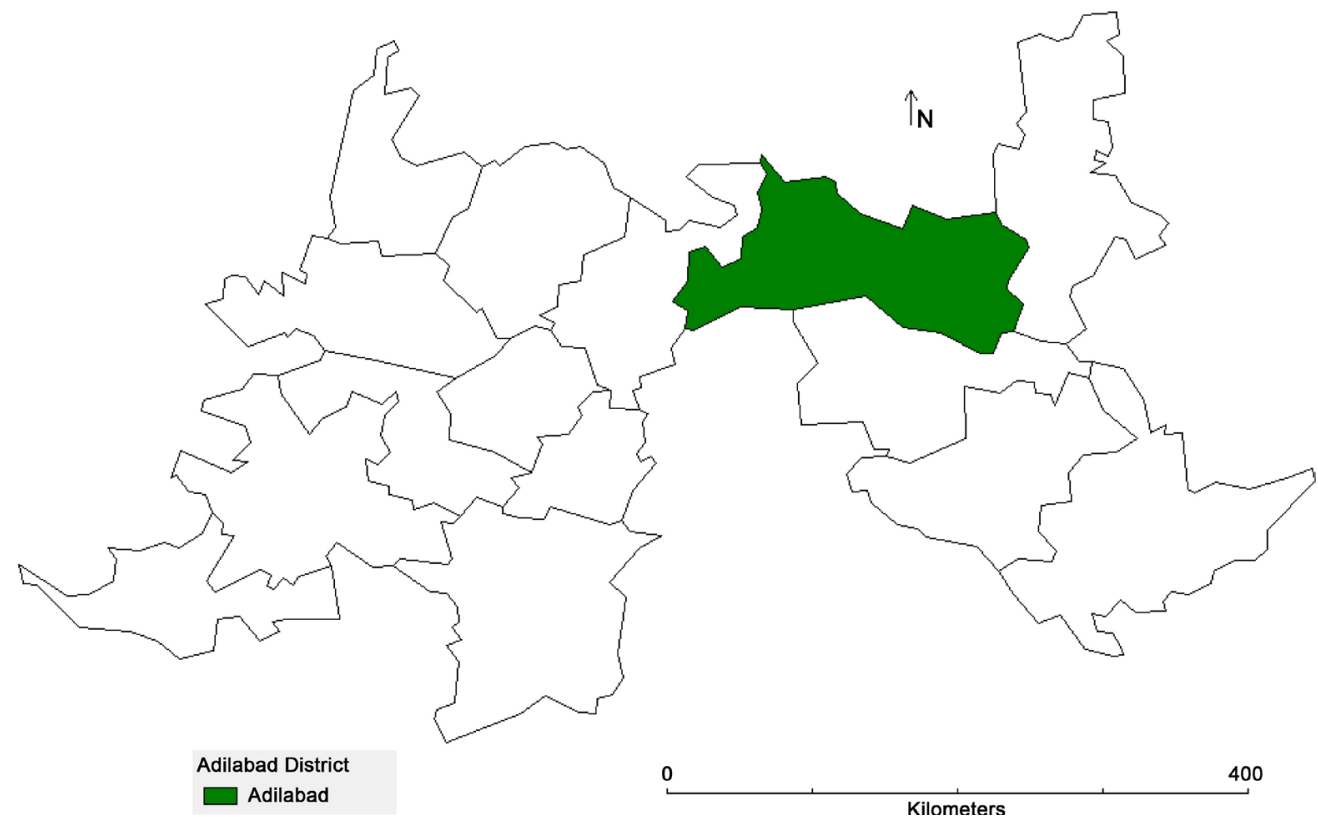

Figure 2. DIVA-GIS mapping of the Adilabad District in the map of Deccan Region, India. 
$32^{\circ} \mathrm{C}-37^{\circ} \mathrm{C}$ and $21^{\circ} \mathrm{C}-25^{\circ} \mathrm{C}$, respectively [49].

\subsection{Data Collection and Analysis}

The study was based on a review of available data on aquatic ecosystems in the District, discussions with key personnel, a week day reconnaissance survey over the study area during the pre- and post-monsoon season and a week day field visit during the dry season (2010-11). The process of studying the nature and extent of aquatic resources vis-à-vis aquatic ecosystems has involved collating data and information from a variety of sources [47] [52] [53]. The process of classifying, characterizing and comparing aquatic ecosystems has involved collating data and information through reconnaissance surveys, field visits and other sources. Reconnaissance surveys and field visits were carried out by Vegetable Research Station, Rajendranagar in collaboration with National Bureau of Plant Genetic Resources, Regional Station, Rajendranagar for several sites within the study area to fill knowledge gaps and to update some of the existing data. The landscape was surveyed by walking along public roads, cart roads, trails and paths or through fields. Throughout the paper, we use biophysical and social, primary and secondary data, stakeholder involvement, from local to landscape level, expert assessments and global meta-data.

We developed three-tiered classification system, which is based on a top-down, hierarchical classification of aquatic ecosystems, following the functionally-oriented HGM approach [35] to classification but incorporating structural attributes at the lower level of the hierarchy. A hydrogeomorphic classification system was defined for wetlands, based on geomorphic setting, dominant water source and dominant hydrodynamics [35]. The HGM classification system has been applied primarily for a functional assessment strategy termed the HGM approach [36]. The tiered structure progresses from HGM classes/systems at the broadest spatial scale (level 1), through HGM sub-classes/sub-systems (level 2) at the narrow spatial scale, to HGM types/units at the finest spatial scale (level 3 ). At level 1 of the classification system, inland (freshwater), estuarine (transitional and brackish waters) and marine aquatic ecosystems are distinguished from each other based on the degree of existing connectivity with the open ocean as the key discriminator or primary criterion, the salinity (saltiness) of a wetland or an aquatic ecosystem does not influence whether or not it is classified as an inland aquatic ecosystem. The major subdivision of aquatic ecosystems is based on the salinity of the medium and defined by the kind of water with which organisms interact. Inland aquatic ecosystems have no direct, existing connection to the sea. Inland aquatic ecosystems are characterized by the complete absence of marine exchange and/or tidal influence. At level 2 of the classification system, inland aquatic ecosystems are distinguished from each other based on the hydrological regime namely lotic ecosystems: rapidly-moving water/flowing water/running water/moving water, where water flows from source to mouth; lentic ecosystems: slowly-moving water/standing/stationary/relatively still water, 
where water is stored according to the specific landscape and topography; wetland and riparian ecosystems: flowing or static water, where the soil is saturated or inundated for at least part of the time [4]. At level 3 of the classification system, several descriptors are incorporated into the classification system, which allow us characterization of inland systems and to distinguish between aquatic ecosystems with different structural, chemical and/or biological characteristics [23]. These descriptors are non-hierarchical in relation to one another and we can, therefore, apply them in any order, depending on their relevance to our purpose and/or the availability of information. HGM unit is the focal point of the classification of aquatic ecosystems [23]. HGM unit is a type of aquatic ecosystem distinguished primarily on the basis of landform, which defines the shape and localized setting of the ecosystem, hydrological characteristics, which describe the nature of water movement into, through and out of the ecosystem and hydrodynamics, which describe the direction and strength of flow through the ecosystem [23]. HGM units were principally identified through fieldwork assisted by colour photographs. HGM units in the landscape which could not be surveyed, were identified using visual inspection from the nearest accessible area. Target notes were taken for the HGM units. Wherever possible we have made use of existing classifications designed for other purposes, so that reference can be made to these on matters of geographical distribution and total area of a habitat available. For HGM unit types where direct matching was not possible, climate, geography, geology and soil characteristics were used as determinants.

\section{Results and Discussion}

\subsection{Nature and Extent of Aquatic Resources vis-à-vis Aquatic Ecosystems in the Study Area}

The total number of inland waterbodies in the study area was 6667 (Table 1). The total water spread area was 76,971 ha, while the effective water spread area was 28,545 ha (Table 1). Inland waterbodies statistics and area estimates of inland waterbodies for Adilabad District (Table 2 and Table 3) are given to have a fairly good idea about the distribution pattern and density of inland waterbodies in the study area. Inland waters are aquatic-influenced environments located within land boundaries. In general, this includes those located in coastal areas, even where adjacent to marine environments. In practice, inland waters considerations tend to focus on freshwater, partly because freshwater environments dominate inland waters, but mainly because of the importance of freshwater globally and locally. Inland waters are everywhere and are part of all landscapes. At the smaller scale, inland waterbodies are also present in all terrestrial biomes including forests, grasslands and agricultural ecosystems. In general, inland water systems can be fresh, saline or a mix of the two (brackish water). However, the inland waters in the study area are exclusively fresh. Inland waters represent parts of the biosphere within which marked biological diversity, complex biogeochemical pathways and an array of energetic processes occur. Although from 
a geographic perspective inland waters represent only a small fraction of the biosphere, when appreciated from an ecological viewpoint, they are seen to be major contributors to biospheric diversity, structure and function. These inland

Table 1. Area estimates of waterbodies in Adilabad District, Telangana, Deccan Region, India.

Total number of inland waterbodies Total water spread area (ha) Effective water spread area (ha)

\begin{tabular}{lll}
\hline 6667 & 76,971 & 28,545
\end{tabular}

Source: http://niti.gov.in/writereaddata/files/Telangana_Report_1.pdf (Task Force Report. Agriculture Challenges and Way Forward, Submitted to NITI Aayog, Government of Telangana, Agriculture \& Cooperation Department, 47)

Table 2. Statistics of inland waterbodies of Adilabad District, Telangana, Deccan Region, India.

\begin{tabular}{cccccc}
\hline \multirow{2}{*}{$\begin{array}{c}\text { Geographical } \\
\text { area }\left(\mathrm{km}^{2}\right)\end{array}$} & \multirow{2}{*}{$\begin{array}{c}\text { Inland waterbodies } \\
\text { area (ha) }\end{array}$} & $\begin{array}{c}\text { Percentage of } \\
\text { District area }\end{array}$ & \multicolumn{2}{c}{ Open water extent (ha) } & Seasonal change \\
& & & Post-monsoon & Pre-monsoon & $(\%)$ \\
\hline 16,105 & 68,907 & 4.28 & 44,355 & 21,557 & 51.40 \\
\hline
\end{tabular}

Source: Space Applications Centre (ISRO) (2010).

Table 3. Area estimates of inland waterbodies vis-à-vis ecosystems in Adilabad District, Telangana, Deccan Region, India.

\begin{tabular}{|c|c|c|c|c|c|}
\hline & Number of & Total inland & Percent of & Open wa & ater (ha) \\
\hline category & waterbodies & area (ha) & $\begin{array}{c}\text { waterbodies } \\
\text { area (ha) }\end{array}$ & Post-monsoon & Pre-monsoon \\
\hline Inland waterbodies-N & tural & & & & \\
\hline Waterlogged & 1 & 15 & 0.02 & 4 & 10 \\
\hline River/Stream & 57 & 34,133 & 49.53 & 15,054 & 9179 \\
\hline Sub-Total & 58 & 34,148 & 49.55 & 15,058 & 9189 \\
\hline Inland waterbodies- $M$ & in-made & & & & \\
\hline Reservoirs/Barrages & 217 & 27,008 & 39.19 & 24,202 & 10,421 \\
\hline Tanks/Ponds & 590 & 7383 & 10.71 & 5090 & 1947 \\
\hline Waterlogged & 1 & 7 & 0.01 & 5 & - \\
\hline Sub-Total & 866 & 68,546 & 99.48 & 44355 & 21,557 \\
\hline $\begin{array}{l}\text { Wetlands }(<2.25 \text { ha, } \\
\text { mainly tanks })\end{array}$ & 361 & 361 & 0.52 & - & - \\
\hline Total & 1227 & 68,907 & 100.00 & 44,355 & 21,557 \\
\hline Area under aquatic ve & etation & & & 4785 & 13,041 \\
\hline Area under turbidity le & vels & & & & \\
\hline Low & & & & 17,976 & 4159 \\
\hline Moderate & & & & 22,756 & 16,303 \\
\hline High & & & & 3623 & 1095 \\
\hline
\end{tabular}

Source: Space Applications Centre (ISRO) (2010). 
Table 4. Three-tier hydrogeomorphic classification of aquatic ecosystems in the landscape of Adilabad District, Telangana, Deccan Region, India.

\begin{tabular}{|c|c|c|c|c|}
\hline \multirow[b]{2}{*}{ Ecosystem } & \multicolumn{3}{|c|}{ Hydrogeomorphic (HGM) } & \multirow{2}{*}{$\begin{array}{l}\text { Vernacular name } \\
\text { of the HGM unit }\end{array}$} \\
\hline & $\begin{array}{c}\text { Class/system } \\
\text { (Level 1) }\end{array}$ & $\begin{array}{c}\text { Sub-class/sub-system } \\
\text { (Level 2) }\end{array}$ & $\begin{array}{c}\text { Type/unit } \\
\text { (Level 3) }\end{array}$ & \\
\hline \multirow[t]{20}{*}{$\begin{array}{l}\text { Aquatic } \\
\text { ecosystems }\end{array}$} & $\begin{array}{c}\text { Inland } \\
\text { aquatic } \\
\text { ecosystems }\end{array}$ & $\begin{array}{c}\text { Lotic } \\
\text { ecosystems }\end{array}$ & Rivers & Eru, Nadi \\
\hline & & & Rivulets & Chinna Yeru \\
\hline & & & Tributaries & Upanadi \\
\hline & & & Streams & Vagu \\
\hline & & & Creeks & Selayeru \\
\hline & & & Waterfalls & Jalapatam \\
\hline & & & Springs & Uta, Bugga, Chelama \\
\hline & & & Canals & Kalava \\
\hline & & Lentic ecosystems & Lakes & Sarassu \\
\hline & & & Ponds & Kumta, Madugu \\
\hline & & & Vernal pools & $\begin{array}{c}\text { Samuham, Niti Gumta, } \\
\text { Madugu }\end{array}$ \\
\hline & & & Seeps & Uta, Bugga, Chelama \\
\hline & & & Reservoirs & Jalasayam \\
\hline & & & $\begin{array}{l}\text { Farm ponds and } \\
\text { reservoirs }\end{array}$ & - \\
\hline & & & Drainage ditches & Kamdakamu, Parikha \\
\hline & & & Water tanks & Cheruvu \\
\hline & & Wetland ecosystems & Swamps & $\begin{array}{l}\text { Chittadinela, } \\
\text { Tamparabhumi }\end{array}$ \\
\hline & & & Marshes & $\begin{array}{c}\text { Uppuparra, Badavanela, } \\
\text { Buradanela }\end{array}$ \\
\hline & & & Rice fields & Varipolam \\
\hline & & Riparian ecosystems & - & - \\
\hline
\end{tabular}

*Vernacular name in Telugu in singular.

waterbodies have, however, provided much more than just water, for example food, medicine and building materials are easily available because of the ubiquitous presence of living aquatic resources. But water is increasingly needed for a range of competing purposes and because people comprise an integral part of these ecosystems, many human activities have a direct or indirect impact on inland aquatic ecosystems which are under much more pressure from these activities than their marine counterparts. Fish and other living aquatic resources from inland waters nevertheless continue to constitute an essential role in people's li- 
velihoods on rural areas in many parts of the world, especially in developing countries.

The total area under inland waters in the study area was 68,907 ha (Table 2), which constitutes to $4.28 \%$ of District's total geographic area $\left(16,105 \mathrm{~km}^{2}\right)$. Open water extent was 44,355 and 21,557 ha during post- and pre-monsoon seasons, respectively. The seasonal change in open water extent was to the tune of $51.40 \%$ (Table 2). The District comprises of 866 inland waters, besides 361 small wetlands ( $<2.25 \mathrm{ha})$. These inland waters account for $68,907 \mathrm{ha}$. Three major inland waterbodies types (Table 3 ) namely rivers/streams (34,133 ha) followed by reservoirs/barrages, (27,008 ha) and tanks/ponds (7383 ha) exist in the District. Aquatic vegetation has an increase from 4785 ha in post-monsoon to 13,041 ha in pre-monsoon. Analysis of inland waterbodies status in terms of open water reveals that the District has recorded 44,355 ha and 21,557 ha of during post-monsoon and pre-monsoon, respectively out of 68,546 ha (excluding inland waterbodies $<2.25 \mathrm{ha}$ ) of wetland extent. This amounts to a large seasonal reduction to the tune of $63 \%$. Qualitative turbidity of the open water dominated by moderate (22,756 ha) followed by low turbidity (17,976 ha) and high turbidity (3623 ha) in post-monsoon. The trend continued in pre-monsoon where the turbidity was dominated by moderate ( $16,303 \mathrm{ha})$ followed by low (4159 ha) and high (1095 ha). The data denotes that inland water is found in various different forms of waterbodies in the study area. The data also indicate inland waters (inland waterbodies/waterways/watercourses) as important landscape features comprising any body of water, standing or flowing, including the water column, littoral zones and bed, such as the sea, lakes, river, stream, etc. The study reports exclusively freshwater in these inland waters across the District. Waterways (e.g., lakes, ponds, rivers, streams and canals) are ways of water flow on land surface within its relief forms. Waterways provide rich wildlife habitats, offer recreational value and can be used as movement corridors. Seasonal waterways are important sources of aquatic plants for farmers. They can be enhanced to provide higher levels of important biodiversity products. About $4.28 \%$ of the total geographical area of the District is covered by inland waters (exclusively freshwaters) and inland aquatic ecosystems (exclusively inland freshwater ecosystems). Adilabad's long geographical history, complex topography and climate coupled with affluent water resources have created an immense variety of inland freshwater aquatic ecosystems.

Waterbodies make up the hydrosphere that covers $71 \%$ of the Earth. Over $71 \%$ of the Earth's surface is covered with water, but freshwater resources accessible for direct human use account for less than $1 \%$. That water is important to life on Earth, including for sustaining human populations, is self-evident to most of us [53]. Aquatic ecosystems, in general, cover $71 \%$ of the Earth's surface. Marine ecosystems cover approximately $70 \%$ of the Earth's surface and include oceans, estuaries, coral reefs, salt marshes and other tropical habitats. Freshwater ecosystems cover only $1 \%$ of the Earth's surface and include lakes, ponds, rivers, 
streams, wetlands, riparian areas and even groundwater. This fraction of water available on Earth is home to an extraordinarily high level of biodiversity that is directly supported through a range of freshwater ecosystem types that includes running waters in rivers, standing waters of lakes and marshes and areas of transient water availability in seasonal or ephemeral wetlands [53]. These inland water ecosystems provide a vital range of goods and services essential for sustaining human well-being [53]. Inland aquatic ecosystems include a variety of natural and man-made inland waterbodies. In spite of only covering about $1 \%$ of the total land surface, inland waters are home to around 100,000 aquatic species, including for instance 10,000 , or $40 \%$ of all fish species. Only $3 \%$ of the Earth's freshwater is found in streams, lakes and reservoirs. The remaining $97 \%$ is underground, which lies below the Earth's surface. Groundwater is the safest and most reliable source of available freshwater.

Water is the most common substance on Earth. Water is the elixir and basis of life and we all depend on water for our survival. The importance of water as resource is not only tied to its availability and quantity, but also to its quality as it supports the aquatic and terrestrial lives. It is found everywhere, from the ground to the sky and in all living things. Human communities also use water for economical and recreational purposes. Water is probably the most essential requirement for economic growth and social development. Water on land which is continuously cycling and has low salt content is known as freshwater. Freshwater is water with a salt concentration less than 5 ppt. Freshwater is defined as having a salinity of less than 0.5 while sea water is generally regarded as having a salinity of $>30$ but these definitions are narrow and open to regional interpretation. The freshwater resources, such as water falling from the skies and moving into streams, rivers, lakes and groundwater, provide people with the water they need every day to live. Freshwater is a finite natural resource of Earth. Freshwater is vital to human life and economic well-being and societies extract vast quantities of water from rivers, lakes, wetlands and underground aquifers to supply the requirements of cities, farms and industries. Freshwater resources also serve as drinking water for grazing livestock. Humans need freshwater not only for drinking, but also for agriculture, industry, transportation and many other important uses [53]. Surface water resources are used for domestic, industrial and municipal supply, irrigation, production of energy, navigation, fishing, hunting and recreation. With the advent of industrialization and increasing populations in early 1980's, the range of requirements for water has increased manifolds together with greater demands for higher water quality. Water shortages are becoming more widespread every year and competition between different uses is increasing.

\subsection{Classification of Aquatic Ecosystems in the Study Area}

The preliminary classification system has a multi-tiered structure (Table 4). The classification system (Table 4) developed for the study area was a three-tier clas- 
sification system. The classification system recognizes only one major HGM class, which was further divided into three HGM sub-classes, which were further divided into 19 HGM units. From a District perspective, classes consist of inland aquatic ecosystems; sub-classes consist of lotic, lentic, wetland and riparian ecosystems. Levels 1 and 2 provide the broad and narrow context for grouping aquatic ecosystems, respectively, while the descriptors at level 3 provide a more detailed description of the characteristics of a particular HGM unit at fine scale. The study reports on exclusively freshwater ecosystems at level 1 . Four main types of aquatic ecosystems were recognized within the study area, namely lotic, lentic, wetland and riparian ecosystems at level 2. At level 3, in total, this classification system led to 19 HGM units being recognized -7 lotic, 9 lentic and 3 wetland. HGM unit is a functional unit, highlighting the fact that functioning of inland aquatic ecosystems is strongly influenced by the hydrogeomorphic characteristics and the hydrological regime of the ecosystem. The term hydrogeomorphic refers to landform characterized by a specific origin, geomorphic setting, water source and hydrodynamics. Hydrogeomorphic is a combination of hydrology (i.e., the nature of the presence or movement of water) and geomorphology (i.e., landform characteristics and processes). It is widely accepted that hydrology and geomorphology are the two fundamental features that determine the way in which an inland aquatic ecosystem functions, regardless of climate, soils, vegetation or origin [54] [55] [56] [57]. This is the basic premise on which the HGM approach to wetland classification is founded [35], whereby hydrological and geomorphological characteristics are used to distinguish primary wetland units. The HGM approach, which covers classification, reference and functional assessment aspects, has proven to be helpful in classifying aquatic ecosystems as to their position in the landscape, their source of water and the flow of that water [23] [35] [36]. Internationally, there is general widespread agreement that wetland and aquatic ecosystem classification systems based on geomorphological and hydrological aspects are far more robust and consistent than classification systems based on structural criteria, at least at the broader levels of classification [55], largely because geomorphology and hydrology are recognized as the fundamental drivers that determine the existence of wetlands and their functioning [35] [54] [56] [57] [58]. This is the basic premise on which the hydrogeomorphic (HGM) classification system for wetlands was developed in the USA [35] and forms the basis of the HGM approach to the classification and functional assessment of wetlands and other aquatic ecosystems internationally [59]. This is just one thematic scale of classification, with coarser or finer levels possible depending on purpose.

Classifying aquatic ecosystems is useful for describing and managing their natural variability. Classification systems have been used for many years, by scientists and resource managers, to partition and organize information about complex ecological systems in an attempt to simplify our understanding of them [60] [61]. It is envisaged that the classification system could be used for a range 
of different purposes. Potential uses include wetland inventories at local scale, conservation planning initiatives for inland aquatic ecosystems (broad scale and fine-scale), wetland and river rehabilitation planning, assessments of wetland and river health, assessments of wetland services/functions, water resource planning and management, design of wetland and river monitoring programs, etc. The tiered structure of the classification system provides increasing amounts of detail at the different levels of the classification system, with more extensive information generally required to classify an aquatic ecosystem unit at each successive level. Where more detailed information is available (e.g., through extensive fieldwork), ecosystem units can be classified to a finer level and with greater confidence. Ultimately, the utility of the classification system is dependent on the level to which ecosystem units are classified, which is in turn constrained by the type and extent of information available.

\subsection{Characterization of Aquatic Ecosystems in the Study Area}

Based on the researching status of aquatic ecosystems in the landscape of Adilabad District, especially, we can present our results as the basic characteristics of these ecosystems:

\subsubsection{Aquatic Ecosystems}

The aquatic ecosystem deals with waterbodies. Aquatic ecosystem is related to water (the word aqua means water). In aquatic ecosystems, organisms interact with water. An aquatic ecosystem is a community of plants and animals that primarily depend on water. Aquatic ecosystem is an ecosystem that is permanently or periodically inundated by flowing or standing water, or which has soils that are permanently or periodically saturated within $0.5 \mathrm{~m}$ of the soil surface. Aquatic ecosystems are plants and animal community found in waterbodies. Aquatic ecosystem is the basic ecological unit composed of living organisms and non-living elements interacting in an aqueous milieu (watery environment). An aquatic ecosystem includes any water environment and the community of organisms that live there. Aquatic ecosystem is any watery environment in which plants and animals interact with the chemical and physical features of the environment. An aquatic ecosystem is a group of interacting organisms dependent on one another and their water environment for nutrients and shelter. It involves living aquatic organisms, which constitute as the biotic factors and their relationship with their environment, which collectively can be referred to as the abiotic factor. Almost all ecological factors like temperature, light, $\mathrm{p}^{\mathrm{H}}$, dissolved gases, dissolved salts in water, turbidity, alkalinity, depth and areal distribution; all of these parameters play an active role in controlling the habitat of aquatic ecosystems. The adaptations of organisms to aquatic environment vary in degree and diversity. Aquatic vegetation refers to plants that grow principally on or below the water surface. The major types of organisms found in aquatic ecosystems are mainly determined by the water's salinity. The healthy aquatic ecosystem depends on the biological diversity and physico-chemical and biological charac- 
teristics. A remarkably diverse assemblage of plants, animals and microbes live in inland waters, with nearly all major groups of living organisms found in one sort of aquatic ecosystem or another. These diverse ecosystems host a broad range of aquatic life from microscopic plants and animals to large trees and major predators and can include rare, endemic species. Aquatic ecosystems also provide a home to many species including the phytoplankton, zooplankton, aquatic plants, insects, fish, birds, mammals and others. Aquatic biodiversity includes all unique species and habitats and the interaction between them. They are organized at many levels, from the smallest building blocks of life to complete ecosystems, encompassing communities, populations, species and genetic levels. It has enormous economic and aesthetic value and is largely responsible for maintaining the overall environment. Nevertheless, improved understanding of the ecosystems associated with water resources has increasingly acknowledged that they provide various useful services, such as flood control, storm protection and maintenance of biodiversity and natural resource stocks. Conservation, management and restoration of waterbodies have become a necessity for ethical reasons and for their aesthetic and cultural importance to societies. Composing $71 \%$ of the Earth's surface, aquatic ecosystems are not only the dominant features of Earth but are also very diverse in species and complexity of interaction among their physical, chemical and biological components. As more water is withdrawn and consumed for human uses, there is growing concern about whether the depleted water supply to lakes, rivers, estuarine ecosystems and associated wetlands is adequate to maintain healthy functioning of these ecosystems. Although the scientific management of rivers, lakes and reservoirs is still relatively new, it promises to be of great value to the advancement of societies. With the development of limnology as a multidisciplinary science, great strides have been made in understanding the functioning of aquatic ecosystems and their interrelationships.

\subsubsection{Inland Aquatic Ecosystems (Inland Water Ecosystems/Freshwater Ecosystems)}

Rather than imposing artificial boundaries, it is better to view inland waters from the perspective of the wider ecosystem of which they are part. From the ecological, hydrological, environmental and socio-economic perspective, all land is an integral part of an inland water ecosystem because freshwater (usually from rain) runs off it into rivers, lakes and wetlands. Inland waters are terrestrial aquatic ecosystems. Inland water ecosystems include land. The water in freshwater ecosystems is non-saline, which means water has no or very little salt content. Inland water ecosystem is a complex of living organisms in free water on continental landmasses. The inland aquatic ecosystems comprise less than $1 \%$ of the Earth's surface, but often are among the most productive areas. Nevertheless, no major group actually evolved in inland waters; all evolved either in the sea or on land, whence the biological invasion of inland waters eventually took place. The long period of time since this original invasion occurred, however, has allowed 
many important taxa of inland waters, to evolve.

Inland water systems encompass a wide range of surface and underground physical, hydrological and biological systems and include lotic, lentic, wetland and riparian ecosystems. These waters range from small or ephemeral (e.g., seasonal pools and intermittent streams) to large regional and national features. Freshwater ecosystems can form naturally where groundwater reaches the Earth's surface. The subject of study of freshwater ecosystems is known as limnology. In freshwater ecosystems, parameters such as temperature, dissolved oxygen, $\mathrm{p}^{\mathrm{H}}$, alkalinity, nitrate and other nutrients may be measured with various tests. The variation in the abiotic environment in terms of size of waterbodies, turnover of water, nutrient content, $\mathrm{p}^{\mathrm{H}}$ and the quantity and fluxes of water in streams cause a significant variation in habitats and species composition.

Surface water resources are the mostly preferred locations for life settlements. Freshwater ecosystems offer important cultural and recreational resources for human populations around the world. Inland water ecosystems provide a vital range of goods and services essential for sustaining human well-being. Functionally intact and biologically complex freshwater ecosystems provide many economically valuable commodities and services to society. These services include flood control, transportation, recreation, purification of human and industrial wastes, habitat for plants and animals and production of fish and other foods and marketable goods. Another ecosystem service of streams, lakes and ponds is the humidification of the local climate, not only for humans, but also for neighboring terrestrial habitats and species vulnerable to desiccation such as lichens, fungi and epiphytic bryophytes. The ecosystem service of the most obvious commercial interest today is the drainage and diversion of water from low-lying agricultural fields and agriculturally improved meadows and this service is in direct conflict with the habitat quality and habitat area of streams and mires in the stream valley. Freshwater habitats are important for invertebrates including molluscs, dragonflies, beetles, benthic invertebrates, amphibians, vascular plants, fish and bats. There are many varieties of plant and animal communities in these ecosystems which have adapted to the physical conditions associated with them. Freshwater ecosystems are essential for sustaining the ecology and economy of grasslands.

Ecological characteristics of inland water ecosystems are strongly influenced by elevation, topography, vegetation, soils and bedrock geology, precipitation, chemical constituents [62] and human alterations-both direct and indirect. Direct alterations of inland water ecosystems can include channelization, water withdrawals and introduction of invasive species, whereas indirect changes may consist of land use effects on sediment supply from the watershed, impacts on groundwater discharge or recharge, or removal of vegetation adjacent to the waterbody which may alter water temperature and food webs. Frequency and duration of extreme events (i.e., flooding and drought) also influence both physical 
and biological features of inland waters. Many of these inland aquatic ecosystems have undergone dramatic changes in recent years as a result of man's activities. Over the long term, intact ecosystems are more likely to retain the adaptive capacity to sustain production of these goods and services in the face of future environmental disruptions such as climate change. These ecosystem benefits are costly and often impossible to replace when aquatic systems are degraded. For this reason, deliberations about water allocation should always include provisions for maintaining the integrity of freshwater ecosystems. At the beginning of the third millennium, the world is facing an increasing demand for large quantities of quality freshwater; however, multiple anthropogenic factors are already putting freshwater ecosystems under stress. Freshwater systems have been critical to the establishment of civilizations throughout human history. Despite the reliance of societies on freshwater systems, only in this century has the importance of protecting the quality of these systems become widely recognized.

\section{1) Lotic Ecosystems}

Lotic ecosystems refer to systems with rapidly flowing waters. Lotic ecosystems include all natural and near-natural channels that hold flowing water. Lotic ecosystems are linear landscape elements. In addition to their linear form, running waters are unique amongst aquatic ecosystems in their unidirectional flow [63], where the water moves continually in one direction. This linear form characteristic shapes the morphology of river channels, makes running waters inherently variable in space and time and has led to a biota that is highly adapted to dynamic conditions [64]. In lotic ecosystems, connectivity is observed longitudinally in relation to the course of the river and laterally in relation to the influence of the hydrological cycle, with the formation of a vast flood plain. The relative narrowness of lotic ecosystems means that they have an intimate contact with their surrounding catchments and the terrestrial ecosystems they contain [65]. Included in the environment are the biotic interactions (amongst plants, animals and micro-organisms) as well as the abiotic interactions (physical and chemical). Variability between lotic ecosystems is quite high. Lotic ecosystems have a low salt content. In lotic ecosystems, water flow from a source such as a spring or glacier to a terminus, which could be at an ocean, a larger stream or river, or some other type of reservoir. Water doesn't stay put for very long. The places where streams begin are called headwaters. Many begin in mountain areas from snowmelt. Some begin or are fed by water seeping up from the water table, which are called as gaining streams. In lotic ecosystems, the surface water moves down along the slopes due to the action of gravity. In lotic ecosystems, velocity and current of flowing water decide most things because it cuts channels and affects living organisms. Water current pervades every facet of existence for life in lotic (flowing water) habitats. The current is more pronounced at the surface than in the bottom substrate of running waters. Hence, the bottom substrate conditions are similar to lentic habitats. Many lotic ecosystems connect to each other and form a path to the ocean (e.g., spring $\rightarrow$ stream $\rightarrow$ river $\rightarrow$ sea/ocean). 
The lotic ecosystem is an essentially open system with respect to energy, in the form of organic matter, under a strong unidirectional flow. Running waters are, however, sustained energetically through a continual energy inflow in the form of solar radiation and through the intimate relationship between streams and the surrounding terrestrial ecosystems. Energy sources in streams and rivers comprise solar radiation, which supports autochthonous primary production and allochthonous organic matter, including coarse particulate organic matter produced by adjacent riparian ecosystems, fine particulate organic matter coming through wind blow, surface runoff, bank erosion, etc. and dissolved organic matter. In response, lotic systems are shaped into a dynamic mosaic of abiotic and biotic conditions to which species, populations and communities are locally adapted.

Only a minuscule proportion $(0.006 \%)$ of the world's freshwater is present in streams and rivers at any one time [66], but this statistic belies the significance of lotic systems to humankind and the biosphere. Lotic ecosystems provide a plethora of utilities for humankind, including a source of water for domestic, industrial and agricultural purposes, a means of power generation and waste disposal, routes for navigation and locations for the pursuit of leisure activities. Running waters have been the focus for human settlement [63]. This great utility of running waters to humankind has also proven their undoing, as they have acted as magnets for human settlement. Lotic ecosystems encompass a wide spectrum of habitats spanning a continuum from small mountain springs to immense lowland rivers. Lotic systems harbor a diverse army of species, including some of the most threatened [67]. In the middle reaches of rivers, riparian vegetation has an important role in buffering potential impacts from the catchment [68].

Running waters are perhaps the most impacted ecosystem on the planet [63]. Running waters are heavily exploited for water supplies, irrigation, electricity generation and waste disposal [63]. There are now very few river catchments that are unaffected by people in some way. Lotic ecosystems are also affected by land uses in the drainage basin, as well as near-stream habitat such as floodplain wetlands and shoreline vegetation. There are myriad natural and anthropogenic sources of disturbance in lotic ecosystems such as flooding and drought, landslides and debris flows, wildfire, dams and river regulation, along with many other forms. Lotic ecosystems also have an intimate contact with their catchments and so land-use alterations affect them directly. Alterations in the structural and functional relationships of landscape elements and stream patches can significantly affect resource distribution and is, therefore, critical to predicting the effect of land management options on lotic ecosystems [69] [70] [71]. As such, a robust understanding of how disturbance affects lotic ecosystems is required for effective management and conservation.

Adilabad is in many ways abounding by its 8 diverse lotic HGM units: rivers, rivulets, tributaries, streams, creeks, waterfalls, springs and canals. Of these, riv- 
ers, rivulets, tributaries, streams, creeks, waterfalls and springs are natural while canals are artificial.

\section{a) Rivers}

Rivers are freshwater free flowing water systems obtained from precipitation that crosses an area of land and flows into the ground towards the ocean, sea or another river which may also flow underground for part of its course. They are important riparian ecosystems and make up about $0.0001 \%$ of the Earth's water. While this may not seem like much, rivers drain as much as $75 \%$ of the Earth's surface. Important river that drains in the District is the river "Godavari" which has an annual discharge of 105,000 million $\mathrm{m}^{3}$. The river "Godavari" originates at Nasika Trayambakam in the Western Ghats and is the most important in Telangana. It is referred to as the "Ganga of the South", since it is the largest of the rivers in South India. It flows for about $770 \mathrm{~km}$ in Telangana and Andhra Pradesh, providing water to Adilabad and other adjoining Districts (Nizamabad, Karimnagar, Warangal, Khammam, East and West Godavari) as well. This river provides important ecosystem services and is also integral to many aspects of Districts' history and agricultural and industrial development.

River is a linear landform with clearly discernable bed and banks, which permanently or periodically carries a concentrated flow of water. River is a large, permanent watercourse with at least some permanent tributary streams and can either be a single stream or several streams of water connected with each other. A river often has a number of streams or tributaries draining into it, when the river is dammed, the impounded water tends to back up into the tributaries. The stream network itself is important to the continuum of river processes. The following are the terms used to denote the small portions of rivers. "Pool" is a segment where the water is deeper and moves slowly. "Riffle" is a segment where the flow is shallower and more turbulent. Headwater, in a river, is the point of origin of the stream. "Channel" is the river courses developed by constant erosion. "Floodplain" is the flatland existing on either side of the stream that is subject to seasonal flooding. "Floodplain" is the lowland that borders a river, usually dry but subject to flooding. The beginning of a river is called the "source". The confluence or end of a river is called the "mouth", the point at which the stream discharges its entire load into a sea or other static body of water. River basin is a terrain over which surface runoff in the form of streams and rivers flows into a receiving waterbody (sea, lake) through a single river mouth, estuary or delta. "Runoff dissipation zone" means the zone where a river flow is depleted due to evaporation and infiltration, as well as diversion for different human needs including irrigation and only is partially replenished by return water. Every river has its own longitudinal profile and different cross-sections. The longitudinal profile indicates the nature of slope existing at different places and levels. The cross-section of a river varies from headwater zone to the mouth. These are called as river valleys which may be ranging from sharp canyons and gorges to wider flat streams nearer to the delta. The natural flow regime and the longitu- 
dinal and lateral connectivity of rivers are essential characteristics that sustain the biophysical and ecological processes necessary for life in freshwaters. The velocity of water flowing in a stream is not uniform along the longitudinal profile, also within their cross sections. The water in a river moves along the bank in one direction. The water in a river flows along a channel, made up of a stream bed between banks. The movement of water along the river is called a "current". Some rivers have been channelized (straightened) by humans to make boat navigation easier or for drainage purposes. The velocity or rate of speed usually changes when a river is channelized. A river may be called as major, medium and minor river based on its catchment area, number and length of streams and tributaries, stage of development and its discharge of water.

Rivers are primarily characterized by the length of time that they flow. A river may be few kilometers long, or it may cross an entire continent. Rivers are as $>8.25 \mathrm{~m}$ in width. River water is always on the move. Rivers are dynamic and complex systems with a unidirectional flow of matter and energy. A river is a powerful geological agent. At higher velocities, larger particles of sediment, sand and soil can be carried away by the current. It has the capacity to erode, transport and deposit the sediments. These are called as "river alluvium". The alluvial deposits, clay and silt of a river are the materials preferred for different activities. The flow of river systems carries the sediments, nutrients and other materials through the landscape and into other systems, providing vital linkages between the land, lakes, wetlands and oceans. It is because of this that rivers are often referred to as the environment's circulatory system. Rivers are part of the hydrological cycle and main source of water for people and animals. Rivers play a major role in the assimilation or in carrying off the municipal and industrial wastewater and run-off from agricultural land. The surface run-off is a seasonal phenomenon, which is largely influenced by the climate prevailing in the basin. Seasonal variations in precipitation, surface run-off, interflow; groundwater flow and water inflows/outflows have a strong effect on the river discharge and subsequently on the concentration of nutrients/pollutants in the river water [72]. River deposits large amount of nutrients. Rivers are larger lotic waterbodies, created mainly by natural processes. A river can be formed in several ways. Rivers are mainly from rain or snow that falls in places with higher elevations; some rivers also form by melting glaciers or underground streams. Some rivers flow during all year, but some rivers dry up in dry seasons. Rain and other types of precipitation move water overland, through terrestrial ecosystems and into river systems. The resulting runoff brings inputs of sediments, nutrients and materials into the river, causing running waters to be highly influenced by their surrounding landscapes. A river carries flowing surface water during some portion of the year. Flowing river water carries enormous amount of salts in solution and sediments in suspension. It also rolls up a lot of bed load along the bottom. The water flowing through a river is called as its "discharge". The volume and velocity of river discharge depends on several geomorphic factors. The suspended and 
bed load sediments carried along with other organic matter in the flowing water control the characteristics of the river ecology. The life along rivers, vary from its head/source to the mouth, from stream to stream, from country to country. The velocity of flow and force, nature of substratum like alluvium or rock bottom may determine some of the habitat of a river course.

The rivers are used for water supply to the domestic, industrial, agricultural processes. Most of the human civilizations were originated near water courses, especially along the major rivers. There are an impressive array of river habitats, which vary in size from the small trickles and seepages in upland areas that form the headwaters of major rivers to broad and deep channels of water, such as the river "Godavari", which has the largest mean annual river flow in District. River is an aquatic habitat comprising river bed-bank-floodplain complex. Rivers are ribbons of life-complex, productive, valuable communities of terrestrial and aquatic plants and animals joined and sustained by the many forces, interactions and pathways that make up a living stream. Rivers usually have extensive catchments and this, combined with the homogenizing action of flowing water, will usually ensure that they are characterized by less variable physico-chemical conditions than small lentic waters. Rivers are natural water resources, which contain sufficient factors responsible for growth of various organisms in the waterbody [73]. In the middle reaches of rivers, riparian vegetation has an important role in buffering potential impacts from the catchment [68]. Interactions between large rivers and their floodplains serve to maintain the biodiversity and ecological importance of these dramatic ecosystems. The role of rivers, however, is far greater than simple drainage since they provide crucial habitat for many of India's aquatic flora. Generally the more variety there is in habitat in and next to a river, the more variety there may be in the types of plants and animals that occur there. River banks form the basis of important riparian ecosystems which are home for a variety of plant species that are major sources of food and nutrition, traditional medicines and spices for local people. The character of a river (size, substrate, plants and animals), changes along its length from source to sea and is also influenced by climate, topography and geology. Flow rates and volumes will also influence the movement of material along the watercourse. These patterns of erosion and deposition create a variety of micro-habitats within the channel, such as bars and riffles, which influence their suitability for different animals and plants. Land consolidation influences the waterside vegetation and ecosystems along the riverbed that are because of the intensive agriculture production often partly or totally removed. The ecosystems along the river hold a significant importance in protecting the aquatic biota against the possible handicaps because of the chemical substances applied in the agricultural production. The nature as well as composition of flora and fauna largely depends on the source or origin of the river and the terrestrial ecosystems through which they pass. The running water of a river is usually well oxygenated, because it absorbs oxygen from the air. Due to mixing of water, dissolved oxygen content is more. Rivers 
are very important in the biosphere as they act as major transporters of materials from the land to the sea/ocean. Rivers deposit large amount of nutrients. Rivers support numerous species of aquatic insects, crayfish, mussels, fish and mammals such as beaver and river otter. A plant found mainly along the banks of rivers may have a greater need for water to grow, or might only be able to reproduce by spreading its seeds in water. Rivers are ecological corridors that promote the dispersal of plant propagules and connect habitats [74] [75]. Large numbers of plant propagules can be transported by rivers over large distances and deposited on the riverside slopes of the dikes and riparian zones [76] [77]. Thus, under the different stages of succession of dike vegetation, many dicot species can also colonize the dike slopes from the landscape species pool. There is a growing body of evidence that the results of human activity in different parts of a river ecosystem and its watershed can significantly affect the functioning of other remote parts of the system and can be harmful for biota and human beings.

\section{b) Rivulets}

Rivulet is a small stream, streamlet or a brook. "Penganga", "Wardha" and "Pranahita" are the rivulets of the river "Godavari". "Penganga" forms part of the northern boundary of the District, while "Wardha" and "Pranahita" form the northern and eastern boundaries of the District and these three rivulets merge in to the river "Godavari". Besides these, there are also rivulets like "Satnala", "Swarnavagu" and "Suddavagu", which drain in the District.

\section{c) Tributaries}

A tributary or affluent is a stream or river that flows into a larger stream or main stream (or parent) river or a lake. A tributary does not flow directly into sea. Most streams are tributaries, meaning that they drain into other streams. An important concept in hydrology is stream order. A streams' order is determined by the number of tributaries that flow into it. First-order streams have no tributaries. Two first-order streams combine to make a second-order stream; two second-order streams combine to make a third-order stream and so on. Some streams begin or are fed by other streams flowing into them. These are called tributaries. Its tributaries "Manjeera", "Pranahitha", "Indravathi", "Sabari” and "Sileru" are of note worthy stature. "Kadem" and "Peddavagu", the tributaries of the river "Godavari", are also drain the District. Pranahita, another important tributary of the "Godavari" is a mix of three small rivers, "Penganga", "Venganga" and "Wardha". It hails from the "Satpura" mountain ranges in Madhya Pradesh and flows in to the District of Adilabad and finally joins the "Godavari" at Chennur.

\section{d) Streams}

Streams are defined by surrounding land use (urban, agricultural and natural), size of the watershed, stream order, geology, soils, topography, flow and vegetation. A stream is a body of running water that occupies a channel. Streams are small lotic waterbodies created mainly by natural processes. It is freshwater and 
free flowing water systems. Streams are primarily characterized by the length of time that they flow. Streams may be permanent or only intermittently occurring during part of the year. Although three main types of streams namely perennial streams, intermittent streams and ephemeral streams occur, most of the streams in the District fall into the intermittent category. These usually occur in arid or semi-arid areas or in areas that are experiencing especially dry conditions. During times of extreme drought, even perennial streams can become intermittent. Although shallow sections of intermittent streams and rivers can dry up, perennial pools are often maintained in the deeper sections of a stream channel. Large pools can often sustain aquatic life through the hot summer months. Ephemeral streams only rarely have water in them, usually after rainfall in desert areas and are intermittent streams that regularly exist for a short period of time. Ephemeral streams are best illustrated by the dry stream beds in the study area that flow only following rainfall and cease to flow soon after. "Sadarmat", "Peddavagu", "Neelwai", "Ralevagu", "Gollavagu", "Suddavagu" and "Chelmelavagu" are the important streams in the District. Streams are found at all latitudes, but most predominant at high latitudes in the study area. Streams with powerful or low stable current are important ecosystems in the rural and tribal landscapes.

Streams are usually part of river drainage systems. Stream orders are numbered based on their role in feeding into another body of water. Streams are being $<8.25 \mathrm{~m}$ in width. Streams may begin as outlets of ponds or lakes. Streams are often spring fed. Streams gain their water through runoff, the combined input of water from the surface and subsurface. Flow is determined by the lay of the land if the stream has not been disturbed. As water flows, it picks up debris that scrapes the bottom and makes the stream bigger. Canalized streams carry water in one direction only. It is normally above ground, eroding the land that it flows over and depositing sediment as it travels. The running water of a stream is usually well oxygenated, because it absorbs oxygen from the air. Due to mixing of water, dissolved oxygen content is more. Streams are dynamic and complex systems with a unidirectional flow of matter and energy. Streams carry water in one direction only. As the water moves, it interacts with air and absorbs oxygen. Freshwater ecosystems in streams can have areas of fast-moving and slow-moving water, with organisms adapted to each area.

Hydrology, geomorphology, water quality, connectivity and biology are the components that influence stream structure and function. The most important part of a stream is its channel or streambed, the natural passage or depression in the ground that holds the water. The channel is always there even if no water is running in it. The deepest part of the channel, the route taken by the last (or first) bit of water, is called the "valley way". The sides of the channel, along the edges of the stream, are its "banks". A stream channel has a "right bank" and a "left bank" and the top end of a stream, where the flow begins is its "source". The bottom end is its mouth and in between, the stream flows through its main course or the trunk. Stream size, network density and geomorphic pattern are 
greatly influenced by the soils, bedrock geology, topography and precipitation [78]. Large streams usually have extensive catchments and this combined with the homogenizing action of flowing water, will usually ensure that they are characterized by less variable physico-chemical conditions than small lentic waters. Small streams represent ecosystems sensitive to environmental changes and attached diatoms can serve as integrative indicator with fast response to environmental changes, which can be demonstrated by much higher nutrient variation in shallow than deep waters.

Our need for freshwater has long caused us to overlook equally vital benefits of water that remain in streams to sustain healthy aquatic ecosystems. Streams are more than simply biodiversity. Streams have the potential to bring new streams of revenue to rural communities as well as enhancing ecosystem services that support food security in the longer term [79] [80]. Streams play an important role in the hydrological cycle, transporting water off the landscape and back to the estuaries and oceans. Streams are conduits for water and nutrients and are natural water resources, which contain sufficient factors responsible for growth of various organisms in the waterbody [73]. Streams are important sources of aquatic plants and animals for farmers. The nature as well as composition of flora and fauna largely depends on the source or origin of the stream and the terrestrial ecosystems through which they pass. Many of the streams have rooted aquatic vegetation and form the basis of important riparian ecosystems. Streams are home for a variety of plant species that are major sources of food and nutrition, traditional medicines for local people. The diversity of aquatic plants and animals depends on the variety of stream habitats and components with the plant and animal communities having coevolved with these components. A stream is a watercourse or freshwater ecosystem that supports fish or flows into fish habitat. Streamsides are linear habitat features and are often relatively highly disturbed. Streamsides act as important refuges for species not favored in the modern intensively managed countryside [81] [82] and could be important for CWR (crop wild relatives) diversity. Stream plants are strongly influenced by both stream bottom composition and flow regime, often changing from the headwaters to river mouths. Streams are home to many organisms and support numerous species of aquatic insects, mussels, fish, mosses and mammals. Anthropogenic modifications of streams have been decisive for the shaping of diversity. Due to physical modification and eutrophication, the rare examples of unmodified streams hold a particularly large number of species that otherwise would have disappeared from the freshwater ecosystems.

\section{e) Creeks}

A creek is a natural stream small to medium sized aquatic ecosystems and often fed by springs. What British people refer to when they say creek and what North American, Australian and New Zealand people refer to when they say creek are two different things. British creek is a very narrow and sheltered wa- 
terway. They actually refer to a tidal water channel by using the word creek. On the other hand, North American, Australian and New Zealand refer to a stream or waterbody that is smaller than a river as a creek. Creek in some parts is used as a synonym for a stream. There are many creeks occurring across the District on the plains, in the gravel terrace hills which are moderately-high gradient streams. Rock creek includes intertidal shore systems such as intertidal sand flats and rocky shoals. Rock creeks vary in depth from inches to several feet in the downstream tidal areas. Creeks on the slopes of the rock creek valley can be steep, high energy systems that pass over rocky cascades. Headwater creeks occur in all landscapes around the globe and may compose almost $80 \%$ of total stream length in many drainage networks [83]. These creeks do not pass over bedrock, but through clay and gravel soils and occasional iron-rich sandstone. Other creeks east of the "Godavari" river pass between those hills and are low gradient, low energy creeks. Creeks and headwater creeks in the District can vary in size and energy level. There is a mile-long, high energy reach of rocky shoals and cascades where the creek passes the fall line. Creek carries flowing surface water during some portion of the year and may dry up each year as the seasons change.

Creeks are usually part of river drainage systems. The role of creeks, however, is far greater than simple drainage since they provide crucial habitat for many of District's aquatic flora. Many of these creeks have rooted aquatic vegetation. Generally the more variety there is in habitat in and next to a creek, the more variety there may be in the types of plants and animals that occur there. They offer an enormous array of habitats for microbial, plant and animal life [84]. A plant found mainly along the banks of creeks may have a greater need for water to grow, or might only be able to reproduce by spreading its seeds in water. Creeks are vulnerable to the same man-made problem as the other natural aquatic habitats. These creeks are impacted by urbanization, including combined sewage outflow, storm water flows, fragmentation and pollution. All creeks in the District are impacted by high-flow events, driven by the piping of street runoff and other storm water into the stream valleys. Sometimes navigable by motor craft and may be intermittent. These characteristics define them as permissive environments, i.e., susceptible to the establishment of non-native species [85]. Creeks are among the most threatened systems in the planet [86]. Creeks are sensitive areas for the conservation of aquatic biodiversity due to their low species richness and high degree of endemism [84].

\section{f) Waterfalls}

A waterfall is a cascade of falling water where there is a vertical or almost vertical drop in the river's course. Waterfalls are common features of lotic ecosystems. Waterfalls are cascades characterized by fast and near-vertical flow. Gravity gives water this power and speed as it forces the river to flow down the mountain. Waterfalls, hereby used to describe near vertical drops in channel elevation where water is in a freefall condition, are not only very common in 
steep bedrock channels but may also persist for millions of years. Waterfalls can be found in many areas of the District. The study area is bestowed with number of scenic waterfalls at various places of the District like "Kuntala Waterfalls" and "Pochara Waterfalls". Waterfalls are highly localized aquatic ecosystems. In the study area, waterfalls were named after deities and were used as places of traditional and ancestral worships. Waterfalls are temporary features and eventually they become rapids and disappear from the landscape.

Waterfalls are formed from stream or river which cascade from a high elevation over a cliff or rock. Waterfalls are found in the youthful stage of a river because the water is flowing the fastest and with the most power. Most waterfalls develop where a river meets a band of softer, less resistant rock like limestone, after flowing over a harder, more resistant rock like granite. Waterfalls may also be formed by river rejuvenation and after mark the knick point of intersection between the old and new river profile. In other places, the intensity of waterfalls and pressure generated from it due to gravity has given the impression of a lifeless zone. Waterfalls are natural monuments for revenue generation, because of their ecotourism potentials and as source for drinking, irrigation and other domestic purposes. Waterfalls are also appreciated for their aesthetics and as valued source of ecotourism experience. The waterfalls represent potential nature-based tourism attractions that are capable of captivating tourist interests when developed. The edge of large waterfalls creates a spray zone which affects adjacent vegetation throughout the growing season. Waterfalls produce intermediate-sized, mainly negative ions. The presence of waterfalls affects the distribution of the fish fauna. Waterfalls are barriers to the dispersal of fish populations.

\section{g) Springs}

Springs are the spots where natural out flow of ground water back to the surface occurs where underground water is discharged onto the land surface forming a pond or stream. Springs are small wetland ecosystems that are hydrologically supported by groundwater discharge. Springs refer to multiple spring vents or seeps located in proximity to each other. A series of seeps and springs may occur along a line, which is then called a "spring line". "Spring pool" is a small body of water, either artificially impounded or naturally occurring, that encompasses one or more "spring vents". It contains spring discharge that flows into a "spring run". The point where a spring's water meets the surface is called an emergence, "arise", or a "boil". Springs often have a more persistent source of water. Depending upon the source of their water, springs may be "exsurgences" or "resurgences". They may also be "part-time exsurgences" and "part-time resurgences". Spring water is usually fed from a sand or gravel water-bearing soil formation called an "aquifer" or a water flow through fissured rock. The flow directly below this point is called a "run". Springs are important natural waterways in the District. Springs are found on the depressions and slopes at high latitudes mainly in hilly terrain viz., hills and secluded valleys of the District. They 
often begin in the hills. Further, springs can be found in a variety of locations in undeveloped habitats. Springs are found in old pastures, fields and forests of the District. Many springs in the District are isolated from other wetlands. Gravity depression springs, gravity overflow springs, artesian depression spring, artesian fissure spring, artesian overflow springs were the types of spring sources observed in the District.

Springs are characterized by groundwater inflow [59]. Springs occur where groundwater flows to the surface. Springs are hydrologically supported by groundwater discharge. Freshwater from ground may come from the last rain or snowfall, or it could have been hidden deep in the Earth for a million years. Springs occur when the water table is higher than the ground surface and pressure forces the water out of the land. Occasionally, rock formations intersect this vast underground network of reservoirs, permitting these hidden pools of water to once again see the light of day. The force of this flow depends on the elevation difference between the point where the water enters the ground and the point where it comes to the surface. These reentry points are usually through porous layers of sand or gravels and witched between harder, less permeable, layers of soil or rock or through cracks and fissures in the underlying rock. Spring water is usually fed from a sand or gravel water-bearing soil formation called an aquifer, or a water flow through fissured rock. Where solid or clay layers block the underground flow of water, it is forced upwards to the surface. Springs supported by local aquifers may periodically dry out, since local aquifers are comparatively small and shallow and the amount of groundwater discharge associated with them varies in response to local precipitation levels. Spring discharge, influenced by geologic and topographic features, occurs in response to hydrologic activity of a much larger area, likely influenced by fog input, recovering vegetation and precipitation. Springs supported by regional aquifers, or aquifers covering thousands of square kilometers, rarely dry, even during droughts, since the quantity of water within the aquifer is high and the groundwater flow is typically slow [87]. Springs have a concentrated flow. They always flow in one direction. Springs frequently flow downward over the land for a short distance before infiltrating back into the ground. They tend to last hundreds or thousands of years.

Some springs form small ponds where animals drink and people may well also scoop water. The water may emerge either in the open as a spring or invisibly as an outflow into a river, stream, lake or pond. Others flow as small streams in secluded valleys and can be traced back to the source. The source, though, is not necessarily the first upstream point at which the stream emerges from the ground. In some cases streams may be buried for quite a length and there can be added risks of contamination unless the investigation continues further upstream to locate the true spring. Large ponds or lakes that are supplied with water through openings in their beds are called spring-fed lakes. Springs are vital head waters of the river "Godavari". Springs are distinctive from other wetland 
and riparian habitats by the relatively constant water temperature and chemistry of the discharging groundwater [87]. This results from the groundwater being in contact with minerals for an extended period of time, which equilibrates solute concentrations. Thus, spring water tends to have constant concentrations of dissolved minerals while surface-fed streams vary in response to rainfall and snowmelt [88]. Spring environments (water temperature, water chemistry, etc.) are typically less variable than other aquatic habitats such as lakes, ponds and streams. Groundwater being in contact with minerals for an extended period of time equilibrates solute concentrations. Thus, spring water tends to have constant concentrations of dissolved minerals while surface-fed streams vary in response to rainfall.

Springs often may provide the only available source of drinkable water. The indigenous tribal community water supplies were, in fact, often based on springs and they remain a favored source, because the water usually has a high natural quality and intake arrangements are relatively straightforward. Because of their popularity, most natural springs have been developed in one way or another as drinking water sources. Local tribes, especially women (as drawers of water), but also farmers, hunters and gatherers and grazers, have a good knowledge of the location of springs and their characteristics. In the dry season, green vegetation in a dry area may also be an indication of a spring source. Many springs have been modified by structures intended to increase their usefulness to tribes.

Springs are unique habitats, which harbor concentrations and refuges of endemic plants and animals [89]. They provide important habitat and serve as a water source for wildlife. Springs are important sources of aquatic plants and animals for farmers. The dominant vegetation in these areas varies depending on elevation, topographic position and the permanence of groundwater discharge. Higher elevation springs often support similar plant species as those found in other wetlands at that elevation. Springs often have a more persistent source of water and thus support a greater diversity of wetland vegetation and often provide aquatic habitat [87]. The plant life found in and near springs is important winter food sources for wildlife and can be enhanced to provide higher levels of important biodiversity products. Their protection and maintenance ensure clean water for wildlife, plants and humans. Springs are important to wildlife during the winter because their movement often keeps the water from freezing. Unique water chemistry and/or edaphic conditions often provide habitat for rare plant species. Springs often exhibit diverse flora composition and structural characteristics which provide potential cover for resting, nesting and feeding for many different organisms, especially birds [87]. Many spring source species do not occupy downstream habitats where temporal fluctuations in water temperature and flow are greater [87] [89]. Springs which are isolated, are especially susceptible to disturbances since they lack connectivity and thus, have few mechanisms for recolonisation via drift and upstream movements. Many springs in the study site have been altered and/or modified from their natural condition due to 
anthropogenic disturbances such as livestock grazing and diversions and impoundments to capture water for human or livestock use. These disturbances can result in an increase of non-native species, a decrease in vegetation cover, inundation of spring brook habitat, replacement of species requiring flowing water with those more adapted to stagnate or slow moving water (lakes, ponds, etc.) and cause the extirpation of endemic spring species. Higher levels of biodiversity in undisturbed springs while disturbed springs have a high percentage of non-native species present.

\section{h) Canals}

Canals are man-made waterways which pass through rural and urban areas. It is an artificial waterway constructed for navigation or the conveyance of water, usually concrete-lined. A man-made waterway or artificially improved river used for irrigation, shipping or travel. Canals were created in the District during the second half of the $20^{\text {th }}$ century as structures for connecting irrigation water from reservoirs built on rivers and streams. Being man-made, the canal channel is a continually changing ecosystem. Built structures associated with canals include bridges, locks, canal side buildings as well as towpath walls.

Canals are artificially created habitats that have helped offset some of the losses but essentially, the disruption of natural river processes, largely connected to modern industry, agriculture and settlements, have much reduced diversity of habitats adjacent to and within rivers. The canals are characterized by slow water flow, which can be used as movement corridors. Canals offer recreational value. Canals are very artificial aquatic habitats. Canals provide wildlife corridors which link fragmented habitats. Canals provide rich wildlife habitats. Areas alongside and adjoining canals provide important wildlife habitat. The wildlife value of canals derives in part from providing an historic continuity for the entire waterway corridor, which includes the open water zone, canal banks, towpath verges, hedgerows, field margins and built structures. Semi-natural plant communities might colonize canals. The canal channel provides a habitat for aquatic and emergent plants and associated invertebrates, fish and semi-aquatic mammals. Canal banks, the area where land and water meet, are colonized by a variety of specialized and opportunistic plants as well as dragonflies, damselflies, reptiles and amphibians. Towpath verges along canals can often provide unimproved or semi-improved grassland habitat which is often less intensively managed than amenity or agricultural grassland. The verge also provides shelter and food for insects and larger animals. Canals adversely impact the structure of riparian vegetation and morphology [90]. In the absence of fast flow and the periodic scouring which occurs in rivers, silt continually accumulates on the bottom of the canal. If left without management, silt accumulation combined with plant succession can lead to reed bed and swamp development and the eventual formation of a terrestrial ecosystem. 


\section{2) Lentic Ecosystems}

The term lentic is derived from the Latin word lentus, which means sluggish. Lentic ecosystems are related to standing waters. Lentic ecosystems such as lakes can be formed by glaciers, volcanoes and shifting of tectonic plates and some are man-made. Waters within the lentic category gradually fill in over geologic time and the evolution is from lake to pond to wetland. This evolution is slow and gradual and there is no precise definition of the transition from one to the next. Some lentic ecosystems are freshwater with low salt content and others have a higher salt content. Lentic ecosystems take many forms, from small temporary pools to large lakes. Lentic ecosystems have a community of biotic (living organisms) and abiotic (physical objects) interactions. Lentic ecosystems vary considerably in physical, chemical and biological characteristics. As low points on the landscape, lentic ecosystems also serve a unique role as integrators of atmospheric and catchment scale climate signals [91]. These signals, or sentinel responses, are shaped by a number of factors including large-scale geographic patterns and internal waterbody processes. Lentic ecosystems have layers from top to bottom that support different organisms, depending on factors such as the amount of light and temperature. In addition to the longitudinal gradient, transversal gradient is also very important, that creates particular lentic ecosystems with specialized biota. Lentic ecosystems are standing water habitats that support a variety of organisms including algae, rooted and floating-leaved plants, frogs, fish and birds. Lentic ecosystems are an ideal habitat for waterfowl and amphibians. Algae and aquatic plants produce food for other organisms in the ecosystem. Many tiny invertebrates, called zooplankton, live in lentic waters. In lentic ecosystems, zoobenthos is very important compared with the pelagic communities of animals, particularly in shallow systems. They feed on algae and plants and provide food for other organisms such as snails and insects like water striders. The kinds of fish and other vertebrates depend on many factors, such as the salt content, amount of light and depth of the water.

Adilabad is in many ways abounding by its 8 diverse lentic HGM units: lakes, ponds, vernal pools, seeps, reservoirs, farm ponds and reservoirs, drainage ditches and water tanks. Of these, lakes, ponds, vernal pools, seeps are natural while reservoirs, farm ponds and reservoirs, drainage ditches and water tanks are artificial.

\section{a) Lakes}

In Greek, Limne means lake or marsh. Small waterbodies are also lentic habitats less than $10 \mathrm{~km}^{2}$ in surface area. Lakes are usually formed when natural depressions or basins in the land surface become filled with water over time. Lake is a shallow stagnant fresh waterbody. It is a permanent waterbody with large water resources. A lake is defined as a natural body of inland water. A lake is defined as an inland body of water of considerable size [92]. A lake is also defined as a depression or a group of depressions partly or fully filled by water, all parts of the waterbody have the same surface, excluding temporary variability, caused 
by wind or ice, the ratio between in-flow and volume is small enough to let most of the suspended, inflowing material to form bottom sediments and the surface area exceeds a given minimum value [93]. Lake can be also described as an area of land that is filled with water, localized in a basin that is surrounded by land and not connected to another body of water. Lakes are defined as naturally occurring low points in the landscape that contain standing water, predominantly in the form of open water habitat, year round. Lake ecosystem is also called as lacustrine environment. The formation of lakes, their physico-chemical conditions and the organisms inhabiting within them, are studied under the science of limnology. Lakes occur practically in every ecosystem. Lakes are commonly encountered in wetlands. Regional distribution and function of lakes is dictated by geomorphology. There are a few lakes mostly found in hilly areas and cascading valleys of Adilabad. The District has a very few natural lakes especially in the landscape of the lowlands. Lakes are an important part of tribal and rural ecosystems.

A lake can be either natural or man-made. Natural lakes are formed by natural phenomena such as glacial activity, volcanic activity, tectonic movement and river erosion. Artificial lakes are created by humans for agricultural or industrial use, hydroelectric power generation or recreational purposes, etc. The lakes form as a result of geologic events such as mountain building or rock displacement can also result in water filled basins. Sunken craters (calderas) of extinct volcanoes can also form lakes. Lakes are supplied with water from rainfall and streams. Lakes are fed by lower order streams. There are many different types of lakes, classified according to lake formation and origin, the amount of water exchange, hydrochemistry and so forth. They vary in size from a few square meters to thousands of square meters. Similarly, their depth varies from a few centimeters to over a hundred meters. The boundaries of lakes are well defined with a shoreline, an air-water interface and bottom sediment. Almost all lakes are freshwater natural lakes in the study area. The majority of the lakes in the world are freshwater lakes. Lakes are characterized by water with a high base content (hard oligomesotrophic waters), most often calcium but very rarely magnesium, are usually confined to areas of limestone and other base-rich substrates, from which the dissolved minerals are derived. In part the rarity of the habitat type is due to the fact that since calcareous rocks are free-draining, waterbodies occur on the surface of these rocks only very rarely. In addition, such waterbodies are characterized by very clear water and low nutrient status. Since the water in a lake moves very slow, it often appears to be still. Lakes contain water permanently; yearly fluctuations in water level are minor. Depth is one of the most critical components for lake ecosystems, as it strongly influences biological and chemical processes, including light penetration, temperature profile, amount of mixing, nutrient cycling and decomposition processes. In moderately shallow lakes light penetration is more. Organic matter and nutrients also accumulate in heavy amounts. In such waterbodies, productivity is higher. The body of water is 
usually moderate to big in size with the water surface being exposed towards the atmosphere. The abiotic components of lakes depend on location, latitude, altitude and the surrounding ecosystem. The external inputs are defined as atmosphere, stream water and terrestrial runoff from areas surrounding the lake. Examples of abiotic factors in a lake environment include sunlight, temperature, rainfall, water depth, soil, rocks and oxygen content and $\mathrm{p}^{\mathrm{H}}$. Lakes are always under the direct influence of rainwater, river water, sedimentation, biomass and productivity of organisms. Lake ecosystem maintains a state of equilibrium with reference to these factors, which are seasonally varying. An important feature of lakes is the evaporation of water from its surface. Sedimentation is a regular process in lakes. The movement of water masses occurs in the form of waves, currents, turbulent mixing and wind tides. Mostly they are caused by the wind. The waves have an abrasive power and the capacity to cut off the Earth's materials. The sediments deposited within the lakes are called as lacustrine deposits.

Lakes play a pivotal role in maintenance of the homeostasis in the system. Lakes play a very vital role in maintaining environmental sustainability particularly in urban environments especially in today's context when the cities are facing the challenges of unplanned rapid urbanization. Lakes perform significant environmental, social and economic functions, ranging from being a source of drinking water, recharging groundwater and acting as sponges to control flooding, supporting biodiversity and providing livelihoods. Water in lakes is an easily available source of water for the needs of many sectors of economy such as agriculture, domestic and industrial. Lakes provide water for consumption, fishing, irrigation, power generation, transportation, recreation and a variety of other domestic, agricultural and industrial uses [94]. Lakes and their basins possess many important values for humans. Lakes are some of the most beautiful and accessible parts of the landscape. They protect downstream areas against both floods and droughts and they serve as sinks for sediments and contaminants to protect downstream areas. Lakes usually contain freshwater and have high potential for aquaculture and conventional or enhanced capture fisheries. In developing countries, they are often centers of livelihood for small-scale local fishermen, as well as a base for much larger fishing operations.

Lakes create little worlds of their own. They serve as habitats for important food species comprising various forms of aquatic life and supporting the Earth's biodiversity. Water-plants of all shapes and sizes live under the surface of lakes. In a lake ecosystem, most of the aquatic habitats exist. Lake ecosystems are characterized by three adaptations as floating vegetation, submerged vegetation and animal adaptations. The floating plants have poorly developed root systems. To remain afloat, the leaves and stems are filled with air-spaces. The upper surface of the leaves is waxy. The floating leaves are larger and broader. The submerged vegetation possesses certain modifications for their growth and survival. The leaves lack a cuticle. Some of the plants are attached to the lake bottom and others float free. This vegetation provides food for water creatures such as bugs, 
snails and fish. Lakes are also the favorite haunts of waterfowl. Land animals use lakes for drinking water. They also obtain food from lakes in the form of fish, birds and plant life. Natural lakes vary widely in habitat and eutrophication. Lakes have a diverse variety of organisms. Associated with them are a variety of biological communities. A lake ecosystem includes biotic (living) plants, animals and micro-organisms, as well as abiotic (non-living) physical and chemical interactions. Less fertile lakes tend to be deep and well oxygenated with sandy substrates. More fertile lakes tend to be shallow with muck bottoms and dense stands of aquatic vegetation. Declining water quality, drainage, eutrophication and catchment disturbances such as development, loss of natural vegetation and poor agricultural practices are changing the fundamental ecology of shallow lakes in much of the world [95]. Lake water and life are subjected to several natural and man-made threats. Lakes involve complex of interrelated mechanical (currents, waves and sediment transport), physical (thermal and ice phenomena), chemical and biological processes. Some plants grow at the edges of lakes. Others live underwater or grow leaves that float on the surface. Lakes contain protists, such as algae and amoebas the eggs and young of frogs and some insects. Clams, bacteria and worms live on the bottom of lakes and break down dead materials for food. Frogs, turtles, fish and ducks have adaptations that let them swim in lakes. Lakes are natural water resources, which contain sufficient factors responsible for growth of various organisms in the waterbody [73]. Eutrophication of lakes has been decisive for the shaping of diversity. Due to physical modification and eutrophication, the rare examples of oligotrophic lakes hold a particularly large number of species that have otherwise disappeared from the freshwater ecosystems.

\section{b) Ponds}

Ponds are smaller bodies of still water located in natural hollows, such as limestone sinks, or that result from the building of dams, either by humans or beavers. Ponds are bodies of water surrounded by land. Ponds are inland depressions containing standing water. Pond is a still body of water of limited size either naturally or artificially confined. Ponds are bodies of water surrounded by land. Ponds are small bodies of standing water of man-made or natural origin, defined here as waterbodies between $1 \mathrm{~m}^{2}$ and 2 ha in area which hold water for four months of the year or more. Ponds are small bodies of still or standing water of natural or man-made origin. An area of still water between 0.5 and 2 ha in size lying in a natural or man-made depression. Ponds are defined as waterbodies between $1 \mathrm{~m}^{2}$ and 2 ha in areas which hold water for few months of the year. Ponds are waterbodies between $25 \mathrm{~m}^{2}$ and 2 ha in area which may be permanent or seasonal [96]. Ponds are found in most regions of the world. Ponds occur within a forested matrix. Riverine ponds occur in floodplains of the river "Godavari" of the District.

It includes both man-made and natural waterbodies. Ponds can develop naturally in a low-lying area. Interrupting the normal flow of a watercourse with a 
dam can also create a pond. These waterbodies often have small catchment areas and can, as a result, have highly individual physico-chemical characteristics that vary considerably between ponds depending on local geology and land use (e.g., entirely wooded, heavily grazed, draining acid- or base-rich strata). It receives enough water during rainy season. Ponds are small lentic ecosystems. Ponds may be permanent or temporary (seasonal). Ponds may exist either seasonally or persist from year to year. Shallow ponds represent sensitive ecosystems and attached diatoms can serve as integrative indicator with fast response to environmental changes. Pond is a stagnant freshwater body. Water is essential to the pond ecosystem. Ponds can be completely enclosed by land or can have either or both an in-flowing or out-flowing stream. The presence of inlet and/or outlet streams would indicate a permanent hydrology of ponds occurring within a forested matrix. The rocky ponds are filled by groundwater seepage and periodic flooding. A pond ecosystem includes biotic (living) plants, animals and micro-organisms, as well as abiotic (non-living) physical and chemical interactions. The abiotic components of ponds depend on location, latitude, altitude and the surrounding ecosystem. Ponds are characterized by the development of dense stands of emergent and submerged vegetation during the growing season. Ponds get polluted easily due to limited amount of water. Physico-chemical features of a pond are dependent upon depth, water source, location within drainage (e.g., a reservoir formed by a dam in a river), latitude, land-use and vegetation within and near the waterbody [97] [98]. Ponds are a good example of an ecosystem in which all elements work together to maintain a balance between physical and biological processes.

Ponds play an important role in aquatic ecosystems. Ponds produce a surrounding ecosystem that is unique. Ponds provide many uses for society. They are used for agricultural irrigation, nutrient and sediment retention, recreation, livestock, fish, wildlife protection and production and aesthetic appeal. The plants and animals of a pond work together for survival. Storm water draining from the nearby land can contain many unwanted chemicals that can be taken up by plants and animals and redistributed within the ecosystem. The quality of the water can determine the type of aquatic animals found and the health of the ecosystem. Their value as landscape elements and wetland ecosystem is widely recognized and especially the large ponds with their extended reed belts are designated catchment areas. But on the other hand, these ponds are often protected areas which provide habitats for endangered species as well as the special fauna and flora of a wetland ecosystem. Ponds are important to the watershed connection. They capture rainwater as it flows over the ground, reducing erosion and flooding. By holding storm water, ponds allow nutrients and other chemicals to be filtered from the water by plants and animals before it moves into rivers and lakes. Therefore, ponds can help protect the watershed from harmful pollutants. Ponds are important to the overall health of the watershed because they collect storm water before it enters larger waterbodies. Ponds have a di- 
verse variety of organisms. Rocky ponds host native and non-native fish species, many species of dragonfly, wading birds and dabbling ducks. Riverine pond has a slightly higher elevation and can dry out in summer and act as vernal pool habitat for several amphibian species. It contains several types of algae, aquatic plants, insects, fishes and birds. Composition of the plant and animal communities found in the ponds is strongly influenced by these physico-chemical conditions.

Ponds are often overlooked as habitats and sources of biodiversity, but they play many important roles in the landscape. Ponds are physically heterogeneous habitats. In a pond ecosystem, most of the aquatic habitats exist. A high proportion of species that depend on aquatic habitats are associated with both permanent and temporary ponds. The marshy/boggy interface between the pond and the terrestrial habitat is often where much of the important biodiversity is concentrated. It is important to ensure that good quality terrestrial habitat is available in association with the ponds. Ponds are linked by habitat corridors. Landscapes with ponds of various types are created in association with suitable terrestrial habitats. Ponds are rich wildlife habitats and collectively support Adilabad's freshwater plant and animal species. Ponds can provide much needed water for birds and wildlife. Wildlife depends upon ponds for food, shelter and breeding. Ponds are particularly important habitats for aquatic invertebrates and amphibians. Many types of organisms spend at least part of their life in pond habitats, which function as important breeding grounds. Amphibians spend their juvenile stages in ponds, as do many insects. Ponds also function as important stopover spots for migrating birds. These spots provide places to rest, as well as a source of food for migrating waterfowl. Some plants grow at the edges of ponds. Others live underwater or grow leaves that float on the surface. Ponds contain protists, such as algae and amoebas and the eggs and young of frogs and some insects. The seasonality of these waterbodies is, in particular, likely to explain their comparatively low species richness [96]. Threats to pond quality include, nutrient loading, pollution, acid rain and invasive species. Ponds often drain into larger bodies of water such as lakes and streams. Therefore, it is important to maintain the health of the pond. The type of land surrounding a pond is important to maintaining the health of the pond. If the surrounding land is used for agricultural purposes then chemicals used on the land may contaminate the water of the pond, raising the nutrient levels. A pond can become harmful to fish and wildlife when unnaturally high nutrient levels are present. The best way to maintain a healthy pond ecosystem and surrounding watershed is to prevent water pollution by picking up any debris that could be washed into the pond, using fertilizers sparingly on your farm and learning about the native aquatic life of your local pond. Ponds are landscape structures that are not set aside for agriculture production and are often destructed.

c) Vernal Pools (Ephemeral Pools)

Pools are temporarily water-filled depressions on a variety of geological sub- 
strates. Pools are typically temporary standing bodies of freshwater that occur in small and shallow depressions. Originally, vernal means spring and indeed, many vernal pools are filled by spring rains and snowmelt and then dry during the summer [99]. However, many vernal pools are filled by autumn rains (autumn pools) and persist through the winter and others are semi-permanent and do not dry every year. The cup-shaped basin, the general lack of vegetation, the presence of relatively thick organic soil layers compared to surrounding forests and the water stains left on leaves and the forest floor can reveal the locations of these pools. There is no permanently flowing outlet (physical), there is no established, reproducing fish population and breeding evidence of two or more facultative amphibian species (biological) are criteria for evidence of a pool [99]. Ephemeral pools are widespread in arid and semi-arid regions, where they form unique, mostly isolated habitats in an otherwise dry landscape matrix. Vernal pools are found across the landscape where small woodland depressions, swales, or kettle holes collect monsoon runoff or intercept seasonally high groundwater tables. Ephemeral pools are often found on flat inselbergs, either on top or on gentle slopes. There are a number of vernal pools in Adilabad District. Most vernal pools are wetland community types typically occur in depressions and at the bases of slopes in areas of upland forests within a forested context and are characterized as isolated forest depressions. The upland forests surrounding pools are critical to their ecological integrity. Many people associate vernal pools with dry woodland areas. Vernal pools also occur in river floodplains and large vegetated wetland complexes. Vernal pools appear in the same location year after year unless they are disturbed in some way.

Vernal pools occur in small, shallow closed basins. Some are naturally occurring basins but there are a few that are man-made. Vernal pools can vary in size from a few dozen square feet to several acres. Most pools are small, less than one half acre. Vernal pools perhaps may measure only a few feet to few yards across. Unfortunately, very small to identify this makes it more likely that they will be unwittingly disturbed. They are generally only a few feet deep, water depths are usually less than four feet. Pools tend to be irregularly shaped polygons. All pools have very small watersheds. The vernal pools typically fill with monsoon rains or emerge from a seasonally high water table. Many vernal pools fill primarily with precipitation and surface water runoff from the immediate surroundings, although inundation from local groundwater can also occur [100] [101]. Vernal pools are characterized by alternating flooded and dry phases. Some vernal pools are only temporary and only filled with water for part of the year either during a rainy or wet season but dry out early in the growing season. These depressions are typically underlain by a relatively impermeable layer, such as compact basal till, bedrock, or hardpan. The presence of a rich, organic surface layer of soil is a characteristic of pools resulting from the long duration of standing water in the rainy season. Consequently, runoff from rains fills these depressions with water that persists into the winter. Vernal pool habitat can oc- 
cur where water is contained for more than two months in the monsoon and winter of most years. Pools generally lack both stream inlet and outlet, although water may flow out of the pools during monsoon with especially heavy rains. Most pools have no connection to water sources via a permanent or ephemeral inlet. They often have ephemeral inlets or outlets which function only during high-water periods when pools are past capacity. Most vernal pools are hydrologically isolated from other permanent surface water sources and wetlands. Pools are short-lived, unpredictably filled and concomitant to the fluctuating water status. An ephemeral (seasonal) hydrology is one of the most critical characteristics of a vernal pool. Some larger pools may retain water all year long while smaller pools tend to dry up by late summer or early fall. Pools have slack and standing freshwater. As long as the pool has water in it there is always something interesting to be seen if you take the time to look. Water levels can change annually from flooded to dry and depend on the amount of precipitation that occurs each year. Ephemeral pools drying out at least during part of the growing season. They usually dry up after about two months and often leave virtually no trace. Pools may be difficult to identify after water levels have receded. The period of desiccation can last from a few days to several years, dependent on precipitation patterns and evaporative demand of the atmosphere [102]. They typically become dry during the summer but may fill with water again as a result of monsoon rains. Pools are characterized by the high variability and low predictability of environmental conditions. They are characterized by extremely variable conditions both on a diurnal and seasonal time scale [103]. The most important stress factors are frequent and fast desiccation and rehydration, long dry seasons, intensive solar irradiation and high temperatures during the dry season and extreme nutrient shortage, especially nitrogen. In most cases the individual pools lack any direct aquatic continuity, except perhaps for a short time when being flooded. Therefore, for the most part they represent both hydrologically and biologically isolated systems.

Temporary pools are stressful habitats not only in the dry state, but also when being water-filled. Although vernal pools dry up regularly, they are important sites for breeding and feeding for many organisms. Vegetation is usually sparse or absent, although adjacent forest trees may shade the pool. Pools only contain occasional trees. Pools are effectively shaded by the overlapping crowns of the adjacent forest trees. Because of this characteristic, pools are included as a type of forested wetland. Vernal pools generally have very little vegetation as a result of the long periods of inundation. Wetland plants may occur as scattered individuals or a narrow fringe around the margin of the pool's high water level. In some pools, annual plants may become established after water levels recede. Vernal pools contain graminoid or forb ecosystems. Many ephemeral pools are inhabited by either cryptogams or a low number of ephemeral macrophytes. Short-lived, unpredictably filled pools do not harbor truly aquatic macrophytes, but may support flooded terrestrial vegetation. In pools which are predictably 
water-filled for several months, annual aquatic macrophytes will grow.

Pools offer particular environmental conditions for plant growth, animal life and microbial activities. Due to their aquatic nature, ephemeral pools form unique, mostly isolated habitats in an otherwise dry landscape matrix. Pools are best characterized by the associated rich assemblage (communities) of invertebrate and invertebrate animals and amphibians. Yet, despite their small size and ephemeral nature, these seasonal pools support a rich assemblage of invertebrates [104] and breeding amphibians [105], many of which are largely dependent upon vernal pools to complete their complex life cycles. Pools are preferred habitats for many stream fishes during all or part of their freshwater life history. Vernal pools play as stepping stones or corridors for larger aquatic species as they move between larger bodies of water. Pools provide rearing habitat for juvenile fish, resting habitat for adults [106] and refugia from natural disturbances, such as drought, fire and ice [107]. Vernal pools constitute a unique and increasingly vulnerable type of wetland. Vernal pools are inhabited by many species of wildlife, some of which are totally dependent on vernal pools for their survival. Vernal pools do not support fish because they dry out annually or at least periodically [99]. Some may contain water year round, but are free of fish as a result of significant draw downs that result in extremely low dissolved oxygen levels. Invertebrates are both important predators and prey in vernal pool ecosystems. Vernal pools are an important habitat resource for many birds, mammals, reptiles and amphibians. Frog, salamander, egg masses and tadpoles and insects and other creatures are commonly seen. Grasses, sedges and reeds are important plants for stabilizing the soil around vernal pools. Vernal pools are unique wetland habitats that provide essential breeding ground for amphibians such as frogs and salamanders and for invertebrates such as fairy shrimp, clam shrimp and pea clams. There is a race against time for many of these species as they must complete the aquatic stage of their development before the pool dries up. The lack of predators, such as fish, makes vernal pools a safer arena in which these species can breed. Many species of aquatic insects also find refuge in vernal pools. Pools are landscape structures that are not set aside for agriculture production and are often destructed.

\section{d) Seeps}

Seeps are wet areas, normally not flowing, arising from an underground water source. Seeps are a common but often overlooked small wetland community types associated with groundwater seepage. A seep is a variety of spring in which the water comes, not from any definite opening, but through the pores of the ground over a considerable area. Seep is a wetland area located on gently to steeply sloping land and dominated by the colluvial (i.e., gravity-driven), unidirectional movement of water and material down slope [59]. Water inputs are primarily via subsurface flows from an up-slope direction [59]. Seepage is a site where groundwater of a superficial aquifer discharges to the surface, often at the toe of a slope. Seeps are small wetland ecosystems that are hydrologically sup- 
ported by groundwater discharge [89]. Seeps are the spots where water flows back to the surface. Seeps are areas where groundwater continuously surfaces and flows as a sheet down a slope. Seeps are places where freshwater, bubble or pass slowly through fine pores or small openings in the substrate. A seep infers one or more small openings in which water discharges diffusely (oozes) from the ground-water environment. Seeps occur on slopes where the water table intersects the land surface, resulting in groundwater discharge directly to the land surface; land that is down-slope of a break in slope of the ground water table; where subsurface discontinuities in geological units (e.g., faults) cause upward movement of groundwater; or on slopes where a relatively impervious sub soil layer impedes the infiltration of rain derived water into the ground. In these topographic settings, it is common to find a sub-surface layer of bedrock or hard pan that impedes the downward movement of groundwater, resulting in horizontal flow and discharge of water at the surface. It is common to find several locations with groundwater seepage at the upslope end of each seep. Seeps can occur in relatively flat or very gently-sloping landscapes, as long as there is sufficient slope for there to be a unidirectional subsurface flow of water. Seeps are found in old pastures, fields and in the forest of the District. Seeps occur in depressions and on slopes or at the bases of slopes in areas of upland forests. Seeps are common at the base of many gravel terrace hills east of the "Godavari" River. Seeps can be found in a variety of locations in undeveloped habitats. Seeps are located on gently to steeply sloping land. Seeps are often located on the side-slopes of a valley but they do not, typically, extend onto a valley floor. They occur at or near the base of slopes, in caves and on benches in areas of upland forest.

Seeps have no well defined origin. Seeps occur where ground water flows to the surface. Ground water discharge is evident at the seep margin. They are hydrologically supported by groundwater discharge. Water movement through the seep is mainly in the form of interflow, with diffuse overland flow (known as sheet wash) often being significant during and after rainfall events. Seep water may remain underground for many years, or even centuries, before it resurfaces. Water moves slowly through small openings of a porous material. Discharge is from intergranular pore spaces in the matrix and flow is typically laminar. A seep has a diffuse flow. Groundwater discharge provides a constant supply of water to the seep community, with flows at many seeps persisting even through the driest summer months. Seeps are characterized by their association with geological formations (lithologies) and topographic positions that either cause groundwater to discharge to the land surface or rain-derived water to "seep" down-slope as subsurface interflow. The local topography and the linear extent of seepage determine the size of individual seeps. Seeps are typically long and narrow with a total area less than one half acre. Seeps emerge over a larger area. The amount of water yielded by most seeps is small. Seeps can be categorized into those "with channeled outflow" and those "without channeled outflow". 
Water exits from a seep with channelled outflow mostly by means of concentrated surface flow, whereas water exits from a seep without channelled outflow by means of a combination of diffuse surface flow, interflow, evaporation and infiltration. A seep abutting a distinct river channel and feeding into the channel via diffuse surface flow or subsurface flow, but not having a channelized outlet from the seepage area to the adjacent channel, should be classified as a "seep without channeled outflow" even though it feeds into a channel. Many marshes and swamps are actually seeps on a large scale. Seeps are distinctive from other wetland and riparian habitats by the relatively constant water temperature and chemistry of the discharging groundwater [87]. Seeps provide relatively constant water temperature and chemistry, due to their dependence on subterranean flow through aquifers [87] [89].

Seeps are unique habitats, which have often been found to harbor concentrations and refuges of endemic plants and animals [89]. Seeps often exhibit diverse flora composition and structural characteristics which provide potential cover for resting, nesting and feeding for many different organisms, especially birds [87]. Unique water chemistry and/or edaphic conditions often provide habitat for rare plant species. The dominant vegetation in these areas varies depending on elevation, topographic position and the permanence of groundwater discharge. Seeps which are isolated are especially susceptible to disturbances since they lack connectivity and thus, have few mechanisms for recolonisation via drift and upstream movements. They support habitats made up of tiny mosses, lichens, ferns and flowering plants that cling to peaty soils that develop on the slope. They provide habitat for many wetland plant and animal species. Trees and shrubs are usually absent from seeps. Scattered trees may be present but canopy closure is usually from the adjacent forest. Occasional trees may also be found in the seeps themselves, but these usually tip over at a young age as a result of the saturated and unstable ground. Herbs are characteristic of seeps. Herbaceous cover can be lush and dense. They are well shaded by the overhanging canopy of the adjacent upland forest. The plant life found in and near seeps are important winter food sources for wildlife.

\section{e) Reservoirs}

A dam is a structure built in order to store river or tidal water. Dam is a constructed barrier, together with any associated spillways and appurtenant works, across a watercourse or natural drainage area, which permanently impounds and stores water, traps sediment and/or controls flood water. Embankment is a structure of Earth, gravel, or similar material rose to form a dam. Dams are usually located in the upper reaches of river systems and the impacts of the hydrological changes may decrease along the river as more tributaries join and the catchment area increases. Dams alter natural flows and downstream flood regimes and interrupt the continuity of sediment transfer from headwaters.

Increased human demand for water-related ecosystem services has resulted in 
the construction and operation of several dams locally in the District. "Vattivagu Reservoir" is a medium irrigation project. "Lower Penganga River" irrigation project is for drinking water and irrigation. "Kadem Reservoir" is for irrigation. Telangana State has a long tradition of constructing dams and reservoirs. "Kadem Reservoir" and "Vattivagu Reservoir" for Irrigation are dams and reservoirs in Adilabad, Telangana. These are only a subset of the Telangana State's reservoirs. Flowing water systems (rivers and streams) in the District have been greatly affected by building dams. Dams have fragmented the District's major rivers and streams into disjunct, largely disconnected ecosystems. Dams built to generate electricity and for other operations (irrigation, flood control, water supply, etc.) can constitute a serious threat to functioning of river systems [4]. Dam building causes disturbance in the dense forests. Dams can alter the hydrology of a site to the extent that the conditions that are necessary to sustain wetland vegetation or soils no longer exist, even though the soils are still classified as hydric and relict wetland vegetation is present. This is particularly true where rivers are managed for diverse objectives, such as navigation, irrigation, flood control and recreation. Finally, hydroelectric dams use the flow of water over turbines to generate electricity. Humans intentionally create artificial lakes by damming flowing rivers and streams to use them for power, irrigation, water storage and recreation. Damming is a human activity that influence on flowing water systems. Lotic ecosystem is dammed; a reservoir of water may (i.e., storage) or may not (i.e., run of river) be formed. Pre-existing lentic ecosystem is further impounded by the addition of a dam. River systems have been extensively altered through impoundments and diversions to meet their water and energy needs. Catchment-scale impacts of dams on ecosystems are generally well known, with both upstream and downstream effects stemming from inundation, flow manipulation and fragmentation. River basins in the District were strongly affected by fragmentation and altered flows. Strongly or moderately fragmented river systems are widely distributed in the District. Small dams can also have major affects on the ecological condition of inland water systems and many inland surface and groundwater systems have also been affected by modifications at smaller scales. Dams and embankments adversely impact the structure of riparian vegetation and morphology [90]. Freshwater habitats are globally imperiled and the construction and operation of dams is one of the major threats to such systems. Dams also affect the magnitude and timing of water flow and sediment transport of rivers, often for long distances downstream. Damming leads to river fragmentation, which diminishes the natural connectivity within and among river systems [108].

Technically, a reservoir is any human-made body of water that stores water for future use. Open reservoir is an uncovered concrete structure for storing water. Reservoirs, also called impoundments, are man-made lakes or man-made waters whether they are embedded in a river network or not. A reservoir is a man-made body of water, typically formed by building a dam on a river or 
stream and used for the collection and storage of water. Reservoirs are man-made areas holding water for irrigation and human use. Reservoirs are defined as an intermediary between lakes and rivers, but several other characteristics, including outlet control, origin and placement in a river network, more specifically define these systems [109]. Reservoirs are longer, narrower basins with more complex perimeter. Reservoirs or man-made lakes constitute an important inland fishery resource of India. Reservoirs are generally classified as small ( $<1000 \mathrm{ha})$, medium (1000 to $5000 \mathrm{ha})$ and large (75,000 ha). Small reservoirs differ significantly from the large and medium ones. In large reservoir, fisheries management lays emphasis on establishing relatively self-sustaining populations more or less on capture fishery norms, while small reservoirs essentially requires a stocking and recapture policy on an annual basis which is more akin to extensive aquaculture system. The inland fish production in North Telangana Districts is mainly from reservoirs, perennial tanks, village tanks and farmer dugout ponds. Reservoirs are primarily used for irrigation, hydroelectric power and domestic water supply.

A reservoir is formed by a dam in a river. Dams constructed on rivers impound the water forming reservoirs. Reservoirs occur lower in the catchment. Reservoirs are built for many uses. For example, reservoirs formed by dams used for irrigation. Some are built strictly for recreation (such as fishing and boating) or to control floods. Others are built to store water that may be used for drinking water and irrigation. The local expansion of reservoirs in the District has increased access to drinking water, irrigation, flood control and hydropower. Further, it has also fundamentally changed the movement of water, sediment, nutrients and biota through aquatic networks. The term reservoir is used to describe large lakes built for multiple purposes viz., flood control, drinking water, irrigation and recreational activities. Pool area is the location for storing water upstream from the dam. Reservoirs are fed by higher order streams. Surface water dominated reservoirs. The man-made reservoirs are used for water supply to the domestic, industrial and agricultural processes. Often, reservoirs can be thought of as a combination of lakes and rivers because they were created by building a dam and flooding a river valley. This damming and flooding creates an artificial lake, filled by the river inflow, with the same qualities of rivers and lakes. The upstream section of the reservoir has predominantly river-like qualities, meaning there is often still some current and the organisms in this section are usually those found in rivers. As the water moves closer to the dam, the current slows and the reservoir becomes more lake-like. At this point, many of the sediments and materials carried by the river settle to the bottom of the reservoir. Many of the organisms inhabiting this region of the reservoir are those more typically found in lakes. However, some reservoirs maintain river-like qualities throughout. The degree to which riverine properties dominate the reservoirs is often a function of the size of the impounded river and the amount of time water spends in the reservoir (termed residence time). Reservoirs with a short resi- 
dence time are more river-like while reservoirs with a long residence time are more like natural lakes.

Dams, reservoirs and diversions capture and store runoff water and release it as needed. They are used for controlling or moderating floods, producing hydroelectric power and supply water for irrigation, industry and other uses to rural, suburban and urban areas. They support recreational activities such as swimming and boating. It strongly influences the biological and physical characteristics of the modified system. Permanent dam disruption of river systems can have effects from species to ecosystem levels and from local to global scales [110]. The construction of dams poses a major threat to wetland biodiversity by inundating important habitats by reducing downstream water flows and thus disturbing the nutrient dynamics and displacing people into new ecologically-sensitive habitats by altering local microclimates. Inundation destroys terrestrial ecosystems and eliminates turbulent reaches, disfavoring lotic biota. It can cause anoxia, greenhouse gas emission, sedimentation and an upsurge of nutrient release in new reservoirs. Resettlement associated with inundation can result in adverse human health effects and substantial changes in land use patterns. Flow manipulations hinder channel development, drain floodplain wetlands, reduce floodplain productivity, decrease dynamism of deltas and may cause extensive modification of aquatic communities. Dams obstruct the dispersal and migration of organisms and these other effects have been directly linked to loss of populations and entire species of freshwater fish. Flow regulation by dams has disrupted the natural pulse flow regime of most rivers and has altered the processes that sustain biodiversity [111]. Building dams on rivers has major effects on aquatic ecosystems, many of them adverse. Changes to the flow regime can cause irreparable changes to biological communities downstream and to the physical characteristics of river channels, flood plains and coastal deltas. Riverine ecosystem is severely threatened by excessive water withdrawals in the north India and dams and industrial development in the south India as a result of ever-increasing industry, agriculture and tourism.

\section{f) Farm Ponds and Reservoirs}

Farm ponds and reservoirs are the impoundments, which may have outflow control structures (dam), may not have a dam or may not have an outflow. Examples include farm ponds and up-ground (above-ground) ponds (farm reservoirs). Farm ponds and reservoirs are human created waterbodies located in farmlands outside of a river network. Farm ponds are usually small bodies of standing water, surrounded by and containing vegetation, muddy bays of bare ground. Bodies of standing open water in non-crop areas of farm are called farm ponds. Farm ponds are usually small bodies of standing water in farmlands. Farm ponds are small freshwater bodies, usually artificial, occasionally natural, in rainfed and irrigated areas where aquaculture, particularly integrated with agriculture, is possible. Farm reservoirs are also created from old brick works 
or to provide fish. A small man-made farm pond can be called a reservoir. In general, the term farm reservoir is used to describe large lakes built for multiple purposes: flood control, drinking water, irrigation and recreational activities.

Farm ponds and reservoirs may be divided into two general types; namely, embankment and excavated ponds. An embankment pond is a body of water created by constructing a dam across a stream or watercourse. An embankment type pond is one if the depth of water impounded against the embankment exceeds three feet. Embankment ponds usually are built in areas where land slopes range from gentle to moderately steep and where stream valleys are sufficiently depressed to permit the storage of water to a considerable depth. Excavated pond is a reservoir constructed mainly by excavation in flat terrain. A relatively short embankment section on the downstream watercourse side may be necessary for desired storage amount. An excavated pond is a body of water created by excavating a pit or dugout. These usually are constructed in relatively level areas. The fact that their capacity is obtained almost entirely by excavation limits their use to locations where only a small supply of water is required. Farm ponds come under uncultivated land and may be found at lower elevation of the farmland. To create a farm pond, dig a slight depression into the ground and allow it to fill naturally with water. Ponds are also built in gentle to moderately sloping areas where capacity is obtained by both excavation and the construction of a dam. Farm ponds are an important component of agricultural landscapes. Farm ponds in the case study area are essentially man-made waterbodies mostly constructed for rain water storage. In most cases, man-made farm ponds were obvious due to their shape and landscape context. Currently, in Adilabad District, more and more farmers are building farm ponds on a tenth or twentieth of their land. Farmers often build irrigation ponds at the tips of the rivers or took advantage of natural ponds. However, in the traditional rural landscape, farmers often maintain ponds near their fields. Ponds are situated in the agricultural floodplain landscape of rural and urban landscapes. It may be appropriate to create or recreate ponds in naturally wet areas, but care should be taken not to affect fruit trees or areas of species-rich grassland. Ponds are closely connected to their environment; therefore, existence and cultivation of ponds are dependent on environmental changes. These farm ponds are often seasonal and will dry out during hot, dry spells. Farm ponds lack notable flow. While many landscape elements are interconnected, ponds were separated by some distance. Ponds can become ecologically isolated if they are scattered too far apart. Ponds with high biodiversity value are often cited in natural hollows, close to remnants of other habitats such as tree lines, earthen banks, hedgerows and orchards. Ponds close to one another form a network of ponds in the landscape.

Farm ponds play an important role in the landscape and culture of rural people. In the past, farm ponds were created for several reasons, many were 
made to provide water for livestock. Farm ponds are the areas of a high biodiversity. They get colonized naturally with plants that can cope with the changes in water level, if not, can be planted with some species bought from garden centers or a suitable seed mix. Quite unevenness in depth and around the edge can attract as wide a range of biodiversity as possible. All of these areas of open water can be valuable to wildlife, both intrinsically and as a component of the wider habitat mosaic that is collectively termed farmland. Their value as landscape elements and wetland ecosystem is widely recognized and especially the large ponds with their extended reed belts are designated catchment areas. But on the other hand, these farm ponds are often protected areas which provide habitats for endangered species as well as the special fauna and flora of a wetland ecosystem. Ponds are wetland habitats. Farm ponds can be particularly important for amphibians. Where farm ponds are present they add to the mosaic of habitats and benefit a range of wildlife in farms and orchards. Ponds also support a range of plants. Larger ponds can be important for wetland birds. Despite popular belief, ponds that dry out, either partly or completely, during the summer can also be important for wildlife. The muddy margins of these ponds provide important feeding habitat for birds such as lapwing as well as an important micro-habitat for some specialist plant species. Ponds that dry out also tend to lack fish, which makes them more attractive to amphibians. Nowadays, livestock are generally provided with piped water in troughs and steam engines are no longer part of the normal agricultural scene. As a consequence farm ponds have lost much of their original purpose and many have been lost, either through natural succession to dense scrub and woodland or by active infilling. In other instances, the pasture in which farm ponds were once created has been converted to arable leaving them isolated within a sea of intensively cultivated crops or improved grassland and subject to pollution from fertilizer run-off. Intensive stock grazing around farm ponds can also lead to excessive trampling and grazing of the pond edges also leading to loss of biodiversity. Farm ponds are a vital part of the lifecycle for all biodiversity. Farm pond in an orchard will help attract and keep both pollinators and animals that will help control pests on fruit. Different sizes increase the variety of wildlife. Heterogeneity in habitat has a bottom-up effect on biodiversity, maintaining farm ponds as regionally rich habitats. In recent decades, farm reservoirs have been constructed on many farms to provide a store of water to irrigate crops. Farm reservoirs also support a range of plants and invertebrates; the most conspicuous of these being the dragonflies and damselflies. Larger reservoirs can be important for wetland birds and also support a range of plants.

\section{g) Drainage Ditches}

A long, narrow excavation artificially dug in the ground; especially an open and usually unpaved waterway, channel, or trench for conveying water for drainage or irrigation and usually smaller than a canal. Drainage ditches are small, stagnant, line-shaped waterbodies, dug to improve rainwater run-off and regu- 
late the groundwater level of surrounding agricultural areas. Some drainage ditches are natural watercourses, while other ditches are man-made channels (or waters). Both permanent and temporary ditches are often the first concentration point of water draining from agricultural land [112]. Small ditches surrounding fields are common in some river flood plains of the District. Ditches are restricted to flood plains of the river "Godavari". They are a prominent feature in the agricultural landscape of the lowland (bottomland) farmland in the District. Drainage ditches are a common aquatic habitat in the lowland agricultural landscape. Ditches are mostly restricted to those on level ground.

Drainage ditches are small semi-natural lentic ecosystems. Water flow in the drainage ditches is either slow (limited) or negligible; they can be regarded as stagnant waters. Ditches have slow flow of water that can often be in either direction. Drainage ditches are either seasonally flooded or permanent; yearly fluctuations in water level are minor. Possibly, the high degree of physical habitat connectivity in drainage ditches in comparison to small lakes counteracts the effects of their relative instability and small individual size. Drainage ditches can alter the hydrology of a site to the extent that the conditions that are necessary to sustain wetland vegetation or soils no longer exist, even though the soils are still classified as hydric and relict wetland vegetation is present. Whilst most wetlands are designated as nature reserves, drainage ditches are generally viewed purely as hydrological infrastructure in support of agriculture. Ditches of the coastal levels have generally a fine silt or clay substrate and those of the inland moors are generally peat based soils, or silt underlain with peat.

Ditches are primarily for agricultural purposes. Ditches have the potential to reduce the amount of chemicals and sediment entering the wider water catchment. By retaining water across the wider landscape in times of high flow, ditch management may reduce flood risk. These contribute to overall species diversity at local and landscape scales. Ditches are the stronghold for distribution of a wide range of plants and animals in the largest area of lowland wet grassland in the District. Drainage ditches are characterized by the development of dense stands of emergent and submerged vegetation during the growing season. A ditch, initially containing open water, undergoes natural succession through various stages, through colonization by aquatic plants and plants from the banks, resulting in ditches that support dense, species-rich plant communities. It can take several (3 - 5) years for a ditch to reach its maximum plant diversity. Drainage ditches are wetland habitats. Ditches can act as reservoirs for potentially important regional wetland biodiversity. Drainage ditch networks are comprised of spatiotemporal mosaics of habitat patches. These small, shallow, line-shaped waterbodies could harbor a rich macro-invertebrate community, resembling that of natural small lentic ecosystems. As linear wetland areas, they provide very different habitat compared to other farm habitats and are particularly important for aquatic plants [113], aquatic invertebrates [114] and amphibians [115]. Ditch invertebrate communities undergo succession, organisms 
coming in and moving away as the system develops. Ditches and their margins may also function as corridors within the landscape for other groups, including pollinators [116] and small mammals [117]. Ditches supply ecosystem services such as diffuse pollution mitigation.

\section{h) Water Tanks}

Water tank is usually a dugout water storage reservoir with a consolidated embankment. Water tanks are the important feature among waterbodies. In many parts of the District, water tank is an essential feature of the villages and towns. Indian civilizations, for centuries, have either settled near existing waterbodies or created artificial tanks damming streams and harvesting rainwater. Water tanks are nearer to villages and towns of the case study area. The water tanks are well distributed over the case study area and are not linked to each other. The positioning of smaller water tanks is more versatile. Sometimes water harvesting structures connected to it. Water tanks are situated in a place that can be easily accessed by neighboring village people as well. Not all villages have their own water tanks and thus available tanks are shared to take baths and wash clothes and household articles among those who have no alternative. However, with time, the demand on water tanks has increased. Adilabad District is covered with an irrigation network of water tanks locally known as "Cheruvu" [118]. Water tanks in District are mostly man-made with the result of man's activities. In the District, about $28.3 \%$ of the irrigated area is irrigated with tanks. Some of the oldest man-made water tanks in the country are situated in the Telangana State.

These structures can vary widely in size and can be individual or collective. Water tanks are the rainfed waterbodies. Water tanks in Telangana State are classified in to two categories, viz., perennial and long seasonal. They show higher seasonal variations in turbidity levels. They often dry out before the end of the dry season but provide considerable help to the villagers. Tanks perform various important and indigenous functions in any urban, peri-urban and rural areas. Historically, water tanks are constructed in many areas for agricultural use, for domestic water supply and recreational purposes. These impounded waterbodies primarily provided water during periods of scarcity and served to control floods. They are generally used for all water needs of the village. Tanks provide water for human needs and nesting sites for a variety of avifauna. Tanks often have cultural and religious significance for the local population. Festivals and religious ceremonies are also associated with these waterbodies. District has numerous tanks that support important fisheries which provide livelihoods for millions of people and contribute significantly to the food supply. Each of these waterbodies is unique and has its own ecological character that is defined by the flora and fauna and, the urban ecosystem service it performs.

\section{3) Wetland Ecosystems}

A wetland is an ecosystem that depends on constant or recurrent, shallow 
inundation or saturation at or near the surface of the substrate. The term wetland refers to ecosystems dominated by water-loving plants and having wet or saturated soils. The wetland ecosystem includes all moist to wet terrestrial areas that are not under cultivation. Wetlands form a vital link between land and water. Wetlands are intermediate between terrestrial and aquatic ecosystems. Wetlands have extensive boundaries with both terrestrial and aquatic ecosystems. The term wetland covers all natural and artificial inland water habitat types including freshwater, permanent and temporary systems and above ground systems. Freshwater wetlands are areas of land that are covered with freshwater for part of the year. Wetlands are areas intermediate between aquatic and terrestrial habitats. Wetlands are unique, productive ecosystems where terrestrial and aquatic habitats meet. Wetlands are transitional habitats between aquatic and terrestrial environments, where water table is at or near the surface.

The minimum essential characteristics of a wetland are recurrent, sustained inundation or saturation at or near the surface and the presence of physical, chemical and biological features reflective of recurrent, sustained inundation or saturation. Wetlands are temporarily or permanently saturated, or soaked or covered with a shallow layer of water for all or at least part of the year. Wetlands have saturated (water-logged) soils that contain a great deal of moisture. Common diagnostic features of wetlands are hydric soils and hydrophytic vegetation. These features will be present except where specific physico-chemical, biotic, or anthropogenic factors have removed them or prevented their development. Wetlands are characterized by a predominance of hydrophytes, where conditions are at least periodically wet enough, during the growing season, to produce anaerobic soil conditions and thereby influence plant growth. A hydric soil is a soil formed under conditions of saturation, flooding, or ponding long enough during the growing season to develop anaerobic conditions in the upper part. Thus, largely permanent waterbodies such as ponds, lakes, lagoons and rivers below the depth of rooted plants (littoral zone) are excluded. As shown by the reference definition, three major factors characterize a wetland: water, substrate (physico-chemical features) and biota. The states of the three factors that characterize wetlands are the criteria for identification of wetlands: recurrent, sustained saturation (the hydrologic criterion), physical and chemical conditions in the substrate that reflect recurrent, sustained saturation (the substrate criterion) and the presence of organisms that are specifically adapted to recurrent and sustained saturation of the substrate (the biological criterion). Examples of abiotic factors in a wetland include: sunlight, rainfall, soil composition, oxygen content and temperature. According to this definition, a wetland is taken to be a type of aquatic ecosystem. Wetlands are uniquely shaped by a number of interconnected factors, especially the volume, velocity, salinity and permanence or transience of water. Underlying geology, the soil, climate, ground-water levels, water fertility and chemistry and the plants and animals living in them also strongly influence 
the characteristics of wetlands. Depending upon the duration of water logging, freshwater wetlands are grouped into two major types: (i) the perennial wetlands, with water logging throughout the year, include habitats such as river banks and margins of large lakes or reservoirs and (ii) seasonal wetlands which dry up completely for varying periods of time depending upon the vagaries of monsoon. Wetlands have been extensively drained and presently occupy only a fraction of the hydrological potential. The diversity of wetlands is closely related to the hydrological regime and particularly the amount of pure unpolluted ground water and rain water.

Wetlands are found at all latitudes of the study area. Most wetlands are located in the riparian areas of the study area. Wetland ecosystems are directly or indirectly associated with "Godavari" river system in the study Area. Generally, southern Peninsular India has very few natural wetlands. In many cases, wetlands occupy a small portion of the total landscape usually less than $10 \%$. In some cases, they occupy virtually the entire landscape. Wetlands may range in size. The vast majority of wetlands are tiny and show aggregated patterns of distribution on the landscape. Many kinds of wetland ecosystems are found within the District. Classification of some kinds of wetlands has been particularly controversial, typically because of special difficulties associated with identification or delineation. Forested wetlands are found in the forest ecosystem. Non-forested wetlands occur in areas where a periodically or permanently high water table, nutrient deficient ground water and/or grazing and mowing promotes wetland herbs and mosses and prevents the succession towards forest. Riverine wetland is a hydrogeomorphic class of wetlands found in floodplains and riparian areas associated with stream or river channels. Riverine wetland is a hydrogeomorphic class of wetlands found in floodplains and riparian zones associated with stream or river channels. Fringe wetlands are wetlands that occur along or near the edge of a large body of water (e.g., lake) such that the water surface elevation of the wetland is influenced by tides and seiche activity of the adjacent waterbody. Fringe wetland is located near a large body of water, most typically the ocean and receives frequent and regular two-way flow from astronomic tides or wind-driven water-level fluctuations. Slope wetland is a wetland typically formed at a break in slope where groundwater discharges to the surface. Typically there is no standing water. Ephemeral wetlands can be found in land systems other than coastal dunes. After rain, all the hollows fill with water. Some dry out almost immediately, but others take days and weeks and some pools remain as permanent water. It is not known whether this deterioration of the natural character resulted from a lowering of the water table, so that the periodically wet areas are no longer inundated as deeply or for as long, or whether there was over sowing of pasture plants or use of fertilizer. In all seasons, high table water determines the ecological character of these dune hollows. As well as providing conditions for wetland plants and fauna, periodic inundation is essential for weed suppression. Relatively few adventive species seem to cope with the alter- 
nate wet/dry nature of the habitat. Although the term ephemeral is used to describe such wetlands in this paper, other authors have used terms such as temporary or seasonal. Given the flat to gently rolling topography, many of the lost habitats may have been depressional wetlands. We define depressional wetlands as areas with hydric soils that occur in an area of lower elevation, surrounded by higher elevation, so that surface outflow is not sufficient to drain the area. Depressional wetland is a wetland located in a depression in the landscape so that the catchment area for surface runoff is generally small. Depressional wetland is a wetland geomorphic setting that occurs in depressions, but usually at the headwaters of a local drainage. Consequently, surface flows are restricted. Depressional wetlands provide ecosystem services, by contributing to species diversity and genetic diversity in a landscape. The loss or alteration of isolated wetlands can reduce the number of areas at which some species can reproduce and recruit juveniles and increase the distance between neighboring wetlands, so that extirpated populations are less likely to be renewed by a neighboring source population [119]. Wetlands that are isolated from other surface waters or that occupy headwaters are not necessarily less valuable or less functional than other wetlands are and they may even perform some unique or particularly valuable functions, including maintenance of water quality and the support of waterfowl. Especially shallow wetlands that might be dry much of the year, but that are maintained by repeated seasonal saturation or inundation, require protection even at times when they are completely dry if they are to retain their functions.

Artificial wetlands are aquatic ecosystems where hydric soil features have developed, or where wetland plants have colonized, in historically non-wetland areas due to human activities. Agricultural wetlands are artificial wetlands. Wetlands may also develop in former non-wetland areas due to diversion of water for irrigation or other uses. Agricultural wetlands are generally found in extensively altered landscape. Agricultural wetlands, which for present purposes include both farmed wetlands and non-farmed wetlands within farmed areas, are extensive within the District. Agricultural wetlands are defined as wetlands found on agricultural lands. Agricultural lands, in turn, are those that are intensively used and managed for food and fiber production and from which natural vegetation has been removed and cannot be used in making a wetland determination. Examples include cropland and pasture composed of planted grasses and legumes; orchards; plantations; and areas that support wetland crops such as taro, sugarcane and rice. They often perform functions that are similar in nature to those of non-agricultural wetlands. Wetlands in agricultural settings have the same range of natural functions as do wetlands elsewhere. Agricultural wetlands can be particularly important for controlling water quality, preventing floods and maintaining biodiversity. In addition, they often receive sediment, nitrate, phosphate, organic matter and pesticides associated with the agricultural practices on adjacent lands. There has been considerable research on the ability of 
wetlands in agricultural settings to serve as sinks for fertilizers such as phosphate and nitrate [120] [121] [122] [123] and a limited number of studies show the potential for wetlands to adsorb agricultural pesticides [124]. The water quality improvement function is often well developed in these systems, although pollutants can cause stress. Because many former wetlands were drained for crop production, the hydroperiods of wetlands that remain on or near agricultural lands might have been altered and floodwater retention functions diminished. Thus, although the wetlands in agricultural settings are potentially valuable for maintenance of water quality, they can be significantly disturbed and can show reduced functional capacity present the argument that natural wetlands in rural settings should not be used as sinks for processing of nonpoint source pollutants because natural wetlands have been greatly reduced in agricultural settings and should therefore be preserved for their habitat and recreational values [125]. Also, these wetlands in many cases already receive significant amounts of agricultural runoff.

Wetlands are an important part of the environment. Wetlands are among the world's most productive environments. Wetlands provide a myriad of services to society worldwide. Wetlands provide a range of ecosystem services. These include storing and purifying water, providing flood and erosion amelioration, ground-water replenishment, providing nurseries and habitats for native fish and eels, supporting a wide range of threatened plant and animal species, retaining nutrients and sediments, providing carbon storage and delivering recreational opportunities. Wetlands provide storm water filtration and improved water quality, flood protection, shoreline erosion protection, wildlife habitat and recreational opportunities. Many wetlands are home to important biodiversity and areas of cultural, recreational, educational or scientific value. Bursting with biodiversity, wetlands are a vital means of storing carbon. Wetlands are also tremendously productive ecosystems. Wetlands perform several important environmental functions. Wetlands act like filters or sponges that absorb and remove pollutants from the water. They also control flooding by absorbing extra water when rivers overflow. Wetlands collect and filter water, removing some pollutants. They protect nearby land and shore from floods and erosion. They purify and replenish our water and provide the fish and rice that feed billions. They serve as a natural sponge against flooding and drought, protect our coastlines and help fight climate change. Wetland ecosystems are essential for sustaining the ecology and economy of grasslands. The ecosystem services provided by wetlands include their ability to improve water quality, regulate water flow, provide water, food and other natural products for human consumption or use. The vital role played by many wetlands in agro-pastoral production systems and local livelihoods underpins the health and well-being of many rural communities. Wetlands represent high-value ecological infrastructure for gathering, managing and delivering water for human use. The value of access to wetland area is low for people not living in close proximity. People may find it valuable 
to know of high nature content in wetlands, in general, even if they do not themselves visit these areas. They provide essential services, such as maintenance of atmosphere composition. Natural biological functions of all wetlands include food chain production, general habitat and resting-nesting-spawning-rearing areas for animals and fish.

Wetlands are one among the most biologically productive freshwater areas. They provide key habitats for migratory species and important nursery areas [126]. Wetlands are areas of high biodiversity and productivity [127]. Wetlands are ecosystems with a high range of biodiversity. Wetlands are often considered among the most biologically diverse of all ecosystems. Wetlands play a critical role in maintaining many natural cycles and supporting a wide range of biodiversity. Wetlands have high species diversity. Wetlands support a flourishing community of aquatic organisms. Biologically, wetlands are known to be too diverse as it harbors numerous animals and plant species. Wetlands support diverse communities which harbor algal species and higher plant species. Terrestrial wetlands are important habitats, especially for specialized vascular plants, mosses, invertebrates and birds. Wetland ecosystems are ecologically sensitive, diverse places where water is a dominant environmental factor and the plants and animals living there have adapted to living in the wet and often changeable conditions. Wetlands are very important storehouses of plant genetic material; some of which are valuable resources for human wellbeing. This habitat supports plants adapted for life in wet conditions. Plants in wetlands can live in wet soil. Freshwater wetland types are dominated by water-emergent plants rooted in soil. However, aquatic macrophytes are excluded. Sedges are commonly found in wetlands. Trees are the largest kinds of plants in wetland ecosystems. Trees have the greatest ability to modify the environmental effects of solar radiation, precipitation, temperature, humidity and air quality as a result of their above-ground biomass. These natural, localized environmental modifications are of vital importance to the other plants and to the animals that live within and beneath forest cover. Tree leaves produce more tons of biomass per acre than shrubs for consumption by grazers and accumulate larger standing crops of organic material above ground. Tree trunks and limbs provide food for some animals and homes for many, with more complex structure than scrubs or herb lands. Some herbaceous wetlands occupy the shallow fringes of large waterbodies, where they serve to reduce wave action and encourage sedimentation, thereby protecting water quality. Wetlands are important habitats for broadly valued wildlife. These areas provide a home for native and migratory wildlife. Wetlands provide food, shelter and water for numerous species of birds, amphibians, reptiles and mammals. Many migratory birds use wetlands as nesting areas or stopover places. Freshwater wetlands are home to butterflies, dragonflies, mosquitoes, frogs, turtles, ducks and a variety of fish species. Wetland ecosystems have suffered a serious decline worldwide due to human influence [128] [129] [130]. Although they do not fall into any single 
biome type, wetlands have endured intense habitat destruction in many parts of the world.

Adilabad is in many ways abounding by its 3 diverse wetland HGM units. Natural wetlands like swamps, marshes and artificial wetlands like agricultural wetlands are examples of HGM units under wetland ecosystems in the study site.

\section{a) Marshes}

Flat, wet, treeless areas usually covered by standing water and supporting a native growth of grasses and grass like plants. Marsh is a wetland with emergent, herbaceous vegetation. A marsh is also referred to as a morass. Marshes are often found near the fringes of lakes and streams. Freshwater marshes tend to occur on low, flat lands. A marsh often serves as a transitional area between land and aquatic ecosystems. Areas that receive frequent floods and the water does not get drained away easily classify as marshes. Freshwater marshes have little water movement. In shallow waters, plants root themselves in the rich bottom sediments while their leaves stick out about the surface of the water year-round. There are several kinds of marshes, each of which is characterized by its salinity. Brackish marshes have slightly salty water, while salt marshes contain saltier water. The benthic zones of marshes are nutrient rich and contain plants, numerous types of decomposers and scavengers. Marshes also attract migratory birds from temperate and tropical habitats. A marsh is a type of wetland where herbaceous plants are the dominant vegetation. An herbaceous plant is a plant that does not have any woody stems above the ground. Grasses and reeds are the most common plants found in marshes. Most woody plants that live in marshes are shrubs that grow to low heights. A marsh can be thought of as a wetland dominated by grassland. These areas have shallow water levels with small plants in the form of grasses and moss growing over the wetland. Even a few woody plants that are seen in a marsh are shrubs rather than high trees.

\section{b) Swamps}

Swamp is an emergent wetland in which the uppermost stratum of vegetation is composed primarily of trees. Alluvial swamp is a forested floodplain wetland with soils consisting generally of fine-grained sediments that have been deposited by overbank transport of sediments from a stream. Swamps occur on flat, poorly drained land, often near streams. This type of wetland is often found along large rivers and lake shores. A swamp is also a wetland that gets formed because of floods with shallow water remaining in the area permanently. Swamps often have stagnant, slow-moving water. Swampy areas have dry land and that is covered with thick vegetation. This vegetation tolerates water when it comes in the shape of a flood. A swamp is a wetland dominated by trees and other woody plants. Swamp vegetation is often dependent on the water level fluctuation. This in particular is the case with swamps found near large rivers. There are two kinds of swamps: swamp forest and shrub swamps. Swamp forests are better known as freshwater swamp forests or flooded forests. These are swamps in which forests are saturated with freshwater during part of the year, or 
permanently. They exist near freshwater lakes and the lower portions of a river. A shrub swamp is not considered a true swamp like a flooded forest is. This is considered a transitional swamp. This type of swamp is the transitional area between a meadow and a flooded forest. A natural disaster, such as fire, flood, or a storm, will be followed by a shrub swamp. As mentioned before, a shrub swamp is a transitional swamp, from a meadow to a true swamp. A meadow might be drained and this progresses to a shrub swamp and later a true swamp, also known as a swamp forest. The majority of a shrub swamp must consist of shrubs. Tree cover exists within shrub swamps dominated by woody shrubs or water loving trees, however, the tree cover usually makes up $1 / 5^{\text {th }}$ or less of a shrub swamp. Freshwater swamps are the ideal habitat for amphibians because of availability of moisture continuously. Birds are also attracted to hollow trees near or over the water and reptiles are the predators of the swamp, eating almost any organism that crosses their path.

\section{c) Rice Fields (Paddy Fields)}

Rice fields constitute man-made dynamic and rapidly changing aquatic ecosystems where rice (Oryza sativa L.) is grown. A paddy field is a flooded parcel of arable land used for growing semi-aquatic rice. Like natural areas of wetlands, rice cultivation provides a habitat mosaic of temporary and more permanent waters. Paddy fields are the typical feature of rice farming in East, South and Southeast Asia. Rice fields cover extensive areas of the tropics, sub-tropics and warm temperate regions. Rice fields have been in existence since the beginning of organized agriculture [131]. During the $20^{\text {th }}$ century, paddy field farming became the dominant form of growing rice. Since then a rich biodiversity has become associated with rice fields. Due to their long existence, the vast extent of land they occupy in the humid tropics, the array of ecological habitats they encompass and the growth phases they pass through during a cultivation cycle, rice fields have become unique ecosystems.

Examining the paddy field with a biologists' eye, one can recognize that the paddy field is an ecosystem comprising soil, water, air, solar energy and the wetland flora and faunas [132]. Principal environmental characteristics of wetland rice fields are determined by flooding, the presence of rice plants and agricultural practices. So far, most of the wetland rice fields were developed in river valleys, basins, deltas, estuaries, lake fringes and coastal plains. The surface of most of these areas is either level or gently undulating with slopes varying from 0 to $8 \%$. The distribution of water supply to rice crops in these areas is most feasible. On dissected plains with less than $50 \%$ of surface area having 0 to $8 \%$ slope, the topography interferes with the distribution of water supplies making them moderately suitable for wetland rice cultivation. Wetland rice cultivation is limited on undulating to rolling terrain where less than $30 \%$ of the surface has slopes from 0 to $8 \%$, as great effort is required to construct terraces and problems with water supply distribution are usually beyond the scope of farmers. Wetland rice is grown on practically all types of soils, 
from sandy loam to heavy clay. However, it is well established that the heavy soil characteristic of river valleys and deltas are better suited to wetland rice production than lighter soils. An ideal rice soil should contain up to $50-60 \%$ of finer fractions of silt and clay. Variations in soil conditions and the extension of rice cultivation to unsuitable soils are among the factors causing wide disparity in yields. Many wetland rice farmers practice puddling during land preparation to level rice fields and to conserve water. Puddling, however, may create highly unsuitable conditions for upland crops grown in rotation with rice. Soils which have ability to convert to granular aggregated structure after drying are suitable for wetland-rice based cropping systems. Adequate water movement through rice fields is recognized by most rice farmers as essential. Incoming water is normally aerated and its oxygen prevents the soil redox potential from falling too far. In basin, deltas, estuaries and lake fringes the water table rises during the rainy season and comes within easy reach of rice roots. Under rainfed conditions, therefore, the water supply to wetland rice fields depends on both rainfall and the hydrology of the rice fields. Water supply to wetland rice under rainfed conditions, however, is neither adequate nor fully controlled, due to variability in rainfall and its distribution, topography, landform and soil physical characteristics. Adequate and controllable water supply to wetland rice is possible only with the development of irrigation and drainage infrastructures. Run-off water from watershed areas can be stored with the construction of dams and reservoirs and then supplied to rice fields. Water in major rivers can be diverted to rice fields with construction of diversion dams and/or be lifted to rice fields using either modern or traditional water lifting devices. Water in underground aquifers can be lifted through installation of tube/deep wells and utilization of pumps.

Paddy cultivation should not be confused with cultivation of deepwater rice, which is grown in flooded conditions with water more than $50 \mathrm{~cm}$ deep for at least a month. Rice yields in millions of hectares with prolonged stagnant flood with depth of $50 \mathrm{~cm}$ or more are generally low. In these areas, the depth, duration and frequency of flooding are important factors affecting yields of wetland rice. The flooded rice field is a temporary aquatic environment subject to large variations in insulation, temperature, $\mathrm{p}^{\mathrm{H}}, \mathrm{O}_{2}$ concentration and nutrient status. Fields can be built into steep hillsides as terrace and adjacent to depressed or steeply sloped features such as rivers or marshes. They can require a great deal of labor and materials to create and need large quantities of water for irrigation. The paddy field ecosystem is frequently disturbed by cultural practices which prevent it from reverting back to a marshland [133]. Flooding maintains the biological and chemical fertility of the rice field ecosystem through the diversification of microbial environments and the establishment of an aquatic community. Because of their low floral diversity and because their species composition will rarely overlap completely with that of natural ponds, rice fields are not substitutes for natural temporary ponds. 
Paddy field is an ecosystem that sustains the people whose staple diet is rice. In addition to their primary function of rice production, rice fields in many countries are extremely important sources of fish and other aquatic animals and plants for human consumption. The rice field has a surprisingly great biodiversity, perhaps the greatest of any tropical rainfed system. Paddy field is an ecosystem that sustains a diverse assemblage of plants and animals that have made rice fields their niche. The varied agronomic practices conducted on rice fields and the series of growth stages the rice crop passes through during a short passage of time, have made rice fields a heaven for a vast array of plant and animal life. To these life forms, the rice fields offer shelter, food, breeding and nesting grounds. Rice fields are temporary wetlands that harbor many of the same species that breed in natural temporary ponds. The rice fields also offer temporary refuge to those animals that are not permanent inhabitants but visit this ecosystem for a variety of purposes. The rice field agro-ecosystem has the potential to help sustain the regional biodiversity of many invertebrates and vertebrates. Birds, frogs, snakes and various other fauna are high in the paddy field's food chain [132]. Aquatic invertebrates such as pond snails, pond skaters, diving beetles and various microorganisms also inhabit the system. Insects such as grasshoppers, oriental longhead locusts, spiders, butterflies and dragonflies coexist with vegetation. Bird and rat damages are particularly important when rice fields are small and isolated.

Farming methods vary widely and different practices can alter the suitability of rice fields as habitats. Farmers use water management, pesticides and sometimes fish to control crop pests and mosquitoes and other taxa may be affected as well. Farmers may irrigate rice intermittently to control pests and intermittent habitat holds fewer species than areas that are flooded for longer periods. Broad-spectrum pesticides may harm invertebrates and other wildlife and may even cause pest resurgences if they have greater effects on predator populations than on the pests. Because farming practices can affect the conservation value of rice fields, ecologists are encouraged to work with farmers and study the role of rice fields in the population dynamics of temporary pond species and how changing farming methods alter this role. The artificial and temporary nature of the rice field renders it a difficult ecosystem to study, as agrochemical use and frequent disturbances interrupt observations of community structure, population succession and nutrient cycling [134].

\section{4) Riparian Ecosystems}

As the Latin root of the word riparian (ripa = bank) suggests, riparian lands are found along the edge of waterbodies. Given the inherently complex and dynamic of nature of these lands, there is no universally agreed upon definition for riparian lands. Riparian is pertaining to the boundary between water and land. Lowlands along rivers and streams are referred to as riparian areas (bottomlands). Bottomland is the general term that refers to floodplain wetlands. Normally represents the streamside zone and the zone of influence of the stream to- 
wards the upland. Riparian is pertaining to the banks of a river, stream, waterway, or other, typically, flowing body of water as well as to plant and animal communities along such bodies of water. Riparian areas are the vegetated areas adjacent to a watercourse or waterbody (streams, rivers, lakes, ponds, springs, seeps and wetlands). Riparian zones are an unusually diverse mosaic of landforms, communities and environments within the larger landscape. Riparian zone is the area of land directly adjacent to the active channel, which is influenced by river-induced or river related processes) [59]. Riparian ecosystems are the transitional areas where land and water meet and interact [135]. In fact, riparian ecosystem is the stream channel between the low- and high-water marks plus the terrestrial landscape above the high-water mark, where vegetation may be influenced by elevated water tables or extreme flooding and by the ability of the soils to hold water [136]. Riparian habitat include the physical structure and associated vegetation of the areas associated with a watercourse which are commonly characterized by alluvial soils and which are inundated or flooded to an extent and with a frequency sufficient to support vegetation of species with a composition and physical structure distinct from those of adjacent land areas.

Areas closer to the water's edge are more likely to be riparian. Riparian ecosystems occupy the ecotone between upland and aquatic realms. Riparian areas are adjacent to a watercourse or waterbody and estuarine-marine shorelines [135]. These riparian areas are found generally in broad floodplains. Riparian areas are the transitional zone; they exist between surface water (aquatic habitat) and the surrounding drier upland. Riparian areas are transitional between terrestrial and aquatic ecosystems and are distinguished by gradients in biophysical conditions, ecological processes and biota. Riparian areas have gradients in environmental conditions and in functions between uplands and aquatic ecosystems. Although riparian areas encompass some of the wetlands in a typical landscape setting and also include portions of adjacent aquatic and upland environments, important distinctions between these systems are made. Riparian areas are recognized by water-loving emerald threads of vegetation along a watercourse or waterbody. Riparian areas are characterized by seasonal flooding and annual dry periods. Riparian areas contain a diverse assemblage of plant and animal species. Hardwoods are the characteristic biota. Soils, vegetation and wildlife in riparian areas are all influenced by the presence of water and in turn influence the adjacent waterbody.

Riparian lands play a vital role in the healthy functioning of both surface water and the drier uplands. Riparian areas perform several services that maintain the integrity of the adjacent aquatic environment and protect the uses and values of other water users. Riparian areas perform important ecological functions. Riparian ecosystems have many economic and recreational values. Riparian areas are among the most productive and valuable of all landscape types. Riparian areas stabilize stream banks and shorelines. They provide essential habitat for 
wildlife which are influenced by seasonal water levels. Riparian ecosystems offer habitats for many species, function as filters between land and water and serve as pathways for dispersing and migrating organisms [137]. Riparian areas suppress the undesirable effects of flooding, maintain water quality and serve as centers of biological diversity and in this way share some of the functions and values of wetlands. These areas function as habitat for wildlife, support aquatic ecosystems and provide many ecosystem services for society. Riparian areas are used by more wildlife than any other habitat. They comprise only a small amount of our landmass but have some of the highest biodiversity values compared to other ecosystems [136]. Riparian areas act as corridors that link habitat patches and provide dispersal and movement corridors for many plants and animals [138]. Healthy riparian areas provide several important functions for aquatic ecosystems. For instance, they help protect water temperature in waterbodies by providing shade. Riparian areas directly contribute to fish habitat by providing shade, cover and food production areas. Overhanging vegetation and woody debris provide cover for fish and other aquatic species and the litter of organic material provides food for microbes and invertebrates, which are the foundation of the aquatic food chain [139]. These areas support plants and animals and protect aquatic ecosystems by filtering out sediments and nutrients originating from upland areas. Riparian areas serve as a framework for understanding the organization, diversity and dynamics of communities associated with fluvial ecosystems.

\subsection{Comparison of Aquatic Ecosystems in the Study Area}

Our purpose here is to provide an overview of some fundamental differences between aquatic ecosystems. Teasing apart the ecologically, environmentally and geographically relevant differences between aquatic ecosystems can be a daunting task given the background variability in local ecosystems. A rigorous analysis of the similarities and differences between aquatic ecosystems is clearly beyond the scope of this article. It is the intention of this paper to examine some of these as well as the implications for attempting to manage the diverse types of aquatic ecosystems effectively. The search for commonalities and contrasts among ecosystems has yielded some of the most informative patterns and insights in ecology. Ecologists have often claimed that aquatic ecosystems vary in their underlying structure and the processes that govern their dynamics. However, only recently has sufficient data for direct quantitative comparison become available. For clarity, the comparisons and their implications we raise are summarized in respective tables.

\section{1) Aquatic versus Terrestrial Ecosystems}

As the Earth was evolving, gradual degassing and accumulation of liquid water at its surface differentiated aquatic and non-aquatic environments [140]. Because terrestrial environments have always existed, it is possible that life evolved on the land (including in lakes, rivers, streams and flooding areas) as early as 
aquatic life itself [141]. Habitable, non-aquatic environments must have existed all throughout the geologic history of Earth unless its surface was entirely under water, which seems unlikely. The different histories and trajectories of aquatic and terrestrial ecology suggest either that different process are at work in these systems, or that social and disciplinary forces constrain the thinking of scientists and lead to divergent lines of inquiry. While many ecosystems exist on land and in the waters of the world, terrestrial ecosystems are those that are found only on land. Terrestrial is defined here as non-aquatic environments. The definition of a terrestrial environment may not be as trivial as it sounds. However, even fully aquatic ecosystems, such as lakes and coastal environments, cover a wide spectrum of mixed environments where aquatic and non-aquatic landscapes develop and overlap over time. Terrestrial and aquatic ecosystems have the same basic components: an energy source, water, soil and/or sediment, nutrients and autotrophic and heterotrophic organisms, all in constant interaction. Habitats above sea level include aquatic (ice-covered and ice-free lakes, ponds and wetlands, peats, rivers and streams, geothermal fields) and non-aquatic environments (especially areas with low rain regimes) that experience drastic changes governed by tectonic activity and climatic conditions, including the rise and fall of sea level, glaciations and rain regimes [142].

The differences between aquatic and terrestrial ecosystems (Table 5) are expressed in the composition of species that form the biotic component (structure), in the efficiency of recycling and in the scales of time and magnitude that nutrients are imported or exported from each system (operation). Aquatic systems respond on a much shorter time scale than their terrestrial counterparts. Terrestrial ecosystems have been largely regarded as plant-dominated land surfaces. Life evolved in aquatic ecosystems has been stable and better buffered against environmental change than terrestrial systems. When compared to terrestrial communities, aquatic communities are limited abiotically in several different ways. Organisms in aquatic systems survive partial to total submergence. Water submergence has an effect on the availability of atmospheric oxygen, which is required for respiration and solar radiation, which is needed in photosynthesis. Some organisms in aquatic systems have to deal with dissolved salts in their immediate environment. This condition has caused these forms of life to develop physiological adaptations to deal with this problem. Aquatic ecosystems are nutritionally limited by phosphorus and iron rather than nitrogen. Aquatic ecosystems are generally cooler than terrestrial ecosystems which limit metabolic activity. But these differences are not limited to divergences between aquatic and terrestrial ecosystems. There are, of course, numerous exceptions to almost any comparison over such a tremendous variety of organisms and environments encompassed by terrestrial and aquatic ecosystems.

2) Natural versus Artificial Aquatic Ecosystems

It is strongly recommended that, when applying the classification system, we 
Table 5. Key differences between aquatic and terrestrial ecosystems.

\begin{tabular}{|c|c|c|}
\hline Feature & Aquatic ecosystems & Terrestrial ecosystems \\
\hline Prevalence of aquatic medium & Greater & Lower \\
\hline Phyletic diversity ( $a$ and $b$ ) & Greater & Lower \\
\hline Interpopulation genetic diversity & Lower & Higher \\
\hline Dimensions of species distribution & Three-dimensional & Two-dimensional \\
\hline Degree of domestication & Lower & Higher \\
\hline Effective population size & Larger & Smaller \\
\hline Spatial structure of populations & More open & Less open \\
\hline Spatial scale of gene flow & Larger & Smaller \\
\hline $\begin{array}{l}\text { Openness of local environment (i.e., } \\
\text { rates of import and export) }\end{array}$ & Greater & Lower \\
\hline Strength of natural forces & Tides, currents and waves may vary & Wind and rain vary with depth \\
\hline Availability of shelter and space & $\begin{array}{l}\text { Not required for all organisms; substrate, rocks, } \\
\text { vegetation and coral reefs provide shelter; space is } \\
\text { important for animal requiring territory }\end{array}$ & $\begin{array}{l}\text { Most animals require shelter; some plants require } \\
\text { shelter; space is important for organisms } \\
\text { requiring territory, shelter or nesting sites }\end{array}$ \\
\hline Scale of chemical and material transport & Greater & Smaller \\
\hline $\begin{array}{l}\text { Rate of response to environmental } \\
\text { variability }\end{array}$ & Faster & Slower \\
\hline $\begin{array}{c}\text { Sensitivity to large-scale environmental } \\
\text { variability }\end{array}$ & Higher & Lower \\
\hline $\begin{array}{c}\text { Reliance on external sources of } \\
\text { recruitment }\end{array}$ & Higher & Lower \\
\hline Importance of pollination syndromes & Minimal & Great \\
\hline Spatial scale of propagules transport & Greater & Smaller \\
\hline Likelihood of local self replenishment & Low & High \\
\hline Habitat destruction & Spatially focused & Widespread \\
\hline Sensitivity to habitat fragmentation & Lesser & Greater \\
\hline Loss of biogenic habitat structure & Spatially focused & Widespread \\
\hline Sensitivity to smaller scale perturbations & Lesser & Greater \\
\hline Temporal response to large-scale events & Higher (decades) & Slower (centuries) \\
\hline Temperature variation & $\begin{array}{l}\text { Low; less variation in big waterbodies; decreases with } \\
\text { depth; heats up and cools down more slowly than } \\
\text { air; heat loss and gain is not usually a problem }\end{array}$ & $\begin{array}{l}\text { High; very varied both as we move through the } \\
\text { seasons and through latitude and altitude; } \\
\text { temperature varies more than in water; daily and } \\
\text { seasonal variations may be great }\end{array}$ \\
\hline Light availability and penetration & $\begin{array}{l}\text { Affects availability of plants in water; intensity and } \\
\text { wavelength decreases with depth of the water }\end{array}$ & $\begin{array}{l}\text { Very important for plant growth; dense plant } \\
\text { growth can affect light; plenty of light readily } \\
\text { available }\end{array}$ \\
\hline Pressure variation & $\begin{array}{c}\text { Few organisms live at great depths; greatly increases } \\
\text { with increasing depth }\end{array}$ & $\begin{array}{l}\text { Little effect on most organisms; decreases with } \\
\text { altitude }\end{array}$ \\
\hline Water and ions & Readily available & $\begin{array}{l}\text { Vary greatly from deserts to swamps; some soils } \\
\text { are rich others, poor }\end{array}$ \\
\hline $\begin{array}{l}\text { Gases (oxygen and } \\
\text { carbon dioxide) }\end{array}$ & $\begin{array}{l}\text { Oxygen availability is low and gas solubility } \\
\text { decreases with an increase in temperature }\end{array}$ & $\begin{array}{l}\text { No shortage of gases; availability decreases with } \\
\text { altitude }\end{array}$ \\
\hline Viscosity & Higher & Lower, less than water \\
\hline
\end{tabular}


record whether an inland aquatic ecosystem is natural or artificial as a matter of course is a matter of investigation (Table 6). The natural versus artificial descriptor provides a means of recording whether a particular inland system is naturally occurring or artificially created, as defined below. Natural is one existing in, or produced by nature; not made or caused by humankind. Artificial is one produced by human beings, not naturally occurring. This information can be used for regional conservation planning and management initiatives for inland systems, where knowledge of the naturalness of a system is of vital importance. In addition, for certain applications where there could be legal implications, it may be of paramount importance to indicate whether or not an inland system on a particular site is likely to be a naturally-occurring feature. It is important to note that the classification of an inland system as natural or artificial is not the same as the assessment and categorization of the present ecological condition. The assessment of ecological condition is a complex matter, beyond the ambit of classification of ecosystem type. One basis for determining the degree to which an ecosystem has retained its biointegrity is to examine equivalent ecosystems in their natural (or pristine) state. However, because of the widespread and ongoing impact of human activities, very few systems can be said to be natural. Such systems may exist in the upland, mountain catchments, although even such areas can be impacted by atmospheric deposition. In practice, the concept of best attainable ecosystems, representing areas which are minimally impacted, can be used as an equivalent measure. Many natural inland systems have been modified or impacted to some degree by humans and these modifications can greatly influence the character, or even classification, of the system. In the classification system, however, natural systems are not categorized according to degree of modification or impact. If you are classifying the ecosystem type of a modified but naturally-occurring aquatic ecosystem, you should categorize it as natural.

\section{3) Inland Water versus Estuarine and Marine Ecosystems}

Aquatic ecosystems are comprised of all water ecosystems including fresh and saltwater and marine ecosystems refer to saltwater ecosystems only. An inland system is defined as an aquatic ecosystem with no existing connection to the ocean. These ecosystems are characterized by the complete absence of marine exchange and/or tidal influence. While an inland system itself does not have an existing connection to the ocean, the estuaries into which most rivers flow are by definition connected to the ocean, either permanently or temporarily (Table 7). Inland systems have no direct, existing connection to the sea. Inland water systems may be natural, as well as human-altered or engineered waterbodies, such as ponds, reservoirs, canals and ditches [143].

An estuarine system is defined as a body of surface water that is part of a water course that is permanently or periodically open to the sea; in which a rise and fall of the water level as a result of the tides is measurable at spring tides when the water course is open to the sea; or in respect of which the salinity is measurably higher as a result of the influence of the sea. Estuarine system refers to 
Table 6. Some characteristics of natural and artificial aquatic ecosystems.

\begin{tabular}{|c|c|c|}
\hline Characteristic & Natural aquatic ecosystems & Artificial aquatic ecosystems \\
\hline Number of species & Many & Few \\
\hline Genetic diversity & High & Low \\
\hline Ecological succession & Present, takes place over time & Absent \\
\hline Ecological sustainability & Sustainable & Un-sustainable \\
\hline Productivity & Extremely variable & Designed for high productivity \\
\hline Nutrient cycling & Natural & Incomplete \\
\hline Natural resource extraction & Low & High \\
\hline Food chains & Long and complex & Simple and often incomplete \\
\hline Nature of habitat & Heterogeneous & Homogeneous \\
\hline Nature of landscape & Heterogeneous & Homogeneous \\
\hline Use of herbicides, pesticides and insecticides & Low & Heavy \\
\hline Importation of non-solar energy & Small & Large \\
\hline Importation of nutrient supplements & Small & Large \\
\hline Soil characteristics & Divergent & Convergent \\
\hline Hydrological cycles & Natural & Modified \\
\hline Biotic and physical disturbance regimes & Normal & Reduced \\
\hline Mobility of people, goods and services & Local & Global \\
\hline Species diversity & High & Low \\
\hline Production & Low & High \\
\hline Productivity & Medium & Low/medium \\
\hline Diversity & High & Low \\
\hline Human displacement of ecological processes & Low & High \\
\hline Reliance on external human inputs & Low & High \\
\hline Autonomy & High & Low \\
\hline Sustainability & High & Low \\
\hline Output stability & Medium & High \\
\hline Flexibility & High & Low \\
\hline Resilience & High & Low \\
\hline Potentiality as outdoor classrooms & $\begin{array}{l}\text { Provide outdoor classrooms for the study of } \\
\text { biology and ecology }\end{array}$ & $\begin{array}{c}\text { Have little to offer in the way of educational } \\
\text { opportunities }\end{array}$ \\
\hline Landscape diversity & $\begin{array}{l}\text { Diverse landscapes retain the sense of place } \\
\text { that sustains language and cultural differences }\end{array}$ & $\begin{array}{l}\text { Monotonous landscape incapable of stimulating } \\
\text { diversity of thought, language or creativity }\end{array}$ \\
\hline Spiritual value & $\begin{array}{l}\text { Spiritual value associated with natural wilderness } \\
\text { sustains self esteem of indigenous people }\end{array}$ & $\begin{array}{l}\text { No spiritual value; potential to cause mental } \\
\text { illness and increase risk of depression and suicide }\end{array}$ \\
\hline Stimulus on artificial expression & $\begin{array}{l}\text { Stimulate artificial expression through painting } \\
\text { and poetry etc. }\end{array}$ & $\begin{array}{l}\text { Have very little potential for stirring the human } \\
\text { soul }\end{array}$ \\
\hline
\end{tabular}


Table 7. Comparison of inland water, estuarine and marine ecosystems.

\begin{tabular}{|c|c|c|c|}
\hline \multirow{2}{*}{ Characteristic } & \multicolumn{3}{|c|}{ Ecosystems } \\
\hline & Inland water & Estuarine & Marine \\
\hline Nature of water & Freshwater & $\begin{array}{c}\text { Transitional/brackish waters (a mix } \\
\text { of freshwater and saltwater) }\end{array}$ & Saltwater \\
\hline $\begin{array}{l}\text { Connection to the } \\
\text { ocean }\end{array}$ & $\begin{array}{l}\text { Absent; no direct, } \\
\text { existing connection to } \\
\text { the sea }\end{array}$ & $\begin{array}{l}\text { Present; connected to the ocean, } \\
\text { either permanently or temporarily }\end{array}$ & $\begin{array}{l}\text { Present; are part } \\
\text { of the open } \\
\text { ocean }\end{array}$ \\
\hline $\begin{array}{l}\text { Marine exchange } \\
\text { and/or tidal influence }\end{array}$ & Absent & Present & Present \\
\hline Level of biodiversity & Lower & Moderate & Higher \\
\hline
\end{tabular}

deepwater tidal habitats and adjacent tidal wetlands that are usually semi-enclosed by land but have open, partly obstructed, or sporadic access to the open ocean and in which ocean water is at least occasionally diluted by freshwater runoff from the land [25]. The upstream boundary of an estuary is taken to be the extent of tidal influence (i.e., the point up to where tidal variation in water levels can still be detected), or the extent of saline intrusion, or the extent of back-flooding during the closed mouth state, whichever is furthest upstream. Estuaries are transitional zones between rivers and the sea. Transitional waters are often restricted in diversity as a result of a combination of factors but young geological age and high frequency of disturbance and physiological stress are probably especially influential. The ecosystem services that arise include storage of sediment, flood defence and storm buffering, maintenance of water quality and support of coastal and marine food chains. While the systems are considered depauperate, however, many organisms have become adapted to either reside permanently in transitional system or exploit them at certain stages of their life cycle. In addition, not all functional groups are depauperate. Many surveys neglect the smaller organisms that exploit the available resources under conditions where competition from larger forms is restricted by the physical setting. A high diversity of cryptic consumers are found among the meiofauna associated with the surface sediments while the role of primary producer falls to the microphytobenthos (unicellular algae) which show a wide variety of forms, several hundreds of species coexisting in one system.

A marine system is defined as that part of the open ocean overlying the continental shelf and/ or its associated coastline, up to a depth of ten meters at low tide (i.e., not extending beyond the shallow photic zone). Marine systems are generally considered to show higher levels of biodiversity than freshwater systems which are in turn more diverse than transitional (brackish) waters. The number of species in freshwater ecosystems is relatively low in comparison to marine systems, which could be due to the directional flow acting as a barrier to species migration and colonization; the relative variability of physico-chemical conditions in freshwaters and, relative geological youth of freshwater systems 
[144]. Circumstantial evidence of the importance of geological age in the evolution of specialist forms and, therefore, the increase in speciation is given in circumstances where freshwater systems are known to have an extended geological stability. These systems have a long geological record and harbour endemic species showing evidence of specialization and unexpectedly high diversity.

To distinguish inland water systems from marine systems, inland waters end at head of tide. Freshwater ecosystems can be contrasted with marine ecosystems, which have a higher salt content. Marine (saltwater) ecosystems contain much higher concentrations of salts than freshwater ecosystems. While the degree of existing connectivity with the open sea/ocean is the primary factor for distinguishing inland systems from marine and estuarine systems, the salinity or saltiness of a wetland or an aquatic ecosystem does not influence whether or not it is classified as an inland system. Marine systems, in contrast, are part of the open ocean, while estuarine systems are not themselves part of the ocean but are permanently or periodically open to the sea. Most rivers (a type of inland system) are indirectly connected to the ocean via an estuary at the downstream end, where marine exchange (i.e., the presence of seawater) or tidal fluctuations are detectable in a river channel that is permanently or periodically connected to the ocean, that portion of the river is defined as part of the estuarine system. Certain inland systems that are no longer connected to the sea may have had an historical connection to the ocean, which in some cases may have been relatively recent. Such systems often retain the saline character and much of the fauna associated with estuaries but is not considered to be estuarine systems because they do not have an existing permanent or periodic connection to the sea.

Marine and inland aquatic ecosystems are interconnected. Some inland aquatic ecosystems are linked to the ocean ecosystems which they affect for example through nutrient inflows that causes the high productivity in many coastal fisheries, but also negatively by pollutants carried by the water. In addition, a number of marine fishery resources need inland water ecosystems including estuaries and lagoons to complete their life cycles. Marine systems have been stable for far longer than most terrestrial systems and some show extremely high levels of biodiversity. The relative heterogeneity of habitat in marine systems, geological age, volume and therefore, buffering capacity has allowed the diversification and maintenance of varied biological forms.

\section{4) Inland Waters versus Freshwaters}

Inland water ecosystems encompass habitats with a wide variety of physical, temporal, chemical and biological characteristics and include lakes and rivers, floodplains, peatlands, marshes and swamps, small streams, ponds, springs, cave waters and even very small pools of water in tree holes and other cavities in plants and soil. The terms inland waters and freshwaters are often used interchangeably. However, some important inland water ecosystems are saline or brackish (e.g., lagoons, inland seas or lakes) and not freshwaters. Also freshwaters can extend a considerable distance out into the sea at large river mouths 
where water is still potable several kilometres offshore, but such areas of freshwater influence are not usually covered by the term inland waters.

\section{5) Lotic versus Lentic Ecosystems}

In limnology, inland waters (surface waters) are divided into lotic and lentic ecosystems. On the surface of the land, free water habitats can be classified as either lotic or lentic. In aquatic ecosystems, one of the most fundamental habitat constraints is the division between lotic and lentic waters [145]. Lentic ecosystems are discrete aquatic habitats in a terrestrial matrix, while lotic ecosystems are generally continuous habitats linked by unidirectional flow within dendritic river networks. Lotic and lentic ecosystems differ considerably in physical, chemical and biological characteristics (Table 8). Lotic ecosystems can be

Table 8. Comparison of characteristics of lotic and lentic ecosystems.

\begin{tabular}{|c|c|c|}
\hline Feature & Lotic ecosystems & Lentic ecosystems \\
\hline Water flow & $\begin{array}{l}\text { Present; water flows in a continuous and definite } \\
\text { direction (flowing waters/running waters/moving } \\
\text { waters) }\end{array}$ & $\begin{array}{l}\text { Absent; water do not flow in a continuous and definite } \\
\text { direction (standing waters/static waters/still waters/ } \\
\text { stationary waters) }\end{array}$ \\
\hline $\begin{array}{l}\text { Morphometry of waterbody } \\
\text { (size description) }\end{array}$ & $\begin{array}{l}\text { Linear, longer, narrower and shallower basin with } \\
\text { more complex perimeter }\end{array}$ & Circular and deeper basin with less complex perimeter \\
\hline Width of waterbodies & Relatively narrow & Relatively broad \\
\hline Depth of water & Shallower & Deeper \\
\hline Landscape position & Natural placement & Lower in the catchment \\
\hline $\begin{array}{l}\text { Regional distribution and } \\
\text { function }\end{array}$ & Dictated by geomorphology & $\begin{array}{l}\text { Influenced by regional } \\
\text { demand for dam related } \\
\text { ecosystem services }\end{array}$ \\
\hline Permanence & Can last many thousands of years & Usually only last for a few hundred to a few thousand years \\
\hline Source of water & $\begin{array}{l}\text { Fed by lower order streams and diffuse inputs; fed by } \\
\text { rains, precipitation, snow melt and springs }\end{array}$ & $\begin{array}{l}\text { Fed by higher order streams, surface water dominated; in } \\
\text { addition to ground water, lotic waters from rivers, streams } \\
\text { and creeks drain into lakes and ponds to form a lentic } \\
\text { environment }\end{array}$ \\
\hline Current velocity & High & Low \\
\hline $\begin{array}{l}\text { Water retention time/ water } \\
\text { residence time (how long it } \\
\text { holds water) }\end{array}$ & $\begin{array}{l}\text { Sometimes there is a lot of water like after a heavy } \\
\text { rain; sometimes there is a very little water during } \\
\text { drought; will dry up and many organisms will die }\end{array}$ & $\begin{array}{l}\text { Last longer and organisms can continue to live despite the } \\
\text { shortened supplies }\end{array}$ \\
\hline Dissolved oxygen content & $\begin{array}{l}\text { Usually high in dissolved oxygen; higher percentage } \\
\text { of dissolved oxygen in water, due to water flowing }\end{array}$ & $\begin{array}{l}\text { Lower percentage of dissolved oxygen, especially in deeper } \\
\text { water }\end{array}$ \\
\hline Salt content & Lower salt content & Higher salt content as water evaporates over time \\
\hline Adaptability of creatures & $\begin{array}{l}\text { The creatures that live here must adapt to their } \\
\text { past-paced environment }\end{array}$ & $\begin{array}{l}\text { The creatures that live here must also adapt to their } \\
\text { environment }\end{array}$ \\
\hline Speciation rates & Low & High \\
\hline Geographical range size & Higher & Lower \\
\hline Species diversity & Higher & Lower \\
\hline Stability & High & Low \\
\hline
\end{tabular}


contrasted with lentic ecosystems, which involve relatively still terrestrial waters. In lotic ecosystems, waters flow in a continuous and definite direction and where there is a measurable and consistent directional flow, while in lentic ecosystems, waters that do not flow in a continuous and definite direction with no overall direction displacement of the medium. In lotic ecosystems, water flows from source to mouth, while in lentic ecosystems, water is stored according to the specific landscape and topography. The lotic ecosystems tread their course from being narrow, shallow and relatively rapid to increasingly broad, deep and slow moving. Lotic waters can be diverse in their form, ranging from a spring that is only a few centimetres wide to a major river that is kilometres in width. One of the main differences between lotic and lentic communities are the fact that the water is moving at a particular velocity in lotic communities. This can have great bearing on what organisms occupy the ecosystem and what particular ecological niche they can exist in. In general, the diversity of plant species in a lotic community is small compared to that of a lentic community although small parts of the lotic community host similar conditions to that of a lentic community. Most plants have went through evolutionary adaptations to cope with the force and different conditions that running water brings. Such adaptations have allowed a number of species to successfully take advantage of the lotic community as their ecological niche. In aquatic ecosystems, lentic and lotic waters differ fundamentally in their stability and persistence, shaping the comparative population genetic structure, geographical range size and speciation rates of lentic versus lotic lineages [146]. While the drivers of this pattern remain incompletely understood, the suite of traits making up the ability of a species to establish new populations is instrumental in determining such differences [146]. The most important difference between lotic and lentic ecosystems are current velocity, which can affect processing rates directly, through leaf fragmentation and indirectly, by renewing oxygen and favouring microbial activity. The contrasting geological permanence and ecological stability of lotic and lentic waters [147] have been related to the evolutionary and biogeographical differences observed between species in the two habitat types. Taxa in the geologically shorter-lived and more ecologically unstable lentic habitats have less population genetic structure and larger geographical ranges than their lotic relatives, a pattern observed across a range of taxa, regions and systems [148] [149].

Lentic and lotic ecosystems differ fundamentally in local habitat conditions (e.g., presence or absence of flow, water residence time) and also in physical connectivity. Although lotic ecosystems may suffer less from fragmentation than lentic ecosystems, climate-induced transitions from perennial to temporary habitats will decrease habitat connectivity at the landscape level even in lotic ecosystems. As these conditions are harsher for a typical species of plant, more notably larger plants, smaller species have found the conditions of the lotic community more favourable. This is due to the fact that they are more flexible in regards to the physical conditions of the water. Algae can grow in all sorts of dif- 
ferent places and surfaces and, therefore, are a successful constituent of the running water ecosystem. Most of these algae have developed evolutionary adaptations over times that prevent the water current sweeping them away. Drying is a disturbance that occurs in aquatic ecosystems globally and can strongly influence their communities. Although the effects of drying may depend on ecosystem connectivity and the dispersal abilities of resident species, there have been no comparisons of community responses to drying between lentic and lotic ecosystems across different climates. Here, we predicted that drying would have stronger effects on aquatic communities in isolated lentic ecosystems than in dendritic lotic ecosystems, owing to the higher hydrological connectivity of the latter and that drying would have stronger effects on passive than on active dispersers, because of the potentially higher recolonizing ability of the latter. Despite these differences, the following unifying characteristics make the ecology of running waters unique from that of still waters. Flow is unidirectional. There is a state of continuous physical change. There is a high degree of spatial and temporal heterogeneity at all scales (microhabitats).

\section{6) Limnetic versus Littoral Ecosystems}

Limnetic ecosystem is the open water of a body of freshwater (e.g., lakes, reservoirs, etc.) Littoral ecosystem is region along the shore of a non-flowing body of water (e.g., ponds, lakes, wetlands, etc.). Littoral is the more precise term for stationary bodies of water. The depth of a permanently inundated depression is one of the most important criteria for distinguishing between limnetic ecosystems and littoral systems. Limnetic ecosystems are deeper than littoral ecosystems.

\section{7) Terrestrial versus Wetland and Deep Water Ecosystems}

Aquatic ecosystems are not simply isolated bodies or conduits but are closely connected to terrestrial environments. Further, aquatic ecosystems are connected to each other and provide essential migration routes for species. Aquatic ecosystems require sediment loads, chemical and nutrient inputs from the adjoining terrestrial ecosystems for sustenance. Even isolated lakes are linked to the land and water around them through the flow of freshwater. Wetlands are neither aquatic nor terrestrial [150]. Wetlands can be part of a continuum between terrestrial and deepwater aquatic systems [151]. Wetlands show structural and functional overlap and physical interface with terrestrial and aquatic systems. Wetlands are different from these other ecosystems in so many respects that they must be considered a distinctive class (Table 9). Wetlands have not been easily assimilated by the well-established scientific disciplines of terrestrial and aquatic ecology. Wetlands have some of the same features as deepwater systems, including frequently anoxic substrate and some species of algae, vertebrates and invertebrates. Most wetlands share with terrestrial ecosystems a flora dominated by vascular plants, although the species composition of wetlands generally differs from that of uplands. Wetlands often are found at the interface of terrestrial ecosystems (e.g., upland forests and grasslands) and aquatic systems 
(e.g., lakes and rivers). Some are isolated from deepwater habitats and are maintained entirely by ground water and precipitation. It is this gradient and particularly the junction between upland and wetland, that is central to the wetland characterization issue. The junction between wetlands and deepwater systems, while also incorporating a gradient, raises fewer regulatory issues. Thus, wetland ecosystems are more than simple mixtures of water, soil and organisms. Water flows and levels in most wetlands are dynamic [152]. The temporal pattern of water level, or hydroperiod, for an individual wetland is part of its ecological signature [151].

\section{8) Riparian versus Aquatic Ecosystems}

Riparian areas are differentiated from aquatic ecosystems (Table 10) based on the same characteristics such as hydrology, soils and vegetation-used to define them [153]. Riparian areas include those portions of terrestrial ecosystems that significantly influence exchanges of energy and matter with aquatic ecosystems (i.e., a zone of influence). With regard to vegetation (Table 10), riparian areas are normally dominated by woody plants (e.g., trees), grasses and emergent herbaceous plant cover, in contrast to aquatic ecosystems where these plant types are absent [153]. Although riparian areas and aquatic ecosystems obviously differ in their moisture regimes and water depth, it is difficult to identify a boundary that can be used consistently to separate them [153]. In fact, definitions of riparian may include intermittent to permanent aquatic environments, particularly in headwater streams where the vegetated portions of riparian areas provide the aquatic portion with organic matter, shade, fluvial structure and biotic exchanges. Some definitions of wetland ecosystems extend to two meters of water depth [25] and even to six meters in marine environments [154]. In the transition from headwater to larger streams, there is a tendency for flooding to be more protracted and less abrupt because of the cumulative effects to the hydrograph of multiple tributaries originating from regions differing in the quantity

Table 9. Comparison of terrestrial, wetland and deep water ecosystems.

\begin{tabular}{cccc}
\hline \multirow{2}{*}{ Characteristic } & \multicolumn{3}{c}{ Ecosystem } \\
\cline { 2 - 4 } & Terrestrial & Wetland & Deep water \\
\hline Hydrology & Dry & Intermittently to permanently flooded & Permanently flooded \\
Biogeochemical role & Source & Source, sink or transformer & Sink \\
Productivity & Low to medium & Generally high but sometimes low & Generally low \\
\hline
\end{tabular}

Table 10. Comparison of riparian and aquatic ecosystems.

\begin{tabular}{ccc}
\hline Feature & Riparian ecosystems & Aquatic ecosystems \\
\hline Vegetation type & $\begin{array}{c}\text { Normally dominated by woody plants (e.g., trees), } \\
\text { grasses, and emergent herbaceous plant cover }\end{array}$ & $\begin{array}{c}\text { These plant types are } \\
\text { absent }\end{array}$ \\
Moisture regime & Moist & Wet \\
Water depth & Low & High \\
\hline
\end{tabular}


and timing of flow. Floodplains become more expansive in a downstream direction and, in some cases, wetter [155]. Ultimately riparian areas of rivers grade into coastal estuaries where tidally driven hydrologic regimes and salinity combine to support estuarine riparian areas. In anticipation of practical reasons for identifying an aquatic boundary, especially for large rivers, lakes and estuaries, the following perspective is offered. The aquatic boundary of riparian areas could be established where permanent water begins. For waterbodies that have relatively constant elevations, such as estuarine shorelines influenced by slowly changing sea level, a boundary such as mean high tide or mean low tide is relatively easy to identify. For waterbodies with relatively large fluctuations such as streams, permanence is a relative term. Just as it is conventional to assign return periods or frequencies to flood elevations for streams, the same approach could be used to establish a return period for a permanence level during drought. For ephemeral and intermittent streams, this low stage lies below the channel and thus the riparian area using this criterion would include the entire streambed and underlying alluvium. For perennial streams and lakes, a zone of influence could include aquatic portions shaded by riparian vegetation or even a distance equivalent to the height of a canopy tree. For the shoreline of some lakes, levels fluctuate over a multi-year cycle, causing the boundary of the riparian area to migrate back and forth.

\section{9) Riparian versus Wetland Ecosystems}

Riparian areas are differentiated from wetlands based on the same characteristics such as hydrology, soils and vegetation-used to define them [153]. In addition to being characterized by unique assemblages of plants compared to wetlands, riparian areas frequently harbor rare plant species. Many riparian areas are not wetlands (e.g., an area where alluvium is periodically deposited by a stream during floods but which is well drained). Riparian areas share some of the characteristics of wetlands and often include wetlands but cannot be defined wholly as wetlands because they are often saturated at much lower frequencies than wetlands. Riparian areas, which are saturated or flooded for prolonged periods, would be considered wetlands and should be classified as such. The definitions of wetlands provide a useful starting point for differentiating them from riparian areas. One is the jurisdictional, or legal, definition used as the basis for delineating wetlands. The term wetland refers to ecosystems dominated by water-loving plants and having wet or saturated soils. The term wetland means those areas that are inundated or saturated by surface or groundwater at a frequency and duration sufficient to support and that under normal circumstances do support, a prevalence of vegetation typically adapted to life in saturated soil conditions [156]. A wetland is an ecosystem that depends on constant or recurrent, shallow inundation or saturation at or near the surface of the substrate [150]. The minimum essential characteristics of a wetland are recurrent, sustained inundation or saturation at or near the surface and the presence of physical, chemical and biological features reflective of recurrent, sustained inundation 
or saturation [150]. Wetlands are intermediate between terrestrial and aquatic ecosystems; they are covered with water at least part of each year. The term riparian refers to any land adjacent to waterbodies or wetlands. Riparian areas may be upland sites or periodically flooded ecosystems. In contrast to most wetland definitions, a balanced characterization for riparian areas should treat the riparian area as a whole and not place undue emphasis on either its driest or its wettest margin. Moreover, fundamental characteristics of riparian areas are their zonal nature and their position in the landscape. Wetlands are lands transitional between terrestrial and aquatic systems, most wetland definitions do not incorporate concepts of zonation and landscape position. To omit these characteristics of riparian areas, however, would be to disregard two of their diagnostic characteristics. Hence, compared with wetlands, riparian areas are both more expansive from some perspectives and more restrictive from others. They are more expansive because they may include not only portions of wetlands, but also non-vegetated portions of point bars. At the dry end, they encompass terrestrial areas that do not necessarily require inundation and saturation near the surface, as do wetlands. Riparian areas are more restrictive than wetlands because they are confined to specific geomorphic settings of streams, lakes and estuarine-marine environments. Extensive flatwood wetlands, for example, would not be considered riparian areas because most of them lack landscape attributes of linear configuration, distinct zonation and adjacency to waterbodies.

\section{0) Riparian Ecosystems versus Uplands}

Riparian areas are differentiated from uplands (Table 11) based on the same characteristics such as hydrology, soils and vegetation-used to define them [153]. In addition to being characterized by unique assemblages of plants compared to uplands, riparian areas frequently harbour rare plant species. In reference definitions, the emphasis is on minimum conditions that characterize a wetland-upland

Table 11. Comparison of riparian ecosystems and uplands.

\begin{tabular}{|c|c|c|}
\hline Feature & Riparian ecosystems & Uplands \\
\hline Moisture regime & Wetter & Drier \\
\hline $\begin{array}{c}\text { Species } \\
\text { composition }\end{array}$ & $\begin{array}{l}\text { Vegetated cover is dominated by } \\
\text { hydrophytes }\end{array}$ & $\begin{array}{c}\text { Vegetated cover is dominated by upland } \\
\text { or terrestrial communities; forested or } \\
\text { non-forested }\end{array}$ \\
\hline $\begin{array}{l}\text { Biologically } \\
\text { productive } \\
\text { functions }\end{array}$ & More & Few \\
\hline Soil drainage & $\begin{array}{l}\text { Poorly drained soils, the soil surface } \\
\text { is frequently flooded or saturated }\end{array}$ & $\begin{array}{l}\text { Well drained soils, even if the soil } \\
\text { surface is seasonally flooded or saturated }\end{array}$ \\
\hline Source of water & $\begin{array}{l}\text { Moisture in riparian areas may be } \\
\text { supplied from both uplands and } \\
\text { aquatic ecosystems }\end{array}$ & $\begin{array}{c}\text { Precipitation as their principal or only } \\
\text { source of water }\end{array}$ \\
\hline $\begin{array}{l}\text { Lateral transport of } \\
\text { materials }\end{array}$ & Present & Absent \\
\hline
\end{tabular}


boundary rather than on describing the full wetness gradient. With emphasis on the dry end of the gradient, a point in the landscape is identified between wetter (definitely wetland) and drier (definitely upland) conditions. The structure, species composition, diversity and productivity of riparian areas contrast sharply with uplands [153]. Riparian areas are areas through which surface and subsurface hydrology connect waterbodies with their adjacent uplands. Riparian areas, in proportion to their area within a watershed, perform more biologically productive functions than do uplands. Upland system consists of upland or terrestrial communities, forested and non-forested, which have well-drained soils and a vegetated cover that is never dominated by hydrophytes, even if the soil surface is seasonally flooded or saturated. Riparian lands are under the influence of both terrestrial and aquatic processes. Hydrology, both groundwater and surface water, is the driving force behind the physical, chemical and biological processes on these lands. Given that these lands are transitional habitats, i.e., representing a transition from wet (open water) to dry (uplands); environmental processes also show steep gradients from the water's edge to the adjacent uplands. These characteristics result in riparian lands having relatively higher biological diversity and productivity than other habitats of comparable size, especially in dry climates [135]. Riparian areas are wetter than adjacent uplands. Connectivity is a condition whereby riparian lands facilitate connections that allow the transfer of energy and materials between terrestrial and aquatic ecosystems. Riparian lands themselves are under the influence of both terrestrial processes and aquatic processes (e.g. nutrient and sediment transfer). In drier regions, riparian zones can be a source of water and nutrients to underlying aquifers and adjacent uplands, whereas in more humid climates, riparian lands are more often recipients of groundwater discharge. Riparian lands have a disproportionately greater influence on aquatic ecosystems than other terrestrial lands and in many landscapes riparian lands are much more biologically productive and with much higher biodiversity than other habitats that are of comparable size.

Unlike uplands that receive precipitation as their principal or only source of water, moisture in riparian areas may be supplied from both adjacent uplands and aquatic ecosystems. Water enters riparian areas from uplands in the form of groundwater discharge, shallow subsurface flow and overland flow. From the aquatic side, water is supplied by overbank flow, infiltration through adjacent channel banks (bank storage) and by hyporheic flow from alluvium upstream. Unlike uplands, floods are important agents of geomorphic change in riparian areas, eroding soils and sediments from some parts of the riparian area while depositing them in others to create new geomorphic surfaces. The lateral transport of materials to riparian areas from outside the floodplain constitutes a fundamental difference between riparian areas and uplands. These hydrologic conditions are clearly reflected in the distinctive vegetation of riparian and upland areas. First, the flooding regimes of riparian areas select for disturbance-tolerant species and they may also constrain colonization of riparian areas 
by flood-sensitive species. Second, because riparian areas exist where depth of the water table is relatively shallow, specific assemblages of shrubs and trees withdraw water directly from the saturated area [157], a phenomenon not generally possible in uplands. Riparian areas may extend hundreds of meters from stream channels on terraces where surface connections are entirely absent but shallow groundwater is available to plants. Riparian forests persist in arid regions where there is insufficient precipitation to support upland forests [35], thus creating a distinct boundary. In humid climates, water availability is not as crucial and the boundary between uplands and riparian areas is not always easy to distinguish. Nonetheless, there are distinct assemblages of trees in humid riparian areas. In drainage basins with relatively fine sediments, riparian tree species are more likely to be distinguished by their ability to withstand the stresses of sediment anoxia than a requirement for a dependable source of groundwater [158] [159]. Steep slopes, such as rock escarpments or abrupt sediment banks, present a more ambiguous case because there may be no active hydrologic connection with the adjacent stream, river, or lake for the majority of the riparian area. Nevertheless, riparian functions remain strong, with pronounced flows of biotic and abiotic materials between aquatic and terrestrial ecosystems. Such upland riparian areas provide important habitat for a variety of species that respond to topography, water-influenced microclimates and the presence of a natural movement corridor, among other factors. In areas with steep slopes, distinguishing between riparian and the non-riparian areas should be based on function. This can be justified because the zone of influence by moisture or disturbance alone may be quite narrow and insufficient to account for other influences. Riparian areas are areas that significantly influence exchanges of energy and matter with aquatic ecosystems, the upper boundary of such riparian areas can be functionally identified by the potential for trees to contribute portions of their wood to a stream channel, should they fall in that direction. Although precipitation and runoff promote erosion of uplands and the transport of sediment into stream channels, riparian areas may trap some of these particles. Although many riparian areas can be restored and managed to provide many of their natural functions, they are not immune to the effects of poor management in adjacent uplands.

\section{1) Wetlands versus Uplands}

Upland refers to terrestrial ecosystems located away from riparian zones, wetlands, springs, seeps and dry washes; ecosystems made up of vegetation not in contact with groundwater or other permanent water sources. Upland is the land upslope from a wetland that lacks wetland characteristics. This upland system consists of upland or terrestrial communities, forested and non-forested, which have well-drained soils and a vegetated cover that is never dominated by hydrophytes, even if the soil surface is seasonally flooded or saturated. Wetlands frequently are bounded by uplands, but the boundary often lies within a broad transition zone [150]. For gentle gradients, or where microtopography causes 
wetlands to be interspersed with uplands on very fine scales, the boundary of a wetland can be especially difficult to determine. Because vegetation analysis often is used in locating boundaries, the response of plant communities to environmental gradients is fundamentally important to the characterization of wetlands. The wetland boundary as judged by vegetation is not always stable. Natural hydrologic changes from year to year or from one decade to the next may cause the vegetation to shift. Although wetland plants respond to changing environmental conditions, they might not do so immediately. For example, forested wetlands respond more slowly than do marshes because of the long lives of trees. Soil morphology is less responsive than is vegetation and thus tends to integrate conditions over decades. Some of the functions of wetland ecosystems are shared by uplands. Even so, wetlands perform some functions, such as maintenance of breeding habitat for some bird species, which are either unique or particularly efficient in proportion to their size. Also, wetlands are often the last portions of a landscape converted to alternative uses. Because many wetlands are adjacent to surface waters, they often represent the best opportunity for natural improvement of water quality because of their filtering and transformation capacity. Uplands also can provide retention and transformation, but they are often preferentially allocated to other land uses such as agriculture and urban development that generate nutrients and sediments and are more remote from surface waters. Uses of uplands can affect the physical, chemical and biotic characteristics of wetlands. Paving or agricultural uses, for example, affect the amount and quality of water that reaches adjacent wetlands. Where the use of uplands is intensive, as in urban areas, wetlands often show signs of stress. The geology of most wetlands is depositional. In general, uplands lose mass that accumulates in wetlands. As uplands become more intensively managed and as the area of wetlands is reduced, nutrient processing and retention become impaired.

\section{2) Drainage Basins versus Floodplains}

Rivers, streams, lakes, wetlands and their connecting ground waters are literally the sinks into which landscapes drain. Far from being isolated bodies or conduits, freshwater ecosystems are tightly linked to the river basins of which each is a part and they are greatly influenced by human uses or modifications of land as well as water. Both lotic and lentic habitats are free water habitats present on the surface of the land linked into drainage systems of three major sorts: exorheic (i.e., outward-draining), endorheic (i.e. inward-draining) and arheic or dammed (where the outflow drainage is regulated by the nature or operation of an artificial barrier). By definition, water leaves an endorheic depression by means of evaporation and infiltration only, whereas water can leave an exorheic depression as concentrated or diffuse surface flow, or as subsurface flow. Exorheic regions are open systems in which surface waters ultimately drain to the ocean in well-defined patterns that involve streams and rivers temporarily impounded by permanent freshwater lakes. Endorheic regions are considered 
closed systems because, rather than draining to the sea, surface waters drain to inland termini whence they evaporate or seep away. Typically, the termini are permanent or temporary lakes that become saline as evaporation concentrates dissolved salts that either have been introduced by rainwater or have been leached out of substrata within the drainage basin. In arheic systems water falls unpredictably in small amounts and follows haphazard drainage patterns. Apart from rivers that arise outside the region (allogenic rivers) and areas fed from underground sources of water, most bodies of water within arheic regions are temporary.

Drainage basin, alternatively known as a water basin, river basin, drainage area, catchment area, watershed and catchment, refer to the areas drained by a specific outlet, such as a river or lake. The term watershed is used to describe a smaller area of land that drains to a smaller stream, lake or wetland. Watershed consist area of second or third order stream where runoff of all first/ second and third order streams joins. Watersheds are considered part of a drainage basin. Watershed is smallest unit of a drainage basin. Drainage basin has many smaller watersheds. Further, larger watersheds contain many smaller watersheds. It all depends on the outflow point; all of the land that drains water to the outflow point is the watershed for that outflow location. The word watershed is sometimes used interchangeably with drainage basin or catchment. Catchment area is that area through which runoff joins a stream. Catchment is a term similar to watershed, which consists of all of the land upstream from a point where rainfall may potentially flow. But catchment area is the area between the boundary lines that is connected by highest elevation points on a specific area under observation. This may or may not be the command area. But command area is which area comes under cultivable area. When irrigation is applied to any particular land, the area that need to be or wanted to be irrigated is called as the command area. Command area is a part of catchment area.

A drainage basin (river basin) is the portion of land drained by a river and its tributaries. A drainage basin is an area of land where surface water from rain and melting snow or ice converges to a single point at a lower elevation, usually the exit of the basin, where the waters join another waterbody, such as a river, lake, reservoir, estuary, wetland, sea, or ocean. It encompasses the entire land surface dissected and drained by many streams and creeks that flow downhill into one another and eventually into the river. A river threads together the creeks and streams, valleys and hills, lakes and underground springs that share a common assembly of water. River basins are usually separated by ridges, mountains and hills. Whatever happens to surface or groundwater in one part of the river basin will find its way to other parts. A river basin comes closer than any other defined area of land, with the exception of an isolated island, to meeting the definition of an ecosystem in which all things, living and non-living are connected and interdependent. It can have smaller sub-basins that combine to form a larger water basin. When rain falls or when ice and snow melts, the water 
that comes from them flows towards a river basin before exiting towards the river, lakes, oceans, or sea. The water that comes from different sources, such as rivers, ponds, creeks, rainfall, or melting snow and ice flows through them and into the water basin and out into another body of water, usually a larger one.

Streams and rivers are flowing waters while floodplains are the lowland areas, adjacent to watercourses that are subject to periodic or near-permanent inundation and sediment deposition. Streams, rivers and floodplains support substantial inland fisheries and have potential for enhanced fisheries, while many floodplains are important for pastoral production and flood recession agriculture. A flood plain is an area of low-lying ground adjacent to a river, formed mainly of river sediments and subject to flooding. A flood plain (or floodplain) is a generally flat area of land next to a river or stream. It stretches from the banks of the river to the outer edges of the valley. Flood plains often contain permanent waterbodies (lakes and channels) as well as permanent or seasonal wetlands and these are the dominant inland waters in many regions of the world. Floodplain wetlands are one of the world's most extensive wetland types. Flood plains often harbour a diversity of wetland ecosystems that reflects underlying geomorphological diversity as well as variation in water sources and patterns of inundation. Plants and animals show many adaptations to life on flood plains, coping with seasonal flooding, varying water levels and often with low dissolved oxygen availability. Floodplain is mostly flat or gently-sloping land adjacent to and formed by an alluvial river channel, under its present climate and sediment load, which is subject to periodic inundation by overtopping of the channel bank. Floodplains are complex landscapes supporting a variety of features such as backwater depressions, meander cut-offs, alluvial ridges, levees, scroll bars, etc. [59]. It is, however, often difficult to distinguish clearly between certain wetland features within a floodplain (e.g., meander cut-offs vs. backwater depressions), particularly in active floodplain wetlands within which there may be a continuum of younger and older features associated with channel migration [59]. Floodplain is the lowland that borders a stream or river, usually dry but subject to flooding. Floodplains are typically characterized by a suite of geomorphological features associated with river derived depositional processes, including point bars, scroll bars, oxbow lakes and levees. Floodplain wetlands must be considered as wetland ecosystems that are distinct from but associated with the adjacent river channel itself, which must be classified as a river. The normally high biodiversity present on natural floodplains is created and sustained by high environmental heterogeneity in space and time [160] [161] [162]. Floodplain depression is a depression occurring as a feature within a broader floodplain wetland complex, including "backwater depressions", "floodplain pans", "meander cut-offs", "oxbow lakes" and other depressional features typically associated with a floodplain [23]. Floodplain flat is a non-depressional, near-level wetland area forming part of a floodplain. Floodplain wetland is a wetland area within a 
floodplain. Water and sediment input to these wetlands is mainly via overspill from a river channel during flooding. Portions of a floodplain may not be wetland.

\section{3) Inundation versus Saturation of Open Waterbodies and Wetlands}

Waterbodies are natural or semi-natural areas. Open waterbody is an inland aquatic ecosystem that contains standing water on a permanent basis (i.e., it is permanently inundated) [23]. For purposes of the classification system, rivers, streams, canals and other aquatic ecosystems where water moves from one place to another via a channel are not considered to be open waterbodies. Dams along a river (classified as artificial depressions with dammed outflow drainage) are, however, considered to be open waterbodies if they contain water permanently [23]. The temporal dimension of inland waterbodies can be perennial or ephemeral and includes the dynamic dimension of running systems (i.e., rivers or lotic systems), standing systems such as lakes and ponds (i.e., lentic systems) and the seasonality of inundation of wetlands. For all inland systems that are not rivers (i.e., wetlands and open waterbodies), one should classify the hydrological regime according to the period of inundation and saturation, together with the inundation depth-class in the case of permanently inundated open waterbodies [23].

The term saturation (water logging) of soil is a condition in which all the pore spaces between the soil particles are filled with water to the exclusion of a gaseous phase but surface water is not necessarily present [23]. In the classification system, saturation is considered within the upper $0.5 \mathrm{~m}$ of the soil surface, which is the commonly accepted maximum depth to which soil saturation is considered for wetland delineation purposes [163]. Categorization of the saturation period is only really of relevance to wetlands and not to rivers or open waterbodies. The saturation period within the upper $0.5 \mathrm{~m}$ of the soil surface is classified according to the following categories. The term permanently saturated is a condition of wetland soils, where all the spaces between the soil particles are filled with water throughout the year, in most years. Seasonally saturated is a condition where of wetland soils, with all the spaces between the particles filled with water for extended periods (generally between 3 to 9 months duration), usually during the wet season(s), but dry for the rest of the year. Intermittently saturated is a condition of soil with all the spaces between the soil particles filled with water for irregular periods of less than one season (i.e., less than approximately 3 months), but remaining dry the rest of the time.

The term inundation refers to the condition of water occurring above the surface, i.e., flooding. The term inundation relates to the condition of soil covered by water (water is observably present at the surface). The substratum (i.e., bottom) of an inundated aquatic ecosystem is covered by water. In other words, water can be seen on top of the ground surface. The underlying substratum, or soil, of a saturated wetland is waterlogged (i.e., the spaces between the substratum/soil particles are filled with water) but surface water is not 
necessarily present. Four primary categories are provided for classifying the period of inundation associated with non-river inland aquatic ecosystems. Permanently inundated wetlands and open waterbodies are those with surface water present throughout the year, in most years. Seasonally inundated wetlands and open waterbodies are those with surface water present for extended periods during the wet season(s) (generally between 3 to 9 months duration) but drying up annually, either to complete dryness or to saturation. Intermittently inundated wetlands and open waterbodies are those holding surface water for irregular periods of less than one season (i.e., less than approximately 3 months), at intervals varying from less than a year to several years. Never/rarely inundated wetlands and open waterbodies is a condition where soil is covered by water for less than a few days at a time (up to one week at most), if ever.

\section{4) Perennial versus Non-Perennial Rivers}

The term perennial relates to flow regime: flows continuously throughout the year, in most years. The term seasonal is related to non-perennial flow regime: with water flowing for extended periods during the wet season(s) (generally between 3 to 9 months duration) but not during the rest of the year. The term non-perennial relates to flow regime; does not flow continuously throughout the year, although pools may persist. The temporal dimension of inland waterbodies can be perennial or ephemeral. On the basis of river flow types (flow regime), rivers are classified as perennial and non-perennial. Perennial rivers flow continuously throughout the year, in most years. Non-perennial rivers do not flow continuously throughout the year, although pools may persist. A river may be called as a perennial river when there is continuous flow of water throughout the year, an intermittent river when the flow is seasonal, an ephemeral river when the flow is occasional or rare [23].

\section{5) Seasonal versus Intermittent Rivers}

The term intermittent relates to non-perennial flow regime: water flows for a relatively short time of less than one season's duration (i.e., less than approximately 3 months), at intervals varying from less than a year to several years. Seasonal rivers are with water flowing for extended periods during the wet season(s) (generally between 3 and 9 months duration) but not during the rest of the year. Intermittent rivers are water flows for a relatively short time of less than one season's duration (i.e., less than approximately 3 months), at intervals varying from less than a year to several years. Intermittent rivers have a far less predictable flow regime compared to perennial or seasonal rivers and are frequently dry for long periods in arid regions [23].

\section{6) Perennial versus Intermittent and Ephemeral Streams}

There are three main types of streams: perennial streams, intermittent streams and ephemeral streams. Although there are no universally accepted definitions for perennial, intermittent, or ephemeral stream types, most definitions include or imply the following characteristics [164] [165] [166]. Perennial streams have a 
constant flow of water, flow year round. The perennial streams originating from melting glaciers have rapid currents of cold water in their higher reaches. The amount of water can and will, vary with the different seasons, however. Perennial reaches of streams receive substantial groundwater inputs and generally flow continuously throughout the year. Their flows can vary widely from year to year and may dry up during severe droughts, although groundwater is generally near the surface. Perennial streams are found in both humid and arid regions, although in arid regions, the point of initiation for perennial reaches generally occurs further downstream. Intermittent streams may run dry now and then, but have regular periods of water flow. Intermittent stream reaches typically flow for several weeks or months each year when precipitation and associated groundwater inputs are relatively high [153]. The timing of the flow and drying of intermittent streams is broadly predictable on a seasonal basis. Though sometimes associated with arid and semiarid climates, intermittent streams are well represented in humid regions. Ephemeral portions of streams flow only in direct response to precipitation. Thus, their flow is as unpredictable as the rainfall events that drive them. Because the channel of ephemeral streams is generally well above the water table, these streams flow for only a few hours or days following a storm of sufficient magnitude to produce overland flow. Many of the dry washes or arroyos of the more arid regions of North America may be classified as ephemeral streams.

\section{7) Rivers versus Streams}

Rivers and streams are lotic environments. Rivers and streams are both fast moving bodies of freshwater. The water runs permanently or seasonally in one direction (downhill) within a natural channel into another body of water such as a lake, sea, or ocean. Both streams and rivers have a current. It is because of this current that objects are dragged away with water if they fall in the water. Since rivers and streams are linear ecosystems that create a continuum, they are difficult to delineate and differentiate. While most of us speak of rivers, geoscientists tend to call everything a stream. In general, a river is a large surface stream. A river is made up of many smaller rivers or streams. A river is a collection of many streams. What is more, the river is a collection of streams, whereas the stream is a single flowing body of water. The place, where many streams meet to form a large waterbody called river, is referred to as confluence. They not only differ widely in volume of water, but they also differ much in their speed of flow, dissolved oxygen content, temperature and many other physical and chemical parameters. As we can see, the main component that decides whether a waterway is a river or stream is the size. The difference between them depends solely on the size. While by definition they are the same, in reality, the river is a bigger body of water. Rivers are larger, deeper and longer than streams. Since river is larger than a stream, it carries more debris. Though they vary in size, they are both equally important to our survival in this planet. Another difference is that a stream is a small flowing water. A 
stream is smaller and it even allows you to walk across it. Streams flow within narrow banks while rivers flow within wider banks. The number of animals is low in stream.

\section{8) Rivers versus Creeks}

Rivers and creeks are linear flowing bodies of water. Rivers and creeks are part of hydrological cycle. A river is a repository of freshwater and is a natural water course. A creek on the other hand is described as a shallow tributary to a river. Creek is often a shallow branch of a river. Geographers define creeks as small rivers or rivulets. Creek means a narrow inlet of the sea, probably a sunken river valley. In Australia a creek means almost a river. Creek can be a small stream, an inlet from the river or a narrow channel that connects islands. One of the main differences between a river and creek is their size (Table 12). Generally, creeks are much smaller, shorter and shallower than rivers. Geographers believe that although a creek is smaller than a river, there are some creeks that are considerably larger, longer and deeper than some rivers. Rivers flow in channels and have branches or tributaries, while creeks do not. It normally flows towards an ocean or sea. It joins a lake or another river too at times. A creek on the other hand is a small stream. A creek can also be a narrow channel between islands. A river is said to be a natural body of water that leads to an ocean or sea. On the contrary a creek is understood differently by different cultures. In fact they are described as stronger than some rivers too. It is no hyperbole that there are few creeks that flow all through the year. Rivers on the other hand sometimes get dried due to extreme heat and precipitation and are likely to gain flow of water during rainy season. It is interesting to note that rivers flow downhill without taking the compass direction into consideration. A river is usually bigger than a creek although there are instances that the word creek is used for a larger body of water, depending on the place or country where it is located. Rivers, especially the very large ones, are important sources of power supply while creeks do not have enough power to be tapped for this purpose. Rivers are a good means of transporting large and heavy objects like logs downstream while creeks are shallow and are too small to allow this. A creek can be formed by water from the sea while a river usually flows out to the sea.

\section{9) Streams versus Creeks}

Streams and creeks are linear flowing bodies of water. The distinction between streams and creeks is somewhat hazy and depends on who named them and when they were named. A stream is defined as any waterbody with current that

Table 12. Probable differences between rivers and creeks.

\begin{tabular}{ccc}
\hline Parameter & Rivers & Creeks \\
\hline Size description & Much larger, wider and longer & Much smaller, narrower and shorter \\
Depth of waterbody & Deeper & Shallower \\
Branching pattern & $\begin{array}{c}\text { Rivers flow in channels and have } \\
\text { branches or tributaries }\end{array}$ & $\begin{array}{c}\text { Creeks have no branches or tributaries; it } \\
\text { is on most occasions a branch of a river }\end{array}$ \\
\hline
\end{tabular}


moves under gravity to lower levels. We call a waterbody that is smaller than a river as a stream. A creek is a small stream of water that is inland. Generally, streams and creeks differ in size. Creek is shallower and also narrower than a stream. One can jump over a creek, wade across a stream and swim across a river. Creek is more turbulent than a stream.

\section{0) Canals versus Rivers and/or Streams}

Canals differ from natural streams and rivers (Table 13) by having relatively slow water flow and a uniform, shallow profile (Table 13). A canal is man-made, while streams and rivers are natural. Canals differ significantly from natural streams and rivers (running freshwater systems) and as a result of high turbidity and low flow. Water quality in canals is often perceived as poor. Slow water movement can provide conditions for algal blooms in warmer weather, followed by low oxygen levels in canals. In contrast to natural streams and rivers, canals can continue to support specialized fish and invertebrate communities even when chemical tests indicate poor results such as low oxygen levels. If this "poor perception" extends to canal biodiversity, as for urban and post-industrial habitats, efforts to improve their wildlife value may be undermined.

\section{1) Lentic versus Semi-Lotic and Lotic Oxbow-Lakes}

The lentic type is supplied by river waters under high water table level or by ground waters while the semi-lotic and lotic oxbow-lakes types are partly or totally connected to a river. Semi-open oxbow-lakes are hydrologically classified between cut-off and open reservoirs. The oxbow-lakes have limited hydrological connection to the main river. Lotic oxbow-lakes are reservoirs with constant inflow of freshwater whose intensity depends on water flow in the river [75]. They form environmental conditions favourable to fauna typical of both lotic and lentic ecosystems. Limited exchange of water in a river valley as well as its agricultural use causes that oxbow-lake drainage area often undergoes anthropopression which leads to quick eutrophication and massive phytoplankton blooms. As

Table 13. Comparison of canals and rivers and/or streams.

\begin{tabular}{|c|c|c|}
\hline Characteristic & Canals & Rivers and/or streams \\
\hline Rate of water flow & Low, relatively slow & High, relatively fast \\
\hline Size description & $\begin{array}{l}\text { Narrower and } \\
\text { longer }\end{array}$ & Wider and shorter \\
\hline Morphometric profile & $\begin{array}{l}\text { Uniform and } \\
\text { relatively shallow }\end{array}$ & Non-uniform and relatively deep \\
\hline $\begin{array}{l}\text { Temperature of the } \\
\text { waterway }\end{array}$ & $\begin{array}{l}\text { Higher, relatively } \\
\text { warmer }\end{array}$ & Lower, relatively cooler \\
\hline Oxygen content & Low & High \\
\hline Turbidity of water & High & Low \\
\hline Water quality & Poor & Good \\
\hline Source of water & Fed by reservoirs & $\begin{array}{l}\text { Fed by lower order streams and diffuse inputs; fed by } \\
\text { rains, precipitation, snow melt and springs }\end{array}$ \\
\hline
\end{tabular}


a result, water contains considerable amounts of biogenes, mineral salts but low oxygen content. Additional unfavorable factors are hydromorphological features of oxbows, i.e., small area (between a few hundred squared meters and a few hectares) and depth which usually does not exceed 3 meters. As a result oxbows quickly react to changes in temperature and thanks to that they are perfect objects for the research on climate changes even in the global depiction [167]. Limited hydrological connectivity between cut-off oxbow-lakes and the river causes that those reservoirs are predominated by taxa belonging to eurybionts [168]. The domination structure also depends on hydrological connectivity. Benthofauna structure in lentic oxbow-lakes depends on the specific features of consecutive river basins. Therefore, we distinguish lentic, semi-lotic and lotic oxbow-lakes.

\section{2) Dam (in-Channel) versus Dam (off-Channel)}

An in-channel dam is, by definition, a type of depression [23]. Dam (in-channel) is an artificial body of water formed by the unnatural accumulation of water behind an artificial barrier that has been constructed across a river channel or an unchannelled valley-bottom wetland. An off-channel dam is, by definition, a type of depression. Dam (off-channel) is an artificial body of water created specifically for the storage of water and which is not located along the course of a river channel or an unchannelled valley-bottom wetland which includes irrigation ponds and farm dams [23]. Water accumulates within these dams through surface runoff, precipitation and the diversion or pumping of water from other locations such as from rivers via canals/pipelines, or from groundwater via wind pumps. Excavation is an artificial depression created by digging out material from the ground.

\section{3) Run-of-the-River Reservoirs versus Storage Reservoirs}

Currently, the most common classification scheme for reservoirs divides these ecosystems into two groups: run-of-river reservoirs and storage reservoirs [169]. Storage reservoirs typically store large volumes of water and have large hydraulic heads, long hydraulic residence times and allow for relatively fine-tuned control over the rate at which water is released from the dam. Run-of-the-river reservoirs, on the other hand, typically store less water and have relatively small hydraulic heads, short hydraulic residence times and little or no control over the rate that water is released from the dam [169]. In many ways, these categories represent two extremes on a spectrum of reservoirs with larger lacustrine zones that are more like lakes (storage) to reservoirs with larger river zones that are more like rivers (run-of-river). The greatest differences exist between run-of-the-river reservoirs and storage reservoirs, with the former generally more diverse because they often contain elements of the pre-dam riparian communities (i.e., ecological legacies) [23]. In contrast, storage reservoirs have usually destroyed pre-existing natural riparian vegetation, requiring shoreline vegetation to develop a new around reservoir margins at higher elevations, often on poor soils and without riparian seed banks [170]. 


\section{4) Lakes versus Ponds}

Both systems lack notable flow and may be found at any elevation. The origin of ponds and lakes may be natural or human-made. Ponds and lakes are surface waters and subject to the same water quality standards. Terms lakes and ponds as part of a waterbody name are arbitrary and not based on any specific naming convention. From a naming convention there is no precise difference between a lake and pond (Table 14). Names for lakes and ponds generally originated from the early settlers living near them and the use of the terms lakes and ponds was completely arbitrary. Many have changed names through the years, often changing from a pond to a lake with no change in size or depth. Early limnologists in the late $18^{\text {th }}$ and early $19^{\text {th }}$ centuries attempted to define the transition

Table 14. Probable differences between lakes and ponds.

\begin{tabular}{|c|c|c|}
\hline Parameter & Lakes & Ponds \\
\hline Origin & Naturally made bodies of water & Usually man-made \\
\hline $\begin{array}{c}\text { Type of } \\
\text { waterbody }\end{array}$ & Standing body of water & Standing body of water \\
\hline Size of waterbody & Big & Small \\
\hline $\begin{array}{l}\text { Morphometry of } \\
\text { waterbody }\end{array}$ & Larger and/or deeper & $\begin{array}{l}\text { Smaller and/or shallower, shallow } \\
\text { enough for rooted water plants to } \\
\text { grow throughout }\end{array}$ \\
\hline Type of water & Surface waters & Surface waters \\
\hline Water flow & Absent & Absent \\
\hline $\begin{array}{l}\text { Point of light } \\
\text { reach of the } \\
\text { waterbody }\end{array}$ & $\begin{array}{l}\text { Light does no reach the bottom of the } \\
\text { deepest point of the waterbody }\end{array}$ & $\begin{array}{l}\text { Light reach the bottom of the deepest } \\
\text { point of the waterbody }\end{array}$ \\
\hline $\begin{array}{l}\text { Temperature of } \\
\text { the waterbody }\end{array}$ & $\begin{array}{l}\text { Relatively non-uniform in temperature; } \\
\text { lakes have more stable water } \\
\text { temperatures, but they may develop } \\
\text { distinct layers with different water } \\
\text { temperatures }\end{array}$ & $\begin{array}{l}\text { Relatively uniform in temperature; } \\
\text { ponds generally have a uniform water } \\
\text { temperature from top to bottom that } \\
\text { may change with air temperature }\end{array}$ \\
\hline $\begin{array}{l}\text { Size of waves of } \\
\text { the waterbody }\end{array}$ & Waterbody only get big waves & Waterbody only get small waves \\
\hline $\begin{array}{l}\text { Wave action on } \\
\text { the shoreline }\end{array}$ & $\begin{array}{l}\text { Present; lakes have enough surface water } \\
\text { exposed to the wind to develop waves }\end{array}$ & $\begin{array}{c}\text { Absent; ponds experience very little } \\
\text { wave action }\end{array}$ \\
\hline $\begin{array}{c}\text { Fluctuations in } \\
\text { water level }\end{array}$ & $\begin{array}{l}\text { Yearly fluctuations in water level are } \\
\text { minor }\end{array}$ & $\begin{array}{c}\text { Yearly fluctuations in water level are } \\
\text { more }\end{array}$ \\
\hline $\begin{array}{l}\text { Water retention } \\
\text { time }\end{array}$ & Longer; lakes contain water permanently & $\begin{array}{l}\text { Shorter; ponds contain water } \\
\text { temporarily }\end{array}$ \\
\hline Species richness & Relatively high & Relatively low \\
\hline $\begin{array}{l}\text { Plant life at the } \\
\text { bottom }\end{array}$ & $\begin{array}{l}\text { Absent; because sunlight is unable to } \\
\text { reach that point }\end{array}$ & $\begin{array}{c}\text { Present; plant life abounds in almost } \\
\text { every level }\end{array}$ \\
\hline
\end{tabular}


from a lake to a pond in various ways. In simple definition both are defined as stationary pool of water that are completely surrounded by land and apart from any river or other outlet that serves to feed or drain the lake. What would be considered a pond in one region might be considered a lake in another. In general, waterbodies that are considered lakes in dry areas would only be considered ponds in regions with abundant water resources where there are more (and larger) bodies of water.

From a regulatory viewpoint, there is no distinction between a lake and a pond. From an ecological perspective, there is a difference between the two. The difference, however, is somewhat arbitrary and not consistent or precise. Lakes are naturally made bodies of water while ponds are usually man-made. Area and depth or both are an essential part of most definitions, but what area or what depth differed. Lakes and ponds are diverse in form and function and are typically distinguished by size and depth [171]. The primary difference between the two is their size. Ponds are typically smaller than lakes [171]. Lakes are bigger or wider in area than ponds. Lake is larger than a pond, however smaller than a sea or ocean. However, numerous examples exist of ponds that are larger than lakes. Unlike ponds, these bodies of water have to be of a significant size for it to be considered as a lake. Although there is no international standard, or concrete measurement as to what a lake's size must be in order be considered as one, many experts believe that lakes must be at least 2 to 5 ha in size. The secondary difference between the two is their depth. In general, lakes tend to be deeper than ponds, but numerous examples exist of ponds that are deeper than lakes. Most would say its size, a lake is bigger and a pond is smaller. That's actually wrong. The difference is actually a result of the depth. Ponds are shallow enough where plants could conceivably grow across the entire surface. This area, where plants could grow is known as the photic zone, meaning where the sun's rays can reach the bottom. A lake, by contrast, has an aphotic zone, meaning there is an area deep enough that sunlight can't reach the bottom. As a result, there are some very small bodies of water, less than an acre, that are deep enough to be called lakes. Conversely, there are some very large, but shallow waterbodies, particularly in the south that are technically ponds, because their photic zone expands the entire length and width. So, at least with lakes and ponds, size doesn't really matter. Finally, if the lake is large enough, it can affect the surrounding climate, whereas ponds are usually affected by the surrounding climate.

With respect to plant growth, a pond is shallow enough that sunlight can penetrate to the bottom and support rooted plant growth across its entire width. Some included all plant growth including submerged plants while others said a pond was shallow enough to support emergent or floating-leafed rooted plants throughout. Ponds contain shallow water for aquatic plants and animals. If the water is deep enough that light does not penetrate to the bottom and photosynthesis is limited to the top layer, the body of water is considered a lake. Ponds 
must have characteristics such as light penetrates to the bottom of the waterbo$\mathrm{dy}$, bodies of water shallow enough for rooted water plants to grow throughout and bodies of water which lack wave action on the shoreline. A lake would be too wide and deep for sunlight to reach its bottom and instead is unofficially categorized by a small shoreline surrounded by vegetation. Lakes are too deep for plants to grow to the surface except around the shore, while ponds are shallow enough to allow sunlight to reach the bottom so rooted plants may grow in even the deepest sections. Ponds are bodies of water where light penetrates to the bottom of the waterbody. Bodies of water which lack wave action on the shoreline. In addition, ponds experience very little wave action while lakes have enough surface water exposed to the wind to develop waves. There is little wave action and the bottom is usually covered with mud. Plants can and often do, grow along a pond's edge. Lakes do not have plant life at the bottom because sunlight is unable to reach that point unlike in the case of a pond wherein plant life abounds in almost every level. Ponds often have rooted plants at their bases or deepest levels. Many times plants grow all the way across a shallow pond. A waterbody that has rooted plants growing in it should be classified as a pond because it is shallow and small; enough to allow sunlight to shine to the bottom, allowing photosynthesis. Other informal distinctions involve temperature. There are also differences in water temperatures between lakes and ponds. Lakes typically have stratified hot and cold temperatures between layers of their water in summer months, while ponds usually have consistent temperatures throughout. Lakes, because they are deeper, have a stratified temperature structure that depends on the season and three distinct layers develop during summer months. Lakes, however, have more stable water temperatures, but they may develop distinct layers with different water temperatures. Ponds have a more consistent water temperature across all their water levels from top to bottom that may change with air temperature. The productivity of a lake or pond ecosystem differs depending upon the depth, nutrients, light penetration, light availability and biota.

\section{5) Lakes versus Reservoirs}

Indeed, it may be difficult to discern any obvious differences between a lake and reservoir but differences there are, as well as similarities. Standing on the shoreline, a large lake or reservoir look much the same and both often contain the word lake in their name (Table 15). Reservoirs are artificial waterbodies, while lakes are natural waterbodies. Both are standing waterbodies are also lentic habitats less than $10 \mathrm{~km}^{2}$ in surface area. Both are usually freshwater and have high potential for aquaculture and conventional or enhanced capture fisheries. The same principles of biology, chemistry and physics are applicable to both types of waterbodies. Reservoirs are broadly defined as any human made lake, whether it is embedded within a river network or not. Reservoirs, also called impoundments, are man-made lakes. Often, reservoirs can be thought of as a combination of lakes and rivers because they were created by building a dam 
Table 15. Probable differences between natural lakes and reservoirs.

\begin{tabular}{|c|c|c|}
\hline Property & Natural lakes & Reservoirs \\
\hline Origin & $\begin{array}{l}\text { Lakes are naturally formed } \\
\text { depressions }\end{array}$ & $\begin{array}{c}\text { Reservoirs are broadly defined as } \\
\text { human-made lakes }\end{array}$ \\
\hline Location & $\begin{array}{c}\text { Typically located in the central part } \\
\text { of a drainage basin }\end{array}$ & $\begin{array}{l}\text { May be embedded within a river } \\
\text { network or not }\end{array}$ \\
\hline Landscape position & $\begin{array}{l}\text { Natural placement; fed by } \\
\text { lower order streams; diffuse } \\
\text { inputs }\end{array}$ & $\begin{array}{l}\text { Lower in the catchment; } \\
\text { fed by higher order streams; } \\
\text { surface water dominated }\end{array}$ \\
\hline $\begin{array}{l}\text { Regional distribution (and } \\
\text { function) }\end{array}$ & Dictated by geomorphology & $\begin{array}{l}\text { Influenced by regional } \\
\text { demand for dam related } \\
\text { ecosystem services }\end{array}$ \\
\hline $\begin{array}{l}\text { Proportion of catchment } \\
\text { area to surface area }\end{array}$ & $\begin{array}{c}\text { Catchment area is relatively greater } \\
\text { than surface area }\end{array}$ & $\begin{array}{c}\text { Catchment area is much greater } \\
\text { than surface area }\end{array}$ \\
\hline Shape of waterbody & Bowl shaped & Dendric shape \\
\hline Shoreline & Shorter & Longer \\
\hline Drainage basin & Shorter & Longer \\
\hline Location of deepest part & $\begin{array}{l}\text { Its deepest part is usually at its } \\
\text { centre }\end{array}$ & Its deepest part is near the dam \\
\hline Reservoir morphometry & $\begin{array}{l}\text { Circular basin; less complex } \\
\text { perimeter }\end{array}$ & $\begin{array}{l}\text { Longer, narrower basin; more } \\
\text { complex perimeter }\end{array}$ \\
\hline Secchi depth & Generally deeper & Generally more shallow \\
\hline Temperature & Somewhat lower & Somewhat higher \\
\hline Waterbody management & Less managed & More managed \\
\hline Catchment management & $\begin{array}{l}\text { Watersheds both developed } \\
\text { and undeveloped }\end{array}$ & $\begin{array}{l}\text { Watersheds more } \\
\text { developed }\end{array}$ \\
\hline
\end{tabular}

Adapted and modified from Thornton et al. (1990).

and flooding a river valley. This damming and flooding creates an artificial lake, filled by the river inflow, with the same qualities of rivers and lakes. The upstream section of the reservoir has predominantly river-like qualities, meaning there is often still some current and the organisms in this section are usually those found in rivers. As the water moves closer to the dam, the current slows and the reservoir becomes more lake-like. At this point, many of the sediments and materials carried by the river settle to the bottom of the reservoir. Many of the organisms inhabiting this region of the reservoir are those more typically found in lakes. However, some reservoirs maintain river-like qualities throughout. The degree to which riverine properties dominate the reservoirs is often a function of the size of the impounded river and the amount of time water spends in the reservoir (termed residence time). Reservoirs with a short residence time are more river-like while reservoirs with a long residence time are more like natural lakes.

The shape and form of lakes and reservoirs is determined largely by how they were formed. This also affects some of their fundamental characteristics. Because 
lakes are naturally formed, bowl-shaped depressions typically located in the central part of a drainage basin, they usually also have a more rounded shape than reservoirs. Similar to a bowl, the deepest part of a lake is usually at its centre. Determining lake water quality is typically based on measurements of water samples taken from its deep centre part and a lake exhibits more consistent water quality characteristics throughout its water basin than a reservoir. The shallowest part of the water basin is usually located near the outflow channel. In contrast, a reservoir often has a shape that is fundamentally different from lakes; its deepest part is near the dam. Moreover, because a river often has a number of streams or tributaries draining into it, when the river is dammed, the impounded water tends to back up into the tributaries. As a result, many reservoirs have a characteristic dendritic shape, with the arms radiating outward from the main body of the reservoir. In contrast, a reservoir formed by damming a river with high banks will tend to be long and narrow. Depending on how they were constructed, off-river storage reservoirs can have many shapes. The dendritic shape or branching form of many reservoirs provides a much longer shoreline than in lakes of similar volume. Reservoirs also usually have longer drainage basins than lakes. Because of their larger drainage basins and their multiple tributary inputs, the inflow of water into reservoirs is more directly tied to precipitation events in the drainage basin than it is in lakes. Further, because the deepest parts of most reservoirs are just upstream of the dam, the possibilities for draining the reservoir are facilitated. A lake typically cannot be emptied; its deepest part is usually in its centre. The presence of a dam downstream also allows a greater degree of control of water-levels and volumes for reservoirs than for lakes. One of the most common lake typological divisions is based on water source (i.e., relative contribution of groundwater versus surface water), of which reservoirs are a single lake type [147] [172]. While natural lakes are generally subdivided based on hydrology (i.e., seepage, glacial, oxbow, intermittent, etc.), reservoirs are often categorized based on their size or their designed purpose (i.e., their primary reason for being constructed). Lakes and reservoirs are more or less closed but mostly dynamic ecosystems. Lake, as an ecosystem has several budgets as heat budget, water budget and biomass budget. These physical and chemical attributes are separated into four basic categories: catchment characteristics, waterbody characteristics, management and geographic distribution [109] [173].

Drainage basins are generally wider and less elongated with lakes than with reservoirs. Many lakes include a considerable part of adjacent drainage areas, while reservoirs usually have the greatest proportion of the drainage basin upstream from them and the drainage basin is nearly identical between the reservoir and the upstream river. Larger drainage basins associated with reservoirs may result in greater annual flows entering reservoirs than lakes. The energy of rainfall determines the rate of erosion and transport of particulate matter from the watershed to the stream, so the process of watershed runoff is similar between lakes and reservoirs. Watershed characteristics, however, affect the quan- 
tity and quality of material delivered to the impoundment system. In general, upstream from lakes the stream order is lower and the relative drainage basin size to the impoundment is smaller than for reservoirs. Watershed characteristics influence the sediment delivery ratio to the impoundment system. As watershed size increases, the interception and deposition of transported particulate matter potentially increases, so the sediment delivery to the steam is inversely proportional to the watershed size. The absolute quantity of sediment and its adsorbed constituents continuously increase with increased drainage area and the relationship between drainage area and sediment delivery ratio is logarithmic. Land use in the flood plain has a greater impact on stream water quality than land use outside the flood plain. Lakes are generally located in upper parts of a drainage basin while reservoirs are located near the mouth of the drainage basin. Thus, the stream order above the lake is generally lower than that of reservoirs. The river continuum concept implies differences in the contribution of various forms of organic carbon to lakes and reservoirs. Autotrophic production tends to increase with stream order, at least until the ninth order. Autochthonous autotrophic production is an important contributor to the organic carbon supply in larger streams of forested areas and in open-canopy streams of all sizes. Sediment, particulate organic matter and adsorbed constituents are transported primarily during storm events or increased flows. For rivers, this transport occurs through a series of storm events with intermittent periods of deposition and processing in the stream between storm events. The spatial distribution of sediment loading is different between lakes and reservoirs. In lakes the inflow is generally equitably distributed around the periphery of the stream. Reservoirs in contrast generally receive the majority of their inflow from one or two major tributaries at a considerable distance from the outflow. This promotes the development of pronounced physical and chemical gradients within reservoirs that have important consequences for reservoir biological productivity and water quality. Abiogenetic turbidity and large water-level fluctuations for flood control and hydropower operations often restrict the development of attached algal and rooted macrophyte communities in reservoirs and so the contribution of planktonic production increases. Distinguishing the dominant processes between lakes and reservoirs is necessary for general understanding of these ecosystems.

\section{6) Lakes versus Drainage Ditches}

Lakes in wetlands are compared with the drainage ditches located in the agricultural lands surrounding the wetlands (Table 16). In contrast to drainage ditches, lakes have, amongst others, a lower edge to water column ratio, a lower rate of terrestrialization and a low level of disturbance. It is worth noting, however, that although drainage ditches are the most species-poor of the waterbody types, they are still a valuable habitat. However, they would be expected from few other habitats, except perhaps temporary ponds and it seems more probable that the temporary drainage ditches in the survey area are a significant habitat for temporary water species. 
Table 16. Comparison of lakes and drainage ditches.

\begin{tabular}{ccc}
\hline Characteristic & Lakes & Drainage ditches \\
\hline Edge to water column ratio & Lower & Higher \\
Rate of terrestrialization & Lower & Higher \\
Level of disturbance & Low & High \\
\hline
\end{tabular}

Table 17. Probable differences between seeps and vernal pools.

\begin{tabular}{|c|c|c|}
\hline Property & Seeps & Vernal pools \\
\hline Location & $\begin{array}{c}\text { Seeps often are located along stream margins; } \\
\text { seeps also occur on slopes }\end{array}$ & $\begin{array}{l}\text { Vernal pools do not occur } \\
\text { on slopes }\end{array}$ \\
\hline $\begin{array}{l}\text { Presence of inlet and/or } \\
\text { outlet }\end{array}$ & $\begin{array}{c}\text { Distinct stream drainage is visible as an inlet } \\
\text { or outlet }\end{array}$ & $\begin{array}{l}\text { Pool with no permanently } \\
\text { flowing outlet }\end{array}$ \\
\hline $\begin{array}{l}\text { Nature of the wetland } \\
\text { border or edge }\end{array}$ & Many seeps have a fairly diffuse border & $\begin{array}{l}\text { Typically have a more } \\
\text { distinct border }\end{array}$ \\
\hline Vegetation type & $\begin{array}{l}\text { Contain occasional trees; may have dense } \\
\text { herbaceous vegetation that is composed of } \\
\text { species characteristic of this community type }\end{array}$ & $\begin{array}{l}\text { Contain occasional trees; } \\
\text { generally lack herbaceous } \\
\text { vegetation }\end{array}$ \\
\hline $\begin{array}{l}\text { Association with } \\
\text { assemblage of amphibians } \\
\text { and invertebrates }\end{array}$ & Absent & Present \\
\hline
\end{tabular}

\section{7) Seeps versus Vernal Pools}

Although seeps and vernal pools have many differences (Table 17), they also share some important ecological features. Seeps and vernal pools are natural communities, which do not fit well into other wetland categories. These two wetland community types typically occur in depressions and at the bases of slopes in areas of upland forest. Groundwater seepage wetlands typically display a similar photo-signature to vernal pools. Seeps are sources of groundwater discharge and typically contain open water in the spring. They also typically occur in a forested context. All known examples of seeps and vernal pools are small, usually less than one half acre. Although seeps and vernal pools only contain occasional trees, both are effectively shaded by the overlapping crowns of the adjacent forest trees. Because of this characteristic, seeps and vernal pools are included as a type of forested wetland. Despite the shade, seeps may have dense herbaceous vegetation that is composed of species characteristic of this community type, while vernal pools generally lack vegetation and are best characterized by the associated assemblage of invertebrates and amphibians. The main distinguishing feature of seeps in contrast to vernal pools is that seeps often form the headwaters of streams or are located along stream margins. Therefore, if distinct stream drainage was visible as an inlet or outlet to a site in question, the site was typically considered a seep wetland and not considered as a vernal pool. Likewise, if a potential site was located along the margins of a stream, it was thought to be a seepage wetland and was typically not regarded as a vernal pool. Seeps also occur on slopes, whereas vernal pools do not. Therefore, if a site occurred 
on a slope lacking suitable topography it was not considered as a potential vernal pool. Another distinguishing feature between seeps and vernal pools is the nature of the wetland border. Many seeps have a fairly diffuse border, while vernal pools typically have a more distinct border or edge. In some cases, this characteristic could be used to distinguish the two wetland types.

\section{8) Rivers versus Lakes}

There are various types of waterbodies on Earth, among which are the lakes and rivers. Lakes and rivers are both bodies of water that contains freshwater. A river is defined as a natural stream of water of fairly large size flowing in a definite course or channel or series of diverging and converging channels. Rivers are bodies of water with land masses, or long stretches of land bordering their sides. Conversely, lake is a still waterbody usually land-locked, i.e., enclosed or surrounded by land from all four sides except a side where it is fed by any moving body of water (Table 18). Both of them are freshwater sources, but lakes are inland and do not communicate with other sources of water. They are also not connected to the seas or oceans, because they are inland. Rivers take water from one place to another and they have a source and a mouth where the water is poured into an ocean, sea, lake or river. In theory, man can make both artificial lakes as well as rivers and harness their energy to create electricity or to reshape the ecosystem in an area. Additionally, rivers may occasionally form lakes (e.g., oxbow lakes) when portions of a river become geologically separated from the main flow path over time.

It is not very difficult to distinguish the difference between river and lake by just looking at them. Rivers are more diverse than lakes for many reasons: surrounding land use, size of the watershed, stream order, geology, soil type, topography, rate of stream flow and vegetation type. In a river, water basically moves or runs along its banks. The main difference between a river and a lake lies in their size, shape and movement. Firstly, rivers are longer, wider and

Table 18. Probable differences between rivers and lakes.

\begin{tabular}{|c|c|c|}
\hline Parameter & Rivers & Lakes \\
\hline Formation & Natural bodies of water & Can be either natural or artificial \\
\hline Flow of water & Flowing body of water & Standing body of water \\
\hline $\begin{array}{l}\text { Link to another } \\
\text { body of water }\end{array}$ & Connects to a larger body of water & Does not connect to another body of water \\
\hline Appearance & Looks like a snake slithering away & Looks like a huge puddles of water \\
\hline $\begin{array}{l}\text { Connection with } \\
\text { other inland } \\
\text { waterbodies }\end{array}$ & $\begin{array}{l}\text { Moves along its water banks and } \\
\text { communicates with other } \\
\text { waterbodies }\end{array}$ & $\begin{array}{l}\text { Inland, does not communicate with other } \\
\text { waterbodies }\end{array}$ \\
\hline Land-locking & $\begin{array}{l}\text { Not enclosed by a body of land; } \\
\text { rivers are bodies of water with } \\
\text { land masses, or long stretches of } \\
\text { land bordering their sides }\end{array}$ & $\begin{array}{l}\text { Enclosed by a body of land; lake is a still } \\
\text { waterbody usually land-locked, enclosed or } \\
\text { surrounded by land from all four sides } \\
\text { except a side where it is fed by any moving } \\
\text { body of water }\end{array}$ \\
\hline
\end{tabular}


deeper than lakes. In rivers, flowing water continually cuts into the channel, making it deeper and wider as it ages. This also determines their difference in appearance, as a river is long and its shape is defined by its course. Secondly, rivers and lakes differ in how they look or appear. Rivers look like snakes slithering away, whereas lakes are more like huge puddles of water.

In contrast to flowing streams, lakes provide a means for pooling or storing water for varying periods of time. The main difference between lakes and rivers consists in (based on) the fact that a river is a moving body of water, whereas a lake is a standing body of water. Lakes are standing bodies of water while rivers are distinguished by a fast-moving current. Fast movement of water can be observed in rivers while slow movement of water can be observed in lakes. A natural movement of water can be observed in rivers while an artificial movement of water can be observed in lakes. While there appear to be clear distinctions, the differences become subtle in regions where rivers widen and current slows such that the river could be considered a lake or a pond. Additionally, rivers may occasionally form lakes such as oxbow lakes when portions of a river become geologically separated from the main flow path over time. Generally, rivers often flow in only one direction (downhill). On the contrary, lakes seem to be immobile, that's why they are often regarded as still bodies of water. If ever the lakes seemingly move, they just move very slowly. Most of its movements are influenced by the blowing of the wind. Rivers are generally more oxygenated than lakes and they tend to contain organisms that are adapted to the swiftly moving waters. With respect to thermal stratification, a lake is a body of water that is deep enough to thermally stratify into two or three layers during the summer in temperate regions. Lakes have stratified water temperatures as their uppermost surface where water is the warmest while the deepest water level is very cold. In rivers, water temperature from top to bottom is usually the same.

\section{9) Streams versus Lakes}

Streams and lakes are both bodies of water. Lakes are standing bodies of water while streams are distinguished by a fast-moving current. Streams are more diverse than lakes for many reasons: surrounding land use, size of the watershed, stream order, geology and soil type, topography, rate of stream flow, vegetations type. Streams differ from lakes in size, shape and water movement (Table 19). The main difference between streams and lakes is water movement. In a stream, water basically moves or runs along its banks. Generally, streams often flow in only one direction. On the contrary, lakes seem to be immobile, that's why they are often regarded as still bodies of water. Streams are generally more oxygenated than lakes and they tend to contain organisms that are adapted to the swiftly moving waters. In contrast to flowing streams, lakes provide a means for pooling or storing water for varying periods of time.

\section{0) Streams versus Drainage Ditches}

Drainage ditches in intense agricultural areas are often rather different to natural streams (Table 20). The ditches are restricted to those on level ground in 
which there is a limited or slow flow of water that can often be in either direction. Canalized streams carry water in one direction only. Stream differ from drainage ditches by usually having a sinuous plan form, not following field boundaries, or if they do, pre-dating boundary creation and showing a relationship with natural landscape contours (e.g., running down valleys). Drainage ditches are linear features, which have a linear plan form. They follow linear field boundaries and show no or little relationship to natural contours. In many respects, they can be considered as linear ponds. Drainage ditches support lower biodiversity than streams; however, they can act as reservoirs for important regional wetland biodiversity.

Table 19. General differences between streams and lakes.

\begin{tabular}{|c|c|c|}
\hline Characteristic & Streams & Lakes \\
\hline Type of waterbody & Fast-moving current & Standing bodies of water \\
\hline Water flow & $\begin{array}{l}\text { One direction of flow, upstream to } \\
\text { downstream }\end{array}$ & $\begin{array}{l}\text { Various flows, no particular } \\
\text { direction }\end{array}$ \\
\hline Oxygen content & $\begin{array}{l}\text { Normally oxygen rich because of the constant } \\
\text { mixing }\end{array}$ & $\begin{array}{l}\text { Oxygen depletion exists at times } \\
\text { in deeper water or older lakes }\end{array}$ \\
\hline General depth & Shallower on average & Deeper than average \\
\hline Size description & Narrower and longer & Wider and shorter \\
\hline $\begin{array}{l}\text { Riparian zone } \\
\text { description }\end{array}$ & $\begin{array}{c}\text { Various effects from different terrestrial } \\
\text { environments along the stream's course; the } \\
\text { shoreline has more potential to affect water } \\
\text { quality because a larger portion of the } \\
\text { waterbody is near shore }\end{array}$ & $\begin{array}{l}\text { Terrestrial environment similar } \\
\text { all around the lake shore; a } \\
\text { smaller portion of the water is } \\
\text { in close proximity to the shore }\end{array}$ \\
\hline $\begin{array}{l}\text { Changes in shape / } \\
\text { depth over time }\end{array}$ & $\begin{array}{l}\text { Stream continually cuts into the channel, } \\
\text { making it longer, wider and deeper }\end{array}$ & $\begin{array}{l}\text { Lakes become shallower over } \\
\text { time from depositing sediments }\end{array}$ \\
\hline Age progression & $\begin{array}{c}\text { Age progression of a stream goes from } \\
\text { young, narrow and shallow stream to mature, } \\
\text { wider and deeper stream }\end{array}$ & $\begin{array}{l}\text { Age progression of a lake or } \\
\text { pond goes from lake to marsh } \\
\text { or swamp to land }\end{array}$ \\
\hline $\begin{array}{l}\text { Water retention } \\
\text { time (how long it } \\
\text { holds water) }\end{array}$ & $\begin{array}{l}\text { Shorter retention time for water as it is } \\
\text { always flowing }\end{array}$ & $\begin{array}{l}\text { Longer retention time for water } \\
\text { because it stores water }\end{array}$ \\
\hline $\begin{array}{l}\text { Temperature } \\
\text { characteristics }\end{array}$ & $\begin{array}{l}\text { Top and bottom waters generally have the } \\
\text { same temperature because of the constant } \\
\text { mixing }\end{array}$ & $\begin{array}{l}\text { May have different } \\
\text { temperatures from the top to } \\
\text { bottom because it has layers } \\
\text { based on density }\end{array}$ \\
\hline
\end{tabular}

Table 20. Probable differences between streams and drainage ditches.

\begin{tabular}{ccc}
\hline Parameter & Streams & Drainage ditches \\
\hline Rate of water flow & Fast & Slow \\
Direction of water flow & Carry water in one direction only & Can often be in either direction \\
Biodiversity value & Higher & Lower \\
\hline
\end{tabular}




\section{1) Ponds versus Rivers and/or Streams}

While there appear to be clear distinctions, the differences become subtle in regions where rivers widen and current slows such that the river could be considered a pond. Rivers and streams are generally more oxygenated than ponds (Table 21) and they tend to contain organisms that are adapted to the swiftly moving waters. Ponds are the waterbodies that often have small catchment areas and can, as a result, have highly individual physico-chemical characteristics that vary considerably between ponds depending on local geology and land use. Rivers and large streams, in contrast, usually have extensive catchments and this, combined with the homogenizing action of flowing water, will usually ensure that they are characterized by less variable physico-chemical conditions than small lentic waters. It is possible, therefore, that such heterogeneity in water chemistry and habitat has a bottom-up effect on biodiversity, maintaining ponds as regionally rich habitats.

\section{2) Springs versus Seeps}

People confuse between springs versus seeps; and this article aims to remove all such doubts. Although they are similar, there are marked differences between the two (Table 22). Seeps and springs are the spots where water flows back to the surface. Seeps and springs are the points where an aquifer intersects with the ground surface and discharges water into a stream channel that flows into a wetland or other waterbody. Seep and spring water may remain underground for many years, or even centuries, before it resurfaces. During this time underground it reaches a temperature much cooler than typical surface waters in the summer and much warmer in the winter. This is a significant characteristic of springs and seeps that is important to the plants and animals that depend on them. Springs and seeps can vary seasonally and depend on the depth and size of the groundwater resource supporting them. Springs usually emerge from a single point, while seeps emerge over a larger area, having no well-defined origin. Discharge from relatively deep groundwater flow systems rising to form distinctive springs with associated often unique aquatic ecosystems. Whether the surface water flow is a seep or a spring is determined by the geology of the site and the water pressure below the surface. Seeps generally have a lower flow rate than springs and only rarely have a volume large enough to form a stream. Springs, on the other hand, can be the source of a small trickle, a stream, or even a sizable river. A spring has a concentrated flow, whereas a seep has a diffuse flow. Seeps differ from springs in that they often periodically dry and consequently support a lower diversity of wetland vegetation. Springs often have a more persistent

Table 21. Comparison of ponds and rivers and/or streams.

\begin{tabular}{ccc}
\hline Characteristic & Ponds & Rivers and/or streams \\
\hline Size of catchment area & Small & Big \\
Physico-chemical conditions & Highly individual & Less variable \\
Habitat richness & High & Low \\
\hline
\end{tabular}


Table 22. Probable differences between springs and seeps.

\begin{tabular}{|c|c|c|}
\hline Property & Springs & Seeps \\
\hline $\begin{array}{l}\text { Origin (emergence of } \\
\text { ground water) }\end{array}$ & $\begin{array}{l}\text { Usually emerge from a single point, } \\
\text { having a well-defined origin }\end{array}$ & $\begin{array}{l}\text { Usually emerge over a larger area, } \\
\text { having no well-defined origin }\end{array}$ \\
\hline Flow type & Concentrated flow & Diffuse flow \\
\hline Flow rate & $\begin{array}{l}\text { Higher; can be the source of a small } \\
\text { trickle, a stream, or even a sizable river }\end{array}$ & $\begin{array}{l}\text { Lower; only rarely have a volume } \\
\text { large enough to form a stream }\end{array}$ \\
\hline Hydrology & $\begin{array}{l}\text { Often have a more persistent source of } \\
\text { water }\end{array}$ & Often periodically dry \\
\hline Biodiversity & $\begin{array}{l}\text { Support a higher diversity of wetland } \\
\text { vegetation }\end{array}$ & $\begin{array}{l}\text { Support a lower diversity of } \\
\text { wetland vegetation }\end{array}$ \\
\hline
\end{tabular}

source of water and thus support a greater diversity of wetland vegetation and often provide aquatic habitat. Just as on the surface, underground water flows down hill.

\section{3) Springs versus Wells}

A spring is a place where water issues from the ground and flows or where it lies in pools that are continually replenished from below, except that wholly artificial openings, such as artesian wells, are not regarded as springs.

\section{4) Marshes versus Swamps}

Swamps and marshes are both types of wetland, where the water is completely or partially shallow. Swamps and marshes are wetlands, landforms with the trait of being saturated in water. Swamps and marshes can be composed of freshwater, saltwater, or brackish water (a mixture of both). The terms marsh and swamp are frequently used in connection with wetlands in an interchangeable manner and are very similar in appearance. If you have been to either of the two places, you know that the entire area seems flooded with water, which is shallow and is surrounded by vegetation. These are large land pieces where people can move in boats though there are areas that are dry and covered with vegetation. Swamps and marshes are easily interchanged as they are both areas of vegetation that are susceptible to flooding. However, they are not same as there are characteristic differences between the two. To define both landforms briefly, a marsh is a transitional area between terrestrial and aquatic ecosystems, while a swamp is a wetland ecosystem. Marshes are found near the fringes of lakes and streams, while swamps are found along large rivers and lake shores (Table 23). A swamp has a bigger area covered with water than a marsh. Swamp is, in general, deeper than a marsh and makes it possible for people to move around in boats. Marshes and swamps also both have aquatic vegetation. Swamps are dominated by woody plants, like trees, while marshes are dominated by herbaceous (non-woody) plants, like grasses. Marshes are nutrient-rich wetlands that support a variety of reeds and grasses, while swamps are defined by their ability to support woody plants and trees. The word swamp is used for a wetland that has many more trees than a marsh, which is characterized by the presence of grasses and low 
Table 23. Comparison of marshes and swamps.

\begin{tabular}{|c|c|c|}
\hline Feature & Marshes & Swamps \\
\hline Landform & $\begin{array}{l}\text { A marsh is typically a transitional area } \\
\text { between terrestrial and aquatic ecosystems }\end{array}$ & $\begin{array}{l}\text { A swamp is typically a wetland } \\
\text { ecosystem }\end{array}$ \\
\hline Distribution & Widespread & Restricted \\
\hline Location & $\begin{array}{l}\text { Marshes are found near the fringes of lakes } \\
\text { and streams }\end{array}$ & $\begin{array}{l}\text { Swamps are found along large } \\
\text { rivers and lake shores }\end{array}$ \\
\hline Hydrology & Seasonal to permanent flooding & $\begin{array}{l}\text { Prolonged saturation and } \\
\text { flooding }\end{array}$ \\
\hline $\begin{array}{l}\text { Area covered } \\
\text { with water }\end{array}$ & Smaller & Bigger \\
\hline Water depth & Shallower & Deeper \\
\hline $\begin{array}{l}\text { Dominant } \\
\text { vegetation }\end{array}$ & $\begin{array}{l}\text { Low proportion of trees; dominated by low } \\
\text { lying herbaceous (non-woody) plants like } \\
\text { reeds and grasses }\end{array}$ & $\begin{array}{c}\text { High proportion of trees; } \\
\text { dominated by high lying woody } \\
\text { plants like trees }\end{array}$ \\
\hline
\end{tabular}

shrubs. If the wetland has a high proportion of trees, it is a swamp and if the vegetation is low lying, it is a marsh. Both swamp as well as marsh is a rich source of fauna as aquatic plants provide places to fish to hide their eggs, while predators find the place full of prey. Both swamps and marshes are great place for wildlife. With so many plants in the water, fish use marshes and swamps as a nursery ground. The plants are a great place to hide their eggs and are a hiding spots for juvenile fish to hide from predators.

\section{Conclusions and Recommendations}

The findings of this study suggest several basic conclusions. The study recognizes inland waters as important landscape features and reports exclusively freshwater in these surface waters across the landscape of Adilabad District, Telangana, "Deccan Region", India. Inland water resources vis-à-vis inland aquatic ecosystems, in general, cover $4.28 \%$ of the total geographical area of the District.

The study develops preliminary three-tier HGM classification system of aquatic ecosystems in the landscape of Adilabad District. The study reports only one category of HGM class (inland aquatic ecosystems) at first level, four categories of HGM sub-classes (lotic, lentic, wetland and riparian ecosystems) at second level and 19 categories of HGM units (8 lotic: rivers, rivulets, tributaries, streams, creeks, waterfalls, springs and canals; 8 lentic: lakes, ponds, vernal pools, seeps, reservoirs, farm ponds and reservoirs, drainage ditches and water tanks; 3 wetlands: swamps, marshes and rice fields) at third level of the classification system. Our classification system breaks the complexity down to units that can be used by local authorities as the scientific basis for the formulation of laws and which can be understood by the practitioners, who will be expected to follow them.

Adilabad District is in many ways abundant by its vast and diverse inland freshwater aquatic natural resources and a wide variety of inland aquatic ecosys- 
tems owing to the varied edaphic, climatic and topographic conditions. These standardized inland aquatic ecosystems are intricately tied to the landscape and provide a variety of ecosystem services. Diversity in aquatic ecosystem has another great issue of interest because it provides huge resources to human beings. They provide municipal and industrial water supplies, energy production, irrigation, flood control and transportation. There are many types of HGM units that differ widely with respect to several biophysical and ecogeographical attributes in the study area. The size of HGM units ranged from small ephemeral pool to large river in the District. These HGM units, recognized and described for the entire District at a relatively fine scale, are useful for a variety of biodiversity conservation and resource management applications. These data can be used to identify areas deserving of management attention due to their value for biodiversity conservation, as well as the production of ecosystem goods and services.

This study to a large extent has been able to throw light on the significance of waterfalls like "Kuntala Waterfalls" and "Pochara Waterfalls" for tourism. It is, therefore, rational to articulate that these waterfalls in the District be harnessed and promoted for sustainable development. Reservoirs, lakes and water tanks are important inland aquatic ecosystems throughout the District but increasing human populations result in an accelerating demand on water supplies for domestic, industrial and agricultural use. Despite their small size and ephemeral nature, vernal pools support a rich assemblage of invertebrates and breeding amphibians. The vast majority of wetlands that remain were tiny and showed aggregated patterns of distribution on the rural and tribal landscapes in the District. These conditions indicate that further conversion of wetlands is likely to be rapid. Springs, seeps and natural ponds in hills and secluded valleys are important to the District's natural heritage as they provide critical water and food resources to wildlife, livestock and humans, they are point sources of biodiversity and bioproductivity in otherwise low productivity landscapes and they are the focus of human activities, regional history and land and wildlife management. However, a proper feasibility study, application of some basic design principles and vigilance in protecting these inland waterbodies and their catchment areas will usually lead to improvements in the quantity, quality and sustainability of many such supplies.

Local variability, past disturbance or management may mean that some aquatic ecosystems are not present at all areas. Better knowledge about the biophysical and ecogeographical attributes of aquatic ecosystems allows us to build a more comprehensive and balanced picture of the assets that support human well-being and human's interdependence with the well-being of all life in the landscape of the District. In general, a detailed assessment of aquatic ecosystem properties provides a broad scale perception of the conservation requirements in the District and will allow re-arrangement of the nature conservation policy and management by giving future conservation endeavors an ecosystem approach. 
This has many important implications for conservation planning.

One of the most significant findings to emerge from this study is that the study area has many different kinds of HGM units, which harbor and sustain immense biological diversity. The present study has contributed to a better understanding of existing aquatic ecosystems in the District. Furthermore, such landscape in the District provides a research environment for understanding basic ecological relationships on a large scale. The results of this study should serve as a basis for future research on the change in the spatial pattern of the targeted aquatic ecosystem and the biophysical and ecogeographic attributes specific for each aquatic ecosystem.

For major research needs, we propose that the following issues be addressed to move towards ecologically sustainable development at a landscape perspective.

In the context of the classification system presented in the current paper, there is a dire need for the field-based collection of detailed data on the hydrogeomorphic and ecological characteristics of inland aquatic ecosystems, particularly for different types of wetlands in different areas, as a means of testing whether the HGM units of the classification system adequately reflect ecosystem functioning.

Detailed information is lacking for important inland aquatic ecosystem properties, such as structural heterogeneity; ecosystem size, borders and connectivity to neighboring systems; inflow and outflow of matter; and the spatial and temporal distribution of substrates. Proper evaluation of these patterns will improve our qualitative and quantitative understanding of inland aquatic ecosystem services.

Syntheses of data across aquatic ecosystems indicate that aquatic and terrestrial ecosystems, subsystems like lotic and lentic ecosystems, HGM units like lakes and ponds, natural lakes and reservoirs show unambiguous differences in their structure and function. However, the causes of systematic variation among these aquatic ecosystems remain controversial and poorly elucidated. Contrasts between HGM units in particular have inspired much speculation, but only recent empirical quantification. Additional features could be added.

Although, the reservoir and tank resources of the District is enormous and diverse in ecological characteristics, they need to be classified on the basis of ecological and production characteristics for proper management. Further in-depth understanding of the physics, chemistry and biology of our lakes and rivers is urgently needed, before these systems are changed irrevocably by increasing anthropogenic activities. Limnologists have an important role to play in this vital matter.

Our ability to identify the current status of and subsequently monitor, the biodiversity of inland waters and the ecosystem services they provide for the planet is a fundamental requirement. If we cannot do this, we cannot assess our progress towards meeting key conservation and sustainable use goals in this important area. Assessing the current local status of biological diversity of aquatic 
ecosystems in quantitative as well as qualitative terms is problematic, because of the difficulties quantifying biological diversity. An immediate need exists to categorize and substantially improve the understanding of biological diversity, with a view to measuring trends, particularly on landscape scale. It is important to urgently develop a range of incentive measures, or measures to tackle disincentives, to achieve the conservation of biodiversity within aquatic ecosystems and move towards a more sustainable-use-oriented society. As knowledge increases, so will the need to develop cost-effective and appropriate condition assessment techniques.

Freshwater ecosystems have been described as biological assets (that are) both disproportionately rich and disproportionately imperiled. They need not be so threatened. There is an urgent need to conserve these waterbodies and protect them from environmental degradation due to anthropogenic activities. Reopening or excavation of the linkages wherever possible is one of the prime needs. Sustainable protection and management of these important freshwater ecosystem services will require quantitative understanding of processes at different spatial and temporal scales and assessment of their resistance and resilience with regard to common anthropogenic impacts.

The studies of freshwater ecosystems are at low level: the species composition, quantity and distribution. The research methodology is not consistent. Researchers have not yet focussed on studies of methodology. Development of tools and protocols for quantifying material and energy flows through aquatic ecosystems at field, farm, landscape and regional scales are needed.

As a prerequisite, ecologists must conduct inter- and transdisciplinary work while studying inland aquatic ecosystems to fill these still-open research gaps. However, filling these gaps will require the intimate involvement of expertise in the fields of geohydrology, geophysics and geochemistry. Understanding dynamics in aquatic environments will take focused effort on the part of scientists, educators and land managers. Successfully carrying out these recommendations will depend on a broad network of organizations and individuals working together, sharing information, finding resources and supporting each other in ecologically sustainable development of the study area.

\section{Acknowledgements}

We would like to thank a very large number of institutions and District teams with which we worked, including our collaborators and their field workers. Very large numbers of local people, especially local tribes, farmers, gatherers, hunters and grazers have provided valuable primary information on the location of inland waterbodies and their characteristics for undertaking the study and we would like to gratefully acknowledge their contributions.

\section{References}

[1] Mojses, M. and Boltiziar, M. (2011) Using Spatial Metrics for Assessment of the 
Landscape Structure Changes of the Besa Dry Polder. Tajokologiai Lapok, 9 , 415-428.

[2] Reeves, G.H. and Duncan, S.L. (2009) Ecological History vs. Social Expectations: Managing Aquatic Ecosystems. Ecology and Society, 14, 8.

http://www.ecologyandsociety.org/vol14/iss2/art8/ https://doi.org/10.5751/ES-02976-140208

[3] Concannon, J.A., Shafer, C.I., DeVelice, R.L., Sauvajot, R.M., Boudreau, L.S., Demeao, T.E. and Dryden, J. (1999) Describing Landscape Diversity: A Fundamental Tool for Landscape Management. In: Szaro, R.C., Johnson, N.C., Sexton, W.T. and Malick, A.J., Eds., Ecological Stewardship: A Common Reference for Ecosystem Management, Volume 2, Elsevier Science Ltd., Oxford, 195-218.

[4] GWP (Global Water Partnership)/INBO (International Network of Basin Organizations) (2015) The Handbook for Management and Restoration of Aquatic Ecosystems in River and Lake Basins, 94.

[5] Department of the Environment, Water, Heritage and the Arts (2009) Assessment of Australia's Terrestrial Biodiversity 2008. Report Prepared by the Biodiversity Assessment Working Group of the National Land and Water Resources Audit for the Australian Government, Canberra.

[6] Baron, J.S., Poff, N.L., Angermeier, P.L., Dahm, C.N., Gleick, P.H., Hairston, Jr. N.G., Jackson, R.B., Johnston, C.A., Richter, B.D. and Steinman, A.D. (2003) Sustaining Healthy Freshwater Ecosystems. Issues in Ecology, 10, 1-16.

[7] Dugan, P. (1993) Review: Wetlands in Danger: A World Conservation Atlas. Oxford University Press, New York, 192.

[8] Lewis, P. (1996) U.N. Report Warns of Problems Over Dwindling Water Supplies. The New York Times, January 20.

[9] Grossfeld, S. (1997) A River Runs Dry: A People Wither. The Boston Sunday Globe, September 21, A1, A18.

[10] Akinnibosun, F.I., Asowata, J. and Osigbeme, P. (2009) Assessment of Benin Rivers for Water Quality Levels. African Journal of Bioscience, 2, 44-51.

[11] Johnson, N., Revenga, C. and Echeverria, J. (2001) Managing Water for People and Nature. Science, 292, 1071-1072. https://doi.org/10.1126/science.1058821

[12] The World Water Organization (2010) Water Facts and Water Stories from Across the Globe. http://www.theworldwater.org/water_facts.php

[13] Kitchell, J.F., Carpenter, S.R., Bayley, S.W., Ewel, K.C., Howarth, R.W., Nixon, S.W. and Schindler, D.W. (1991) Aquatic Ecosystem Experiments in the Context of Global Climate Change: Working Group Report. In: Mooney, H.A., et al., Eds., Ecosystem Experiments, SCOPE \#45, John Wiley and Sons, Chinchester, 229-235.

[14] Wilson, M.A. and Carpenter, S.R. (1999) Economic Valuation of Freshwater Ecosystem Services in the United States: 1971-1997. Ecological Applications, 9, 772-783.

[15] Postel, S.L. and Carpenter, S.R. (1997) Freshwater Ecosystem Services. In: Daily, G., Ed., Nature's Services, Island Press, Washington DC, 195-214.

[16] Matero, J. and Saastamoinen, O. (1998) Monetary Assessment of the Impacts of Forestry on Water-Based Benefits in Finland. Boreal Environment Research, 3, 87-96.

[17] Aylward, B., Bandyopadhyay, J., Belausteguigotia, J.C., Borkey, P., Cassar, A.Z., Meadors, L., Saade, L., Siebentritt, M., Stein, R., Tognetti, S. and Tortajada, C. (2005) Freshwater Ecosystem Services. Ecosystems and Human Well-Being: Policy Responses, 3, 213-256.

[18] Vorosmarty, C.J. and Leveque, C.R. (2005) Fresh Water. In: Hassan, R., Scholes, R. 
and Ash, N., Eds., Millennium Ecosystem Assessment: Current Status and Trends 1, Island Press, Washington DC.

[19] Carpenter, S.R., Stanley, E.H. and Vander Zanden, M.J. (2011) State of the World's Freshwater Ecosystems: Physical, Chemical, and Biological Changes. Annual Review of Environment and Resources, 36, 75-99. https://doi.org/10.1146/annurev-environ-021810-094524

[20] Strayer, D.L. and Dudgeon, D. (2010) Freshwater Biodiversity Conservation: Recent Progress and Future Challenges. Journal of the North American Benthological Society, 29, 344-358. https://doi.org/10.1899/08-171.1

[21] Ricciardi, A. and Rasmussen, J.B. (1999) Extinction Rates of North American Freshwater Fauna. Conservation Biology, 13, 1220-1222. https://doi.org/10.1046/j.1523-1739.1999.98380.x

[22] Ausubel, J.H. (1991) A Second Look at the Impacts of Climate Change. American Science, 79, 210-221.

[23] Ollis, D.J., Snaddon, C.D., Job, N.M. and Mbona, N. (2013) Classification System for Wetlands and Other Aquatic Ecosystems in South Africa. User Manual: Inland Systems. SANBI Biodiversity Series 22. South African National Biodiversity Institute, Pretoria.

[24] Singers, N.J.D. and Rogers, G.M. (2014) A Classification of New Zealand's Terrestrial Ecosystems. Science for Conservation 325, Department of Conservation, Wellington, 87.

[25] Cowardin, L.M., Carter, V., Golet, F.C. and LaRoe, E.T. (1979) Classification of Wetlands and Deepwater Habitats of the United States. FWS/OBS-79/31. Fish and Wildlife Service, Washington DC.

[26] Maxwell, J.R., Edwards, C.J., Jensen, M.E., Paustian, S.J., Parrott, H. and Hill, D.M. (1995) A Hierarchical Framework of Aquatic Ecological Units in North America (Nearctic Zone). General Technical Report NC-176. U.S. Department of Agriculture, Forest Service, North Central Forest Experiment Station, St. Paul.

[27] Melles, S., Jones, N. and Schmidt, B. (2013) Aquatic Research Series 2013-05: Aquatic Ecosystem Classification for Ontario: A Technical Proposal. Ontario Ministry of Natural Resources, 52.

[28] Gravelius, H. (1914) Flusskunde. Goschen'sche Verlagshandlung, Berlin.

[29] Horton, R.E. (1945) Erosional Development of Streams and their Drainage Basins-Hydrophysical Approach to Quantitative Morphology. Geological Society of America Bulletin, 56, 275-370. https://doi.org/10.1130/0016-7606(1945)56[275:EDOSAT]2.0.CO;2

[30] Mock, S.J. (1971) Classification of Channel Links in Stream Networks. Water Resources Research, 7, 1558-1566. https://doi.org/10.1029/WR007i006p01558

[31] Pennak, R.W. (1971) Toward a Classification of Lotic Habitats. Hydrobiologia, 38, 321-334. https://doi.org/10.1007/BF00036842

[32] Frissell, C.A., Liss, W.J., Warren, C.E. and Hurley, M.D. (1986) A Hierarchical Framework for Stream Habitat Classification-Viewing Streams in a Watershed Context. Environmental Management, 10, 199-214. https://doi.org/10.1007/BF01867358

[33] Higgins, J.V., Bryer, M.T., Khoury, M.L. and Fitzhugh, T.W. (2005) A Freshwater Classification Approach for Biodiversity Conservation Planning. Conservation Biology, 19, 432-445. https://doi.org/10.1111/j.1523-1739.2005.00504.x

[34] Groves, C.R., Jensen, D.B., Valutis, L.L., Redford, K.H., Shaffer, M.L., Scott, J.M., 
Baumgartner, J.V., Higgins, J.V., Beck, M.W. and Anderson, M.G. (2002) Planning for Biodiversity Conservation: Putting Conservation Science into Practice. A Seven-Step Framework for Developing Regional Plans to Conserve Biological Diversity, Based upon Principles of Conservation Biology and Ecology, Is Being Used Extensively by the Nature Conservancy to Identify Priority Areas for Conservation. BioS cience, 52, 499-512. https://doi.org/10.1641/0006-3568(2002)052[0499:PFBCPC]2.0.CO;2

[35] Brinson, M.M. (1993) A Hydrogeomorphic Classification for Wetlands. Technical Report WRP-DE-4, U.S. Army Corps of Engineers, Waterways Experiment Station, Washington DC, 79.

[36] Smith, R.D., Ammann, A., Bartoldus, C. and Brinson, M.M. (1995) An Approach for Assessing Wetland Functions Using Hydrogeomorphic Classification, Reference Wetlands, and Functional Indices Wetlands Research Program Technical Report WRP-DE-9. U.S. Army Corps of Engineers, Waterways Experiment Station, Washington DC, 79.

[37] Kellerhals, R. and Church, M. (1989) The Morphology of Large Rivers: Characterization and Management. In: Dodge, D.P., Ed., Proceedings of the International Large River Symposium, Canadian Special Publication of Fisheries and Aquatic Sciences, 106, 31-48.

[38] Rosgen, D.L. (1994) A Classification of Natural Rivers. Catena, 22, 169-199. https://doi.org/10.1016/0341-8162(94)90001-9

[39] Pimm, S.L. and Brooks, T.M. (2000) The Sixth Extinction: How Large, Where and When? In: Raven, P.H. and Williams, T., Eds., Nature and Human Society: The Quest of a Sustainable World, National Academy Press, Washington DC, 46-62.

[40] World Resources Institute (2005) Chapter 20: Inland Water Systems, Millennium Ecosystem Assessment. World Resources Institute, Washington DC. http://www.millenniumassessment.org/en/index.aspx.

[41] Myers, N., Mittermeier, R.A., Mittermeier, C.G., da Fonseca, G.A. and Kent, J. (2000) Biodiversity Hotspots for Conservation Priorities. Nature, 403, 853-858. https://doi.org/10.1038/35002501

[42] Laurance, W.F. (2010) Habitat Destruction: Death by a Thousand Cuts. In: Sodhi, N.S. and Ehrlich, P.R., Eds., Conservation Biology for All, OXFORD University Press, Oxford, New York, 73-87.

http://ukcatalogue.oup.com/product/9780199554249.do https://doi.org/10.1093/acprof:oso/9780199554232.003.0005

[43] Nayar, M.P., Singh, A.K. and Nair, K.N. (2009) Agrobiodiversity Hotspots in India: Conservation and Benefit Sharing, Volume I and II. PPV and FR Authority, New Delhi, 217-307.

[44] Pullaiah, T., Ramamurthy, S.K. and Karuppusamy, S. (2007) Flora of Eastern Ghats, Volume 3. Regency Publications, New Delhi.

[45] Reddy, M.T., Pandravada, S.R., Sivaraj, N., Sunil, N., Dikshit, N. and Kamala, V. (2017) Backyard Farming of Okra (Abelmoschuses culentus L. Moench) in Traditional Agricultural Landscapes of Adilabad District, Telangana, India. Journal of Global Agriculture and Ecology, 6, 147-161.

[46] Hijmans, R.J., Guarino, G. and Macathur, P. (2012) DIVAGIS Version 7.5.0. Manual. http://www.diva-gis.org

[47] Reddy, M.T., Pandravada, S.R., Sivaraj, N., Kamala, V., Sunil, N. and Dikshit, N. (2017) Classification and Characterization of Landscapes in the Territory of Adilabad District, Telangana, Deccan Region, India. Open Access Library Journal, 4, 
e3745.

[48] Pullaiah, T. (2015) Flora of Telangana-The $29^{\text {th }}$ State of India. Journal of Indian Botanical Society, 94, 1-8.

[49] Pandravada, S.R., Sivaraj, N., Sunil, N., Jairam, R., Prasanthi, Y., Chakrabarty, S.K., Ramesh, P., Bisht, I.S. and Pareek, S.K. (2013) Sorghum Landraces Patronized by Tribal Communities in Adilabad District, Andhra Pradesh. Indian Journal of Traditional Knowledge, 12, 465-471.

[50] Kumar, K.A. (2010) Local Knowledge and Agricultural Sustainability: A Case Study of Pradhan Tribe in Adilabad District. Working Paper No. 81. Centre for Economic and Social Studies, Begumpet, Hyderabad, 36.

[51] Pandravada, S.R., Sivaraj, N., Sunil, N., Jairam, R., Chakrabarty, S.K., Ramesh, P., Jadhav, S.N., Bisht, I.S. and Bansal, K.C. (2012) NAIP Brochure on Adilabad, Andhra Pradesh. National Bureau of Plant Genetic Resources, Regional Station, Rajendranagar, Hyderabad, 1-4.

[52] Space Applications Centre (ISRO) (2010) National Wetland Atlas: Andhra Pradesh, SAC/EPSA/AFEG/NWIA/ATLAS/ 33/2010. Ahmedabad, India, 172.

[53] Revenga, C. and Kura, Y. (2003) Status and Trends of Biodiversity of Inland Water Ecosystems. Secretariat of the Convention on Biological Diversity, Montreal, Technical Series No. 11.

[54] Semeniuk, C.A. and Semeniuk, V. (1995) A Geomorphic Approach to Global Classification for Inland Wetlands. Vegetatio, 118, 103-124.

https://doi.org/10.1007/BF00045193

[55] Finlayson, C.M., Begg, G.W., Howes, J., Davies, J., Tagi, K. and Lowry, J. (2002) A Manual for an Inventory of Asian Wetlands: Version 1.0. Wetlands International Global Series 10, Kuala Lumpur.

[56] Ellery, W.N., Grenfell, M.C., Grenfell, S., Kotze, D.C., Mccarthy, T.S., Tooth, S., Grundling, P.L., Beckedahl, H., Le Maitre, D. and Ramsay, L. (2008) WET-Origins: Controls on the Distribution and Dynamics of Wetlands in South Africa. WRC Report No. TT 334/08. Water Research Commission, Pretoria.

[57] Kotze, D.C., Marneweck, G.C., Batchelor, A.L., Lindley, D.S. and Collins, N.B. (2008) WET-EcoServices: A Technique for Rapidly Assessing Ecosystem Services Supplied by Wetlands. WRC Report No. TT 339/09. Water Research Commission, Pretoria.

[58] Jones, M.G.W. (2002) Developing a Classification System for Western Cape Wetlands. M.Sc. Thesis, University of Cape Town.

[59] Ollis, D.J., Ewart-Smith, J.L., Day, J.A., Job, N.M., Macfarlane, D.M., Snaddon, C.D., Sieben, E.J.J., Dini, J.A. and Mbona, N. (2015) The Development of a Classification System for Inland Aquatic Ecosystems in South Africa. Water $S A, 41,727-745$. https://doi.org/10.4314/wsa.v41i5.16

[60] Naiman, R.J., Lonzarich, D.G., Beechie, T.J. and Ralph, S.C. (1992) General Principles of Classification and the Assessment of Conservation Potential in Rivers. In: Boon, P.J., Calow, P. and Petts, G.E., Eds., River Conservation and Management, John Wiley and Sons, Chichester, 93-123.

[61] Froude, V.A. and Beanland, R.A. (1999) Review of Environmental Classification Systems and Spatial Frameworks. Report Prepared for Ministry for the Environment, New Zealand Government, Report Reference No. TR88.

[62] Heinz Center (The H. John Heinz III Center for Science, Economics and the Environment) (2008) The State of the Nations Ecosystems. Island Press, Washington 
DC.

[63] Malmqvist, B. and Rundle, S. (2002) Threats to the Running Water Ecosystems of the World. Environmental Conservation, 29, 134-153. https://doi.org/10.1017/S0376892902000097

[64] Giller, P.S. and Malmqvist, B. (1998) The Biology of Streams and Rivers. Oxford University Press, Oxford.

[65] Hynes, H.B.N. (1975) The Stream and its Valley. Internationale Vereinigung Für Theoretische Und Angewandte Limnologie. Verhandlungen, 19, 1-15.

[66] Shiklomanov, L.A. (1993) World Freshwater Resources. In: Gleick, P.H., Ed., Water in Crisis: A Guide to World s Freshwater Resources, Oxford University Press, New York, 13-24.

[67] Allan, J.D. and Flecker, A.S. (1993) Biodiversity Conservation in Running Waters. BioScience, 43, 32-43. https://doi.org/10.2307/1312104

[68] Osborne, L.L. and Koviacic, D.A. (1993) Riparian Vegetated Buffer Strips in Water-Quality Restoration and Stream Management. Freshwater Biology, 29, 243-258. https://doi.org/10.1111/j.1365-2427.1993.tb00761.x

[69] Schlosser, I.J. (1991) Stream Fish Ecology: A Landscape Perspective. BioScience, 41, 704-712. https://doi.org/10.2307/1311765

[70] Rice, S.P., Greenwood, M.T. and Joyce, C.B. (2001) Tributaries, Sediment Sources, and the Longitudinal Organisation of Macroinvertebrate Fauna along River Systems. Canadian Journal of Fisheries and Aquatic Sciences, 58, 824-840. https://doi.org/10.1139/f01-022

[71] Poole, G.C. (2002) Fluvial Landscape Ecology: Addressing Uniqueness within the River Discontinuum. Freshwater Biology, 47, 641-660. https://doi.org/10.1046/j.1365-2427.2002.00922.x

[72] Vega, M., Pardo, R., Barrado, E. and Deban, L. (1998) Assessment of Seasonal and Polluting Effects on the Quality of River Water by Exploratory Data Analysis. Water Research, 32, 3581-3592. https://doi.org/10.1016/S0043-1354(98)00138-9

[73] Dhasarathan, P., Gowsalya, U.G. and Rajkumar, K. (2006) Seasonal Variation in Microbial Population in Sivakasi Soil with Reference to the Influence of Temperature. Pollution Research, 25, 114-118.

[74] Galle, L., Margoczi, K., Kovacs, E., Gyorffy, Gy., Kormoczi, L. and Nemeth, L. (1995) River Valleys: Are they Ecological Corridors? Tiscia, 29, 53-58.

[75] Ward, J.V., Mallard, F. and Tockner, K. (2002) Landscape Ecology: A Framework for Integrating Pattern and Process in River Corridors. Landscape Ecology, 17, 35-45. https://doi.org/10.1023/A:1015277626224

[76] Johansson, M.E., Nilsson, C. and Nilsson, E. (1996) Do Rivers Function as Corridors for Plant Dispersal? Journal of Vegetation Science, 7, 593-598. https://doi.org/10.2307/3236309

[77] Jansson, R., Nilsson, C. and Renofalt, B. (2000) Fragmentation of Riparian Floras in Rivers with Multiple Dams. Ecology, 81, 899-903. https://doi.org/10.1890/0012-9658(2000)081[0899:FORFIR]2.0.CO;2

[78] Gresswell, R.E. and Vondracek, B. (2010) Coldwater Streams. In: Hubert, W.A. and Quist, M.C., Eds., Inland Fisheries Management in North America, $3^{\text {rd }}$ Edition, American Fisheries Society, Bethsda, Maryland, 587-618.

[79] Harvey, C.A., Chacon, M., Donatti, C.I., Garen, E., Hannah, L., Andrade, A., Bede, L., Brown, D., Calle, A. and Chara, J. (2014) Climate Smart Landscapes: Opportuni- 
ties and Challenges for Integrating Adaptation and Mitigation in Tropical Agriculture. Conservation Letters, 7, 77-90. https://doi.org/10.1111/conl.12066

[80] Smith, P., Haberl, H., Popp, A., Erb, K.H., Lauk, C., Harper, R., Tubiello, F.N., Siqueira Pinto, A., Jafari, M. and Sohi, S. (2013) How Much Land Based Greenhouse Gas Mitigation can be Achieved without Compromising Food Security and Environmental Goals? Global Change Biology, 19, 2285-2302.

https://doi.org/10.1111/gcb.12160

[81] Smart, S.M., Bunce, R.G., Firbank, L.G. and Coward, P. (2002) Do Field Boundaries Act as Refugia for Grassland Plant Species Diversity in Intensively Managed Agricultural Landscapes in Britain? Agriculture, Ecosystems \& Environment, 91, 73-87. https://doi.org/10.1016/S0167-8809(01)00259-6

[82] Smart, S.M., Marrs, R.H., Le Duc, M.G., Thompson, K., Bunce, R.G.H., Firbank, L.G. and Rossall, M.J. (2006) Spatial Relationships between Intensive Land Cover and Residual Plant Species Diversity in Temperate Farmed Landscapes: Land-Use and Residual Species Diversity Patterns. Journal of Applied Ecology, 43, 1128-1137. https://doi.org/10.1111/j.1365-2664.2006.01231.x

[83] Sidle, R.C., Tsuboyama, Y., Noguchi, S., Hosoda, I., Fujieda, M. and Shimizu, T. (2000) Streamflow Generation in Steep Headwaters: A Linked Hydro-Geomorphic Paradigm. Hydrological Processes, 14, 369-385.

https://doi.org/10.1002/(SICI)1099-1085(20000228)14:3<369::AID-HYP943>3.0.CO $\underline{; 2-\mathrm{P}}$

[84] Abell, R., Allan, J.D. and Lehner, B. (2007) Unlocking the Potential of Protected Areas for Freshwaters. Biological Conservation, 134, 48-63. https://doi.org/10.1016/j.biocon.2006.08.017

[85] Courtenay Jr, W.R., Sahlman, H.F., Miley II, W.W. and Herrema, D.J. (1974) Exotic Fishes in Fresh and Brackish Waters of Florida. Biological Conservation, 6, 292-302. https://doi.org/10.1016/0006-3207(74)90008-1

[86] Dudgeon, D., Arthington, A.H., Gessner, M.O., Kawabata, Z.I., Knowler, D.J., Leveque, C., Naiman, R.J., Prieur-Richard, A.H., Soto, D., Stiassny, M.L.J. and Sullivan, C.A. (2006) Freshwater Biodiversity: Importance, Threats, Status and Conservation Challenges. Biological Reviews of the Cambridge Philosophical Society, 81, 163-182. https://doi.org/10.1017/S1464793105006950

[87] Bureau of Land Management (2000) A Handbook for the Management of Seeps and Springs in the Great Basin. Sada, D.W., Williams, J.E., Silvey, J.C., Halford, A., Ramakka, J., Summers, P. and Lewis, L., Eds.

[88] McCabe, D.J. (1998) Biological Communities in Springbrooks. In: Botosaneana, L., Ed., Studies in Crenobiology: The Biology of Springs and Springbrooks, Bckhuys Publishers, Leiden, The Netherlands, 221-228.

[89] United States Department of Interior (USDI), Bureau of Land Management (BLM) (2001) Riparian Area Management: A Guide to Managing, Restoring, and Conserving Springs in the Western United States. Technical Reference 1737-17. Bureau of Land Management, Denver, Colorado, BLM/ST/ST-01/001+1737.

[90] Nilsson, C. and Berggren, K. (2000) Alterations of Riparian Ecosystems Caused by River Regulation. BioScience, 50, 783-792. https://doi.org/10.1641/0006-3568(2000)050[0783:AORECB]2.0.CO;2

[91] Williamson, C.E., Saros, J.E., Vincent, W.F. and Smol, J.P. (2009) Lakes and Reservoirs as Sentinels, Integrators, and Regulators of Climate Change. Limnology and Oceanography, 54, 2273-2282. https://doi.org/10.4319/lo.2009.54.6_part_2.2273

[92] UNESCO and WMO (1992) International Glossary of Hydrology, $2^{\text {nd }}$ Edition, 
UNESCO and WMO.

[93] Kuusisto, E. (1985) Lakes: Their Physical Aspects. In: Rodda, J.C., Ed., Facets of Hydrology, Volume II, John Wiley \& Sons Ltd., New York.

[94] Minale, A.S. and Rao, K.K. (2011) Hydrological Dynamics and Human Impact on Ecosystems of Lake Tana, Northwestern Ethiopia. Ethiopian Journal of Environmental Studies and Management, 4, 56-63. https://doi.org/10.4314/ejesm.v4i1.7

[95] Drake, D.C., Kelly, D. and Schallenberg, M. (2011) Shallow Coastal Lakes in New Zealand: Current Conditions, Catchment-Scale Human Disturbance, and Determination of Ecological Integrity. Hydrobiologia, 658, 87-101. https://doi.org/10.1007/s10750-010-0452-Z

[96] Collinson, N.H., Biggs, J., Corfield, A., Hodson, M.J., Walker, D., Whitfield, M. and Williams, P.J. (1995) Temporary and Permanent Ponds: An Assessment of the Effects of Drying Out on the Conservation Value of Aquatic Macroinvertebrate Communities. Biological Conservation, 74, 125-134. https://doi.org/10.1016/0006-3207(95)00021-U

[97] Hansen, M.J., Lester, N.P. and Krueger, C.C. (2010) Natural Lakes. In: Hubert, W.A. and Quist, M.C., Eds., Inland Fisheries Management, $3^{\text {rd }}$ Edition, American Fisheries Society, Bethesda, MD, 449-500.

[98] Willis, D.W., Lusk, R.D. and Slipke, J.W. (2010) Farm Ponds and Small Impoundments. In: Hubert, W.A. and Quist, M.C., Eds., Inland Fisheries Management, $3^{\text {rd }}$ Edition, American Fisheries Society, Bethesda, MD, 501-543.

[99] MacCallum, W.F. (2009) NHESP Guidelines for the Certification of Vernal Pool Habitat. Division of Fisheries and Wildlife, Commonwealth of Massachusetts. Natural Heritage \& Endangered Species Program, Rabbit Hill Road, Westborough.

[100] Brooks, R.T. (2004) Weather-Related Effects on Woodland Vernal Pool Hydrology and Hydroperiod. Wetlands, 24, 104-114. https://doi.org/10.1672/0277-5212(2004)024[0104:WEOWVP]2.0.CO;2

[101] Sobczak, R.V., Canbareri, T.C. and Portnoy, J.W. (2003) Physical Hydrology of Selected Vernal Pools and Kettle Ponds in the Cape Cod National Seashore, Massachusetts: Ground and Surface Water Interactions. Water Resources Office, Cape Cod Commission, Barnstable, MA.

[102] Williams, W.D. (1985) Biotic Adaptations in Temporary Lentic Waters, with Special Reference to Those in Semi-Arid and Arid Regions. Hydrobiology, 125, 85-110. https://doi.org/10.1007/BF00045928

[103] Scholnick, D.A. (1994) Seasonal Variation and Diurnal Fluctuations in Ephemeral Desert Pools. Hydrobiology, 294, 111-116. https://doi.org/10.1007/BF00016851

[104] Colburn, E.A., Weeks, S.C. and Reed, S.K. (2008) Diversity and Ecology of Vernal Pool Invertebrates. In: Calhoun, A.J.K. and deMaynadier, P.G., Eds., Science and Conservation of Vernal Pools in Northeastern North America, CRC Press, Boca Raton, FL, 105-126.

[105] Semlitsch, R.D. and Skelly, D.K. (2008) Ecology and Conservation of Pool-Breeding Amphibians. In: Calhoun, A.J.K. and deMaynadier, P.G., Eds., Science and Conservation of Vernal Pools in Northeastern North America, CRC Press, Boca Raton, FL, 127-147.

[106] Bjornn, T.C. and Reiser, D.W. (1991) Habitat Requirements of Salmonids in Streams. In: Meehan, W.R., Ed., Influences of Forest and Rangeland Management on Salmonid Fishes and Their Habitats, American Fisheries Society Special Publication, 19, 83-138. 
[107] Sedell, J.R., Reeves, G.H., Haver, F.R., Stanford, J.A. and Hawkins, C.P. (1990) Role of Refugia in Recovery from Disturbances: Modern Fragmented and Disconnected River Systems. Environmental Management, 14, 711-724. https://doi.org/10.1007/BF02394720

[108] Moilanen, A. and Hanski, I. (2001) On the Use of Connectivity Measures in Spatial Ecology. Oikos, 95, 147-151. https://doi.org/10.1034/j.1600-0706.2001.950116.x

[109] Hayes, N.M, Deemer, B.R., Corman, J.R., Razavi, N.R. and Strock, K.E. (2017) Key Differences between Lakes and Reservoirs Modify Climate Signals: A Case for a New Conceptual Model. Limnology and Oceanography Letters, 2, 47-62. https://doi.org/10.1002/lol2.10036

[110] Rosenberg, D.M., Berkes, F., Bodaly, R.A., Hecky, R.E., Kelly, C.A. and Rudd, J.W.M. (1997) Large-Scale Impacts of Hydroelectric Development. Environmental Reviews, 5, 27-54. https://doi.org/10.1139/a97-001

[111] Tockner, K., Malard, F. and Ward, J.V. (2000) An Extension of the Flood Pulse Concept. Hydrological Processes, 14, 2861-2883.

https://doi.org/10.1002/1099-1085(200011/12)14:16/17<2861::AID-HYP124>3.0.CO $\underline{; 2-\mathrm{F}}$

[112] Shaw, R.F., Johnson, P.J., Macdonald, D.W. and Feber, R.E. (2015) Enhancing the Biodiversity of Ditches in Intensively Managed UK Farmland. PLoS ONE, 10, e0138306. https://doi.org/10.1371/journal.pone.0138306

[113] Manhoudt, A.G.E., Udo de Haes, H.A. and de Snoo, G.R. (2005) An Indicator of Plant Species Richness of Semi-Natural Habitats and Crops on Arable Farms. Agriculture Ecosystems \& Environment, 109, 166-174. https://doi.org/10.1016/j.agee.2005.01.006

[114] Biggs, J., Williams, P., Whitfield, M., Nicolet, P., Brown, C., Hollis, J., Arnold, D. and Pepper, T. (2007) The Freshwater Biota of British Agricultural Landscapes and Their Sensitivity to Pesticides. Agriculture Ecosystems \& Environment, 122, 137-148. https://doi.org/10.1016/j.agee.2006.11.013

[115] Cushman, S.A. (2006) Effects of Habitat Loss and Fragmentation on Amphibians: A Review and Prospectus. Biological Conservation, 128, 231-240. https://doi.org/10.1016/j.biocon.2005.09.031

[116] Van Geert, A., Van Rossum, F. and Triest, L. (2010) Do Linear Landscape Elements in Farmland Act as Biological Corridors for Pollen Dispersal? Journal of Ecology, 98, 178-187. https://doi.org/10.1111/j.1365-2745.2009.01600.x

[117] Mauritzen, M., Bergers, P.J.M., Andreassen, H.P., Bussink, H. and Barendse, R. (1999) Root Vole Movement Patterns: Do Ditches Function as Habitat Corridors? Journal of Applied Ecology, 36, 409-421. https://doi.org/10.1046/j.1365-2664.1999.00414.x

[118] Socioeconomic Outlook (2015) Reinventing Telangana-The First Steps. Planning Department, Government of Telangana, Hyderabad, 190.

[119] Semlitsch, R.D. and Bodie, J.R. (1998) Are Small, Isolated Wetlands Expendable? Conservation Biology, 12, 1129-1133. https://doi.org/10.1046/j.1523-1739.1998.98166.x

[120] Peterjohn, W.T. and Correll, D.L. (1984) Nutrient Dynamics in an Agricultural Watershed: Observations on the Role of a Riparian Forest. Ecology, 65, 1466-1475. https://doi.org/10.2307/1939127

[121] Jacobs, T.C. and Gilliam, J.W. (1985) Riparian Losses of Nitrate from Agricultural Drainage Waters. Journal of Environmental Quality, 14, 472-478. 
https://doi.org/10.2134/jeq1985.00472425001400040004x

[122] Cooper, J.R., Gilliam, J.W. and Jacobs, T.C. (1986) Riparian Areas as a Control of Nonpoint Pollutants. In: Correll, D.L., Ed., Watershed Research Perspectives, Smithsonian Institution, Washington DC, 166-192.

[123] Mitsch, W.J. (1994) A Comparison of the Nonpoint Source Pollution Control Function of Natural and Constructed Riparian Wetlands. In: Mitsch, W.J., Ed., Global Wetlands. Old World and New, Elsevier, Amsterdam, 351-361.

[124] Rodgers, J.H. and Dunn, A. (1992) Developing Design Guidelines for Constructed Wetlands to Remove Pesticides from Agricultural Runoff. Ecological Engineering, 1, 83-95. https://doi.org/10.1016/0925-8574(92)90026-X

[125] van der Valk, A.G. and Jolly, R.W. (1992) Recommendations for Research to Develop Guidelines for the Use of Wetlands to Control Rural Nonpoint Source Pollution. Ecological Engineering, 1, 115-134. https://doi.org/10.1016/0925-8574(92)90028-Z

[126] Basset, A. and Abbiati, M. (2004) Challenges to Transitional Water Monitoring: Ecological Descriptors and Scales. Aquatic Conservation: Marine and Freshwater Ecosystems, 14, S1-S3. https://doi.org/10.1002/aqc.669

[127] Mitsch, W.J. and Gosselink, J.G. (2000) Wetlands. John Wiley and Sons, New York.

[128] Shine, C. and Klemm, C. (1999) Wetlands, Water and the Law: Using Law to Advance Wetland Conservation and Wise Use. IUCN, Gland.

[129] Solimini, A.G., Bazzanti, M., Ruggiero, A. and Carchini, G. (2008) Developing a Multimetric Index of Ecological Integrity Based on Macroinvertebrates of Mountain Ponds in Central Italy. Hydrobiologia, 597, 109-123. https://doi.org/10.1007/s10750-007-9226-7

[130] Stenert, C. and Maltchik, L. (2007) Influence of Area, Altitude and Hydroperiod on Macroinvertebrate Communities in Southern Brazil Wetlands. Marine and Freshwater Research, 58, 993-1001. https://doi.org/10.1071/MF07073

[131] Edirisinghe, J.P. and Bambaradeniya, C.N.B. (2006) Rice Fields: An Ecosystem Rich in Biodiversity. Journal of National Science Foundation Sri Lanka, 34, 57-59. https://doi.org/10.4038/jnsfsr.v34i2.2084

[132] National Agricultural Cooperative Federation (NCAF) (2001) Paddy, a 'Field for Life'-The Coexistence of Nature and Humankind. Seol, Korea.

[133] Watanabe, I. and Roger, P.A. (1985) Ecology of Flooded Rice Fields. In: Banta, S. and Mendoza, C.V., Eds., Wetland Soils. Characterization, Classification, and Utilization, International Rice Research Institute, Manila, Philippines, 229-243.

[134] Grant, I.F. and Alexander, M. (1981) Grazing of Blue-Green Algae (Cyanobacterial in Flooded Soils by Cyprus sp. (Ostracoda). Soil Science Society of America Journal, 45, 773-777. https://doi.org/10.2136/sssaj1981.03615995004500040019x

[135] Clare, S. and Sass, G. (2012) Riparian Lands in Alberta: Current State, Conservation Tools, and Management Approaches. Report Prepared for Riparian Land Conservation \& Management Team, Alberta Water Council, Edmonton, Alberta. Fiera Biological Consulting Ltd. Report \#1163.

[136] Naiman, R.J., Decamps, H. and Pollock, M. (1993) The Role of Riparian Corridors in Maintaining Regional Biodiversity. Ecological Applications, 3, 209-312. https://doi.org/10.2307/1941822

[137] Naiman, R.J. and Decamps, H. (1997) The Ecology of Interfaces-Riparian Zones. Annual Review of Ecology and Systematic, 28, 621-658.

https://doi.org/10.1146/annurev.ecolsys.28.1.621 
[138] Gregory, S.V., Swanson, F.J., McKee, A.W. and Cummins, K.W. (1991) An Ecosystem Perspective of Riparian Zones. BioScience, 41, 540. https://doi.org/10.2307/1311607

[139] Alexander, L.C., Autrey, B., DeMeester, J., Fritz, K.M., Goodrich, D.C., Kepner, W.G. and Wigington, P.J. (2015) Connectivity of Streams and Wetlands to Downstream Waters: A Review and Synthesis of the Scientific Evidence. U.S. Environmental Protection Agency, Washington DC.

[140] Beraldi-Campesi, H. (2013) Early Life on Land and the First Terrestrial Ecosystems. Ecological Processes, 2, 1. http://www.ecologicalprocesses.com/content/2/1/1 https://doi.org/10.1186/2192-1709-2-1

[141] Retallack, G.J. (1986) Reappraisal of a 2200 Ma-Old Paleosol near Waterval Onder, South Africa. Precambrian Research, 32, 195-232.

https://doi.org/10.1016/0301-9268(86)90007-0

[142] Romans, B.W. and Graham, S.A. (2013) A Deep-Time Perspective of Land-Ocean Linkages in the Sedimentary Record. Annual Review of Marine Science, 5, 69-94. https://doi.org/10.1146/annurev-marine-121211-172426

[143] Cole, G.A. (1994) Textbook of Limnology. $4^{\text {th }}$ Edition, Waveland Press, Inc., Prospect Heights, IL, 426.

[144] Moss, B. (1998) Ecology of Fresh Waters. Man and Medium-Past to Future. Blackwell Science, Oxford.

[145] Ribera, I. (2008) Habitat Constraints and the Generation of Diversity in Freshwater Macroinvertebrates. In: Lancaster, J. and Briers, R.A., Eds., Aquatic Insects. Challenges to Populations, CAB International Publishing, Wallingford, 289-311. https://doi.org/10.1079/9781845933968.0289

[146] Arribas, P., Velasco, J., Abellan, P., Sanchez-Fernandez, D., Andujar, C., Calosi, P., Millan, A., Ribera, I. and Bilton, D.T. (2012) Dispersal Ability Rather than Ecological Tolerance Drives Differences in Range Size between Lentic and Lotic Water Beetles (Coleoptera: Hydrophilidae). Journal of Biogeography, 39, 984-994. https://doi.org/10.1111/j.1365-2699.2011.02641.x

[147] Hutchinson, G.E. (1957) A Treatise on Limnology. Wiley, New York.

[148] Hof, C., Brandle, M. and Brandl, R. (2006) Lentic Odonates have Larger and More Northern Ranges than Lotic Species. Journal of Biogeography, 33, 63-70. https://doi.org/10.1111/j.1365-2699.2005.01358.x

[149] Damm, S., Dijkstra, K.D.B. and Hadrys, H. (2010) Red Drifters and Dark Residents: The Phylogeny and Ecology of a Plio-Pleistocene Dragonfly Radiation Reflects Africa's Changing Environment (Odonata, Libellulidae, Trithemis). Molecular Phylogenetics and Evolution, 54, 870-882. https://doi.org/10.1016/j.ympev.2009.12.006

[150] National Research Council (NRC) (1995) Wetlands: Characteristics and Boundaries. National Academy Press, Washington DC, 328.

[151] Mitsch, W.J. and Gosselink, J. (1993) Wetlands. $2^{\text {nd }}$ Edition, Van Nostrand Reinhold, New York.

[152] Kusler, J.A., Mitsch, W.J. and Larson, J.S. (1994) Wetlands. Scientific American, 270, 64-70. https://doi.org/10.1038/scientificamerican0194-64B

[153] National Research Council (NRC) (2002) Riparian Areas: Functions and Strategies for Management. National Academy Press, Washington DC, 444.

[154] Scott, D.A. and Jones, T.A. (1995) Classification and Inventory of Wetlands: A Global Overview. In: Finlayson, C.M. and vander Valk, A.G., Eds., Classification 
and Inventory of the World $s$ Wetlands, Kluwer Academic Publishers, Dordrecht, The Netherlands, 3-16. https://doi.org/10.1007/978-94-011-0427-2_2

[155] Rheinhardt, R.D., Rheinhardt, M.C., Brinson, M.M. and Faser, K. (1998) Forested Wetlands of Low Order Streams in the Inner Coastal Plain of North Carolina, USA. Wetlands, 18, 365-378. https://doi.org/10.1007/BF03161531

[156] WES Environmental Laboratory (1987) U.S. Army Corps of Engineers Wetlands Delineation Manual. U.S. Army Engineer Waterway Experiment Station Technical Report Y-87-1.

[157] Robinson, T.W. (1958) Phreatophytes. U.S. Geological Survey Water Supply Paper 1423, 84.

[158] Wharton, C.H., Kitchens, W.M. and Sipe, T.W. (1982) The Ecology of Bottomland Hardwood Swamps of the Southeast: A Community Profile. FWS/OBS-81/37, U.S. Fish and Wildlife Service, Washington DC, 133.

[159] Friedman, J.M. and Auble, G.T. (2000) Floods, Flood Control, and Bottomland Vegetation. In: Wohl, E., Ed., Inland Flood Hazards: Human, Riparian, and Aquatic Communities, University Press, Cambridge, 219-237.

https://doi.org/10.1017/CBO9780511529412.009

[160] Hupp, C.R. (1988) Plant Ecological Aspects of Flood Geomorphology and Paleoflood History. In: Baker, V.R., Kochel, R.C. and Patton, P.C., Eds., Flood Geomorphology, Wiley, New York, 335-356.

[161] Gould, W.A. and Walker, M.D. (1997) Landscape-Scale Patterns in Plant Species Richness along an Arctic River. Canadian Journal of Botany, 75, 1748-1765. https://doi.org/10.1139/b97-889

[162] Ferreira, L.V. and Stohlgren, T.J. (1999) Effects of River Level Fluctuation on Plant Species Richness, Diversity, and Distribution in a Floodplain Forest in Central Amazonia. Oecologia, 120, 582-587. https://doi.org/10.1007/s004420050893

[163] Department of Water Affairs and Forestry, South Africa (DWAF) (2005) A Practical Field Procedure for Identification and Delineation of Wetlands and Riparian Areas. Department of Water Affairs and Forestry, Pretoria.

[164] Hewlett, J.D. (1982) Principles of Forest Hydrology. University of Georgia Press, Athens, GA.

[165] Comin, F.A. and Williams, W.D. (1994) Parched Continents: Our Common Future? In: Maralef, R., Ed., Limnology Now. A Paradigm of Planetary Problems, Elsevier Science B.V., New York.

[166] Nevada Division of Water Planning (1999) Water Words Dictionary, $8^{\text {th }}$ Edition, Nevada Department of Conservation and Natural Resources, Carson City, NV.

[167] Klimaszyk, P. (2004) Oxbow-Lakes and Natural Eutrophic Aquatic Reservoirs Nympheion, Potamion. In: Herbich, J., Ed., Fresh Waters and Peatlands. Handbook of Species and Habitat Protection Nature, Vol. 2, Ministerstwo Srodowiska, Warszawa, 59-71.

[168] Kajak, Z. (2001) Hydrobiology-Limnology: Island Aquatic Ecosystems. PWN, Warsaw.

[169] Poff, N.L. and Hart, D.D. (2002) How Dams Vary and Why it Matters for the Emerging Science of Dam Removal an Ecological Classification of Dams is Needed to Characterize How the Tremendous Variation in the Size, Operational Mode, Age, and Number of Dams in a River Basin Influences the Potential for Restoring Regulated Rivers via Dam Removal. BioScience, 52, 659-668. https://doi.org/10.1641/0006-3568(2002)052[0659:HDVAWI]2.0.CO;2 
[170] Johnson, W.C. (2002) Riparian Vegetation Diversity along Regulated Rivers: Contribution of Novel and Relict Habitats. Freshwater Biology, 47, 749-759. https://doi.org/10.1046/j.1365-2427.2002.00910.x

[171] Summerfelt, R.C. (1993) Lake and Reservoir Habitat Management. In: Kohler, C.C. and Hubert, W.A., Eds., Inland Fisheries Management in North America, $2^{\text {nd }}$ Edition, American Fisheries Society, Bethesda, MD, 594.

[172] Wetzel, R.G. (2001) Limnology Lake and Reservoir Ecosystems. Academic Press, San Diego.

[173] Thornton, K.W., Kimmel, B.L. and Payne, F.E. (1990) Reservoir Limnology: Ecological Perspectives. John Wiley and Sons, New York. 